Juan Carlos Zuñiga Torres

\title{
Uma Metodologia para o Desenvolvimento de Aplicações de Realidade Aumentada em Telefones Celulares Utilizando Dispositivos Sensores
}

Dissertação apresentada à Escola Politécnica da Universidade de São Paulo para obtenção do Título de Mestre em Engenharia. 
Juan Carlos Zuñiga Torres

\section{Uma Metodologia para o Desenvolvimento de Aplicações de Realidade Aumentada em Telefones Celulares Utilizando Dispositivos Sensores}

Dissertação apresentada à Escola Politécnica da Universidade de São Paulo para obtenção do Título de Mestre em Engenharia.

Área de concentração:

Sistemas Eletrônicos

Orientador:

Prof. Dr. Sergio Takeo Kofuji 


\section{Resumo}

O uso de dispositivos móveis ou handheld devices na implementação de um sistema de Realidade Aumentada (RA) é denominado Handheld Augmented Reality ou simplesmente Handheld AR. Aplicações do tipo Handheld AR utilizam a câmera integrada no dispositivo móvel para reconhecer marcadores (inseridos no ambiente), o que permite a entrada de dados para o sistema de RA. As informações geradas nestas aplicações são apresentadas como imagens virtuais (gráficos 3D) nas telas dos dispositivos móveis.

Já aplicações do tipo Handheld $A R$ mais complexas e recentes, utilizam dispositivos sensores (com interfaces de comunicação sem fio) como RFID tags, Redes de Sensores Sem Fio (RSSF) e sistemas de GPS (Global Positioning System), como fontes de entrada de dados dinâmicos para o sistema de RA, junto à câmera e os marcadores. Aplicações deste tipo apresentam características interessantes para áreas de aplicação como: sensoriamento, monitoramento, visualização e interação em ambientes inteligentes e ubíquos. Porém, a carência de documentação e a complexidade no desenvolvimento destas aplicações geram a necessidade de metodologias e ferramentas que colaborem para um rápido e simples processo de desenvolvimento.

Neste sentido, esta dissertação apresenta uma "Metodologia de Desenvolvimento" para aplicações de realidade aumentada em dispositivos móveis, a qual visa ajudar no projeto e facilitar o processo de desenvolvimento de aplicações do tipo Handheld $A R$, em especial as que utilizem telefones celulares e dispositivos sensores com interfaces de comunicação sem fio, apresentando uma documentação bem definida e um roteiro claro sobre os requisitos e características no desenvolvimento de aplicações deste tipo.

Já a nossa metodologia proposta apresenta um cenário geral de aplicação, uma arquitetura e orientações (guidelines) de desenvolvimento para aplicações do tipo Handheld AR. Além disso, são apresentados detalhes de implementação relativos: à aquisição dos dados gerados pelos dispositivos sensores (neste caso uma RSSF), a uma modelagem semântica destes dados (como parte da solução para facilitar a aquisição, armazenamento e gerenciamento de dados), à criação de perfis de usuário (para prover interfaces de interação intuitivas) e à disponibilização destas informações utilizando técnicas de RA, apresentando as informações geradas como objetos virtuais (imagens virtuais, efeitos de vibração e efeitos sonoros), os quais são sobrepostos em um cenário real utilizando o telefone celular como dispositivo de interação com o usuário.

Finalmente, nós apresentamos um estudo de caso que desenvolve uma aplicação do tipo Handheld $A R$ (protótipo) para o monitoramento da temperatura na sala de servidores do PAD (Grupo de Sistemas Pervasivos e de Alto Desempenho). Neste estudo de caso, são descritos os materiais, o cenário, os serviços oferecidos, o fluxo de desenvolvimento e as avaliações do protótipo.

Palavras Chave: Realidade Aumentada, Dispositivos Móveis, Telefones Celulares, Dispositivos Sensores, Modelagem e Processamento Semântico. 


\section{Abstract}

Handheld Augmented Reality or Handheld AR is the implementation of Augmented Reality (AR) systems into handheld devices. Handheld AR applications use the handheld device's camera to recognize markers (inserted into the environment). This process enables data entry into AR system. The response generated for these applications are presented as virtual images (3D graphics) on the handheld device's display.

New Handheld AR applications use a mobile phone camera, markers and wireless sensors (inserted into the environment) as elements for dynamic data entry into the AR system. These applications show interesting characteristics for: sensing, visualization and interaction in ambient intelligence (AmI) and ubiquitous environments. But, the lack of documentation and complexity development process produce the need for methodologies and tools for a fast and simple development model.

For these reason, this work presents a "Methodology for Design and development Handheld AR applications", which present an especial support for mobile phones and wireless sensor networks, making a description and clear roadmap of the requirements and characteristics in the Handheld AR development process model.

Our methodology proposed presents a general scenario of application, a software architecture and application development guidelines. Moreover, we present implementation details over: acquisition data process, semantic modeling data, development of user profiles and visualization of the information using AR techniques, showing these information as virtual objects (virtual images, vibration effects and sound effects). These virtual objects use the handheld device as interaction interface between the user and real world.

Finally, we present a case study that develops a Handheld AR application (prototype) to monitoring the temperature in the PAD (Pervasive and Distributed Computing Group) server's room. In this case study, we describe the materials, the scenario, the services offered, the development process and prototype evaluations.

Keywords: Augmented Reality, Handheld AR, Handheld Devices, Mobile Phones, Wireless Sensors, Semantic Web, Semantic Process. 


\section{Conteúdo}

\section{Lista de Figuras}

\section{Lista de Tabelas}

\section{Lista de Abreviaturas}

1 Introdução 1

1.1 Motivação . . . . . . . . . . . . . . . . . . . . . 4

1.2 Justificativas . . . . . . . . . . . . . . . . . 5

1.3 Descrição do Problema . . . . . . . . . . . . . . . . . . . . 6

1.3.1 Handheld $A R \ldots \ldots \ldots \ldots$

1.3.2 Dispositivos Sensores . . . . . . . . . . . . . . . 6

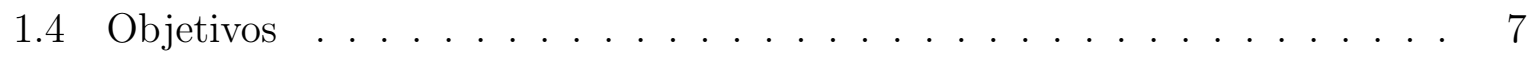

1.4 .1 Objetivo Geral . . . . . . . . . . . . . . . 7

1.4 .2 Objetivos Específicos . . . . . . . . . . . . . 7

1.5 Metodologia . . . . . . . . . . . . . . . . . 8

1.6 Organização da Dissertação . . . . . . . . . . . . . . . . . . . . . . . . 9

2 Computação Móvel e Ubíqua $\quad 10$

2.1 Computação Móvel . . . . . . . . . . . . . . . . . . . . . . . 10

2.1.1 Plataforma Handheld . . . . . . . . . . . . . . . . . . . . . . . 11

2.2 Computação Ubíqua . . . . . . . . . . . . . . . . . . . . . . . . . . . 14

2.2.1 Dispositivos Sensores com Interfaces de Comunicação Sem Fio . . . 15

2.3 Sinergia entre a Computação Móvel, Ubíqua e a Realidade Aumentada . . 19 
3.1 Realidade Aumentada (RA) . . . . . . . . . . . . . . . 20

3.2 Realidade Aumentada Móvel . . . . . . . . . . . . . . . . . . . . . . 21

3.3 Handheld Augmented Reality . . . . . . . . . . . . . . . . . . . . 22

3.3.1 Captura de vídeo . . . . . . . . . . . . . . . 25

3.3.2 Reconhecimento de marcadores . . . . . . . . . . . . 26

3.3.3 Renderização de Objetos Virtuais . . . . . . . . . . . . . . . 33

3.3.4 Estratégias de Processamento . . . . . . . . . . . . . 37

3.3.5 Vantagens da Handheld Augmented Reality . . . . . . . . . . . . . . 40

3.3.6 Limitações da Handheld Augmented Reality . . . . . . . . . . . . . 40

4 Modelagem e Processamento Semântico de Dados 41

4.1 Web Semântica . . . . . . . . . . . . . . . . . . . 41

4.2 Dispositivos Sensores, Dados e Semântica . . . . . . . . . . . . . . . . 42

4.3 Resource Description Framework (RDF) . . . . . . . . . . . . . . 45

4.3.1 O Modelo de Dados do Resource Description Framework (RDF) . . 45

4.3 .2 Especificação da Sintaxe RDF . . . . . . . . . . . . . . . . . 47

4.4 Resource Description Framework Schema (RDF Schema) . . . . . . . . . 48

4.4 .1 Definição de Classes . . . . . . . . . . . . . . . . . . . 49

4.4 .2 Definição de Propriedades . . . . . . . . . . . . . . . . . . 49

4.5 Personalização de Informações . . . . . . . . . . . . . . . . . . . . . . . 51

5 Grupos de Pesquisa e Trabalhos Relacionados 53

5.1 Studierstube . . . . . . . . . . . . . . . . . . 53

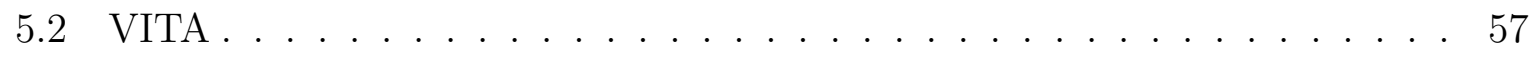

5.3 Nokia Center Research . . . . . . . . . . . . . . . . . . . 58

5.4 Trabalhos Relacionados (Individuais) . . . . . . . . . . . . . 59

5.5 Comparação com os Trabalhos Relacionados . . . . . . . . . . . . . . 60 
6.1 Cenário Geral de Aplicação . . . . . . . . . . . . . . . . . . . . . . . . . 61

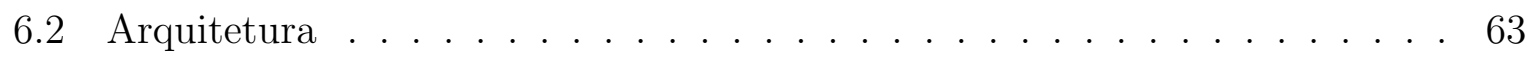

6.3 Orientações ( Guidelines) de desenvolvimento para aplicações do tipo Handheld $A R$. . . . . . . . . . . . . . . . . . . . . . . . 64

6.3 .1 Definição da Aplicação . . . . . . . . . . . . . . . . . . . . . . . . 64

6.3.2 Definição dos Dispositivos Sensores para a Aquisição de Dados . . . 66

6.3.3 Definição da Modelagem Semântica . . . . . . . . . . . . . . . 67

6.3.4 Definição do Dispositivo Móvel . . . . . . . . . . . . . . . . 68

6.3.5 Disponibilização das Informações . . . . . . . . . . . . . . . . . 69

6.4 Modelagem Semântica de Dados . . . . . . . . . . . . . . . 70

6.4 .1 Sensor Schema . . . . . . . . . . . . . . . 71

6.4 Ambient Schema . . . . . . . . . . . . . . . 72

6.4.3 Application Schema...................... 73

6.4.4 Sensor Data Schema . . . . . . . . . . . . . . 74

6.4.5 User Phone Profile Schema . . . . . . . . . . . . . . . 75

6.5 Mecanismos de Aquisição de Dados . . . . . . . . . . . . . . . . . 76

6.5.1 Aquisição de Dados pela Câmera . . . . . . . . . . . . . . . 76

6.5.2 Aquisição de Dados pelos Dispositivos Sensores . . . . . . . . . . . 80

6.6 Componente Lógico da Aplicação . . . . . . . . . . . . . . . . . . . . . 85

6.7 Renderização de Objetos Virtuais . . . . . . . . . . . . . . . . . . 86

$\begin{array}{llr}7 & \text { Estudo de Caso } & 90\end{array}$

7.1 Materiais para o Desenvolvimento . . . . . . . . . . . . . 90

7.2 Definição do Estudo de Caso . . . . . . . . . . . . . . . . . . . . . . . 91

7.2 .1 Cenário . . . . . . . . . . . . . . . . . . . . . 91

7.2 .2 Serviços Oferecidos . . . . . . . . . . . . . . . . 92

7.2.3 Plataforma de Implementação . . . . . . . . . . . . . . . . . . . . 93 
7.3 Desenvolvimento do Protótipo . . . . . . . . . . . . . . . . . 93

7.4 Avaliações . . . . . . . . . . . . . . . . . . . . . . . . . . . . . . . . . . . 98

7.4.1 Avaliações do Reconhecimento dos Marcadores . . . . . . . . . . . . 98

7.4.2 Avaliações dos Dados Transmitidos pela RSSF . . . . . . . . . . . . 100

7.4.3 Avaliações do Resultado da Lógica de Inferência . . . . . . . . . . . 102

7.4.4 Avaliações dos Objetos Virtuais . . . . . . . . . . . . . . . . 103

7.4.5 Análise de Desempenho . . . . . . . . . . . . . 105

8 Considerações Finais $\quad 106$

8.1 Contribuições da Dissertação . . . . . . . . . . . . . . . . 106

8.2 Limitações da Dissertação . . . . . . . . . . . . . . . . . . 107

8.3 Conclusões . . . . . . . . . . . . . . . . . . . . . . . 107

8.4 Perspectivas e Trabalhos Futuros . . . . . . . . . . . . . . . . 109

8.5 Publicação de Artigos em Eventos Nacionais e Internacionais . . . . . . . . 109

Referências $\quad 110$ 


\section{Lista de Figuras}

1.1 Temas de Pesquisa Estudados nesta Dissertação. . . . . . . . . . . . . . . . 4

2.1 Classificação do Computador Pessoal Portátil (Weiss, 2002). . . . . . . . . 11

2.2 Taxonomia dos Dispositivos Computacionais de Tamanho Médio e Pequeno (Rukzio et al., 2005). . . . . . . . . . . . . . . . . . . . . 12

2.3 Rede de Sensores Sem Fio $($ Roca, 2008) . . . . . . . . . . . . . . 16

2.4 Sistemas RFID. . . . . . . . . . . . . . . . . . . 17

2.5 Sinergia entre a Computação Móvel, Ubíqua e RA (Kjeldskov, 2002). . . 19

3.1 Virtuality Continuum (Milgram; Kishino, 1994). . . . . . . . . . . . . 20

3.2 Sistema de Realidade Aumentada Móvel (Studierstube, 2007). . . . . . . . 22

3.3 Handheld AR on Mobile Phone (Neto et al., 2006). . . . . . . . . . . . . . 23

3.4 Handheld AR on PDA (Wagner et al., 2005). . . . . . . . . . . . . . 23

3.5 Handheld AR on Smartphone (Henrysson; Billinghurst; Ollila, 2006). . . . 24

3.6 Fluxo de Processamento de uma Aplicação do tipo Handheld AR. . . . . . 25

3.7 Marcador do tipo QR Code (QrCode, 2006) . . . . . . . . . . . . 27

3.8 Marcador do tipo VSCode (VSCode, 2007). . . . . . . . . . . . . . 28

3.9 Marcador do tipo Data Matrix (Data Matrix, 2007). . . . . . . . . . . . 28

3.10 Marcador do tipo Visual Code (Rohs, 2004; 2005). . . . . . . . . . . . . . . 29

3.11 Marcador do tipo ShotCode (ShotCode, 2007) . . . . . . . . . . . . 30

3.12 Marcador do tipo ColorCode (ColorCode, 2007) . . . . . . . . . . . . . 31

3.13 Marcador do ARToolKitPlus (ARToolKitPlus, 2007). . . . . . . . . . . . 32

3.14 Bibliotecas e Tecnologias para Aplicações do tipo Handheld AR. . . . . . . 36

3.15 Aplicações de RA como Sistemas de Informação (Bertelsen; Nielsen, 2000). 38

4.1 A Semantic Approach to Data Management in Sensor Networks (Lewis, 2006). . . . . . . . . . . . . . . . . . . 43 
4.2 Representação Gráfica de uma Declaração RDF. . . . . . . . . . . . . . . . 47

4.3 Grafo da Declaração RDF da Tabela 4.2 . . . . . . . . . . . . . . . . . . 47

4.4 Sintaxe XML da Declaração RDF para o Sensor TmoteSky do PAD. . . . . 47

4.5 Uma Taxonomia Parcial do UserML (Heckmann, 2005) . . . . . . . . . . . 52

5.1 Fluxo de Processamento de uma Aplicação do Tipo Handheld AR que utiliza Marcadores (Wagner, 2007). . . . . . . . . . . . . . . 55

5.2 Visualization of Sensor Data Using Handheld AR (Rauhala, 2006). . . . . 58

5.3 Mobile Augmented Reality Systems (Kahari;Murphy, 2006). . . . . . . . . . 59

6.1 Cenário Geral de Aplicação da Nossa Metodologia de Desenvolvimento. . . 62

6.2 Arquitetura para Aplicações do Tipo Handheld AR que Utilizam Dispositivos Sensores com Interfaces de Comunicação Sem Fio. . . . . . . . . . . . 63

6.3 Guidelines - Definição da Aplicação. . . . . . . . . . . . . . . 65

6.4 Guidelines - Definição da Aquisição de Dados. . . . . . . . . . . . . . . 67

6.5 Guidelines - Definição dos vocabulários RDF. . . . . . . . . . . . 68

6.6 Guidelines - Definição do dispositivo. . . . . . . . . . . . . . . . . . 69

6.7 Guidelines - Disponibilização da Informação. . . . . . . . . . . . . . . . . . 70

6.8 Sinergia dos Schemas Projetados nesta Dissertação. . . . . . . . . . . . . . 76

6.9 Verificação da Câmera. . . . . . . . . . . . . . . . . . . . . . . . 77

6.10 Acesso e Controle da Câmera. . . . . . . . . . . . . . . . . 77

6.11 Captura da Imagem. . . . . . . . . . . . . . . . . . . . . . . 78

6.12 Criação de Marcadores. . . . . . . . . . . . . . . . . . . . . . . . . . 79

6.13 Reconhecimento de Marcadores. . . . . . . . . . . . . . . . . . . . 79

6.14 Descoberta e Conexão com Dispositivos Bluetooth. . . . . . . . . . . . . . 81

6.15 Seqüência Lógica da Modelagem e Processamento Semântico. . . . . . . . . 82

6.16 O Sensor Schema em formato RDF. . . . . . . . . . . . . . 83

6.17 Classe Java SensorSchema. . . . . . . . . . . . . . . . . . . . . . . . . . . 84

6.18 Diagrama Esquemático do Processamento Semântico de Dados. . . . . . . 84

6.19 Diagrama Esquemático do Componente Lógico da Aplicação. . . . . . . . . 86 
6.20 Renderização de Imagens Virtuais. . . . . . . . . . . . . . . . . . . . . 87

6.21 Renderização de Efeitos de Vibração. . . . . . . . . . . . . . . . . . . . . . 88

6.22 Bibliotecas Proprietárias para Efeitos de Vibração. . . . . . . . . . . . . . 88

6.23 Renderização de streams de Áudio. . . . . . . . . . . . . . . . . . . . . . 89

7.1 Sala de Pesquisa do PAD. . . . . . . . . . . . . . . . . . 92

7.2 Arquitetura Baseada na Plataforma J2ME. . . . . . . . . . . . . . . . . 93

7.3 Transmissão dos Dados Obtidos pelos Nós Sensores. . . . . . . . . . . . . . 94

7.4 Fluxo de Processamento do Estudo de Caso. . . . . . . . . . . . . . . . 95

7.5 User Phone Profile do Administrador do PAD. . . . . . . . . . . . . . . 96

7.6 Quadro de Resultado de $\%$ FFR. . . . . . . . . . . . . . . . . . 99

7.7 Reconhecimento de Marcadores em um Cenário de Controle. . . . . . . . . 99

7.8 Resultados do Reconhecimento de Marcadores na Sala de Servidores do PAD.100

7.9 Resultados da Transmissão de Dados na Sala de Servidores do PAD. . . . . 101

7.10 Renderização de Imagens Virtuais para os Servidores do PAD. . . . . . . . 103

7.11 Renderização de Efeitos Sonoros e de Vibração. . . . . . . . . . . . . . . . 104

7.12 Renderização de Objetos Virtuais para os Dados de Temperatura dos Servidores do PAD . . . . . . . . . . . . . . . . . . . . . . 104 


\section{Lista de Tabelas}

2.1 Características da Plataforma Handheld . . . . . . . . . . . . . . . . 12

2.2 Características de Hardware dos Telefones Celulares e Smart-

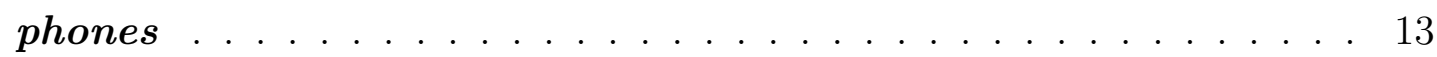

2.3 Características de Software dos Telefones Celulares e Smartphones 13

4.1 Sentenças Sintaticamente Diferentes com o Mesmo Significado . . 46

4.2 Partes de uma Declaração RDF . . . . . . . . . . . . . . 46

5.1 Características da Implementação do ARToolKitPlus . . . . . . . . 54

7.1 Características dos Telefones Celulares Utilizados . . . . . . . . . . 90

7.2 Servidores do PAD $\ldots \ldots \ldots \ldots$. . . . . . . . . . . . . . . . 92

7.3 Taxas Aproximadas de Transmissão em $K B / s \ldots \ldots 1$

7.4 Resultados das Regras de Inferência . . . . . . . . . . . . . . 102 


\section{Lista de Abreviaturas}

3G Terceira Geração de Telefonia Celular

ANATEL Agência Nacional de Telecomunicações

API Application Programming Interface

AR Augmented Reality

B2B Business to Business

FHSS Frequency Hopping Spread Spectrum

GPS Global Positioning System

GPU Graphics Processing Unit

HMDs Head-Mounted Displays

IDE Integrated Development Environment

IEEE Institute of Electrical and Electronics Engineers

ISM Industrial Scientific Medical

ISO do grego ísos, "igual", de uso internacional para designar a International

Organization for Standardization

J2ME Java 2 Micro Edition

JSR Java Specification Request

MARA Mobile Augmented Reality Applications

MARS Mobile Augmented Reality System

MMAPI Mobile Media API

MMS Multimedia Message Service

OSI Open System Interconnection 
OWL Web Ontology Language

PAN Personal Area Network

PDAs Personal Digital Assistants

PWLAN Public Wireless Local Area Network

RA Realidade Aumentada

RDF Resource Description Framework

RDF Schema Resource Description Framework Schema

RFID Radio-Frequency IDentification

RSSF Redes de Sensores Sem Fio

RSSI Received Signal Strength Intensity

SDK Software Development Kit

SMS Short Message Service

Uls User Interfaces

URI Uniform Resource Identifier

URL Uniform Resource Locator

UMPCs Ultra Mobile PCs

VGA Video Graphics Array

W3C The World Wide Web Consortium

WAP Wireless Application Protocol

WECA Wireless Ethernet Compatibility Alliance

Wi-Fi Wireless Fidelity

WLAN Wireless Local Area Network

WSP Wireless Session Protocol

XML EXtensible Markup Language 


\section{Introdução}

Nos últimos anos, os telefones celulares estão sendo desenvolvidos da mesma forma que os computadores pessoais portáteis, com câmeras integradas de melhor resolução, processadores mais rápidos e potentes, telas de cor sensíveis ao tato, interfaces de comunicação sem fio (Bluetooth, ZigBee, padrões IEEE 802.11 ou Wi-Fi, etc.), receptores GPS, sensores integrados (por exemplo: acelerômetros, magnetômetros), unidades de armazenagem com grande capacidade e removíveis (Memory Card), e processadores gráficos 3D dedicados (ANDEL; PETROVSKI, 2006). Além disso, a possibilidade de desenvolver aplicações em linguagens de programação como Java, $\mathrm{C}++$ e Python, proporciona uma enorme aplicação prática. Em conseqüência, o telefone celular transforma-se em uma nova e atraente plataforma para sistemas de Realidade Aumentada (RA) (BILLINGHURST; HENRYSSON, 2006) por permitir ao usuário obter informações e interagir com o ambiente em tempo real, disponibilizando e apresentando estas informações como imagens virtuais que são inseridas no mundo real utilizando as telas dos telefones celulares.

Uma definição bastante difundida de RA é da sobreposição de imagens virtuais geradas por computador em um ambiente real, utilizando para isso algum dispositivo tecnológico, técnicas de visão por computador e de computação gráfica (MILGRAM; KISHINO, 1994). Nesse sentido, entenda-se a RA como um cenário composto por objetos reais e imagens virtuais, onde se faz necessário o uso de dispositivos para a captura (câmeras) e visualização (telas) das imagens virtuais inseridas no mundo real, assim como o uso de ferramentas de software que permitam a geração das imagens virtuais e sua mistura com o mundo real. Já Azuma et al. (2001) evitando a relação da RA com qualquer tipo de tecnologia para sua implementação, define três características fundamentais e distintivas para um sistema de RA: combinar o mundo real com o virtual; interagir em tempo real; e alinhar as imagens reais e virtuais de forma que a visualização esteja sincronizada fisicamente e em tempo real, o que é chamado de "Registro".

O uso de dispositivos móveis ou handheld devices ${ }^{1}$ na implementação de um sistema

\footnotetext{
${ }^{1}$ Handheld devices: Dispositivos computacionais pequenos, compostos tipicamente por uma tela pequena para a apresentação das informações e um teclado integrado ou uma tela sensível ao toque para o ingresso de dados, como por exemplo: os telefones celulares, PDAs, etc.
} 
de RA é denominado Handheld Augmented Reality ou simplesmente Handheld AR (WAGNER; SCHMALSTIEG, 2003). Entenda-se por "handheld devices" ou "dispositivos móveis" os seguintes dispositivos: telefones celulares, Smartphones, Personal Digital Assistants (PDAs) e Ultra Mobile PCs (UMPCs) (RUKZIO et al., 2005). Portanto, nesta dissertação é utilizado o termo "Handheld $A R$ " para descrever as aplicações de RA instaladas e executadas nestes tipos de dispositivos móveis.

Aplicações do tipo Handheld $A R$ se desenvolveram e evoluíram nos últimos anos em muitas áreas de aplicação como: sistemas de informação (ASSAD et al., 2003), navegação (HENRYSSON; OLLILA, 2004), engenharia (TRäSKBäACK; HALLER, 2004), entretenimento (jogos) (WAGNER et al., 2005), educação (WAGNER; SCHMALSTIEG; BILLINGHURST, 2006), colaboração (ANDEL; PETROVSKI, 2006) e turismo (BRUNS et al., 2007). Estas aplicações utilizam a câmera integrada no dispositivo móvel para reconhecer marcadores ${ }^{2}$ (inseridos no ambiente), este processo de reconhecimento permite a entrada de dados para o sistema de RA. As informações geradas nestas aplicações são apresentadas como imagens virtuais nas telas dos dispositivos móveis.

Já aplicações do tipo Handheld $A R$ mais complexas, utilizam dispositivos sensores (com interfaces de comunicação sem fio) como RFID tags (BROLL et al., 2006), Redes de Sensores Sem Fio (RSSF) (RAUHALA; GUNNARSSON; HENRYSSON, 2006) e GPS (KäHäRI; MURPHY, 2006), como fontes de entrada de dados dinâmicos para o sistema de RA, junto à câmera e os marcadores. Por exemplo, em (RAUHALA; GUNNARSSON; HENRYSSON, 2006) o telefone celular permite ao usuário visualizar informações, que não lhes são perceptíveis a simples vista, como a umidade de um ambiente. Nesse sentido, aplicações deste tipo foram apresentadas como uma das dez tecnologias emergentes no 2007 (JONIETZ, 2007).

Portanto, aplicações que combinam técnicas de RA, dados obtidos por dispositivos sensores com interfaces de comunicação sem fio e dispositivos móveis como os telefones celulares, apresentam características interessantes para áreas de aplicação como: sensoriamento, monitoramento, visualização e interação em ambientes inteligentes e ubíquos. Entretanto, alguns desafios aparecem ao se pensar em aplicações deste tipo:

- Como produzir um cenário adequado, com imagens e informações juntas nas telas pequenas dos telefones celulares para possibilitar interfaces de interação eficientes, intuitivas e personalizadas?

- Como adquirir eficientemente as informações dos dispositivos sensores, levando em consideração as capacidades de processamento e taxas de transmissão de dados?

\footnotetext{
${ }^{2}$ Marcador: pedaços de papel com formatos e desenhos geométricos que permitem, ao sistema de RA, definir um sistema de coordenadas espacial e a orientação dos objetos do mundo real a partir do ponto de vista do usuário, para sobrepor as imagens virtuais nos objetos do mundo real de forma adequada.
} 
- Como armazenar e gerenciar as informações adquiridas dos dispositivos sensores contornando a limitação de memória dos telefones celulares?

- Como aperfeiçoar o processo de desenvolvimento de aplicações do tipo Handheld $A R$, facilitando o trabalho do desenvolvedor?

Nesse sentido, diversos trabalhos vêm sendo desenvolvidos com diversos enfoques buscando superar estes desafios. Nilsen (2006) e Dunser et al. (2007) apresentam trabalhos focando o desenvolvimento de técnicas e modelos a serem utilizados no projeto e desenvolvimento de aplicações baseadas em RA. Billinghurst e Henrysson (2006) propõem interfaces de interação para aplicações do tipo Handheld $A R$.

Já na área de sensores, a utilização de técnicas da web semântica são apresentadas por Tolksdorf et al. (2005) e Lewis et al. (2006), como soluções simples para a coleta, armazenamento e gerenciamento de dados obtidos por dispositivos sensores. Nestes trabalhos se apresentam aplicações que utilizam o RDF e RDF Schema para tratar os processos de armazenamento e gerenciamento dos dados gerados por RSSF em cenários do mundo real, como no controle de tráfego e ambientes industriais. Noguchi, Mori e Sato (2006) propõem aplicações de sensoriamento em função do contexto. Também é introduzido por eles o conceito de sensor services, que são serviços de informação gerados pelos dados adquiridos nas aplicações de sensoriamento. Porém, todos estes trabalhos não utilizam dispositivos móveis para a coleta e processamento dos dados nas suas arquiteturas e nem técnicas de RA para a apresentação das informações.

Portanto, baseado na pesquisa bibliográfica realizada, constata-se a inexistência de um mecanismo ou infra-estrutura que auxilie no desenvolvimento de aplicações do tipo Handheld AR. Neste sentido, surge a idéia de desenvolver uma "metodologia" que permita ajudar no projeto e facilitar o processo de desenvolvimento de aplicações do tipo Handheld $A R$, em especial aplicações que utilizem telefones celulares e dispositivos sensores ${ }^{3}$, permitindo assim complementar a literatura existente nesta linha de pesquisa.

A metodologia proposta apresenta detalhes de implementação relativos à aquisição dos dados gerados pelos dispositivos sensores (neste caso uma RSSF), a modelagem semântica destes dados e das preferências do usuário em um perfil (para prover interfaces de interação intuitivas) e a disponibilização destas informações utilizando técnicas de RA, apresentando as informações geradas como objetos virtuais (imagens virtuais, efeitos de vibração e efeitos sonoros), os quais são sobrepostos em um cenário real utilizando o telefone celular como dispositivo de interação com o usuário.

\footnotetext{
${ }^{3}$ Note-se que na presente dissertação, o termo "dispositivos sensores" faz referência só a sensores com interfaces de comunicação sem fio, o que é detalhado no Capítulo 2, na subseção 2.2.1.
} 
Nesse sentido, os temas de pesquisa a serem estudados no desenvolvimento da presente dissertação incluem a combinação de técnicas de RA, técnicas da web semântica, dispositivos sensores com interfaces de comunicação sem fio e dispositivos móveis. Esta combinação é apresentada na figura 1.1.

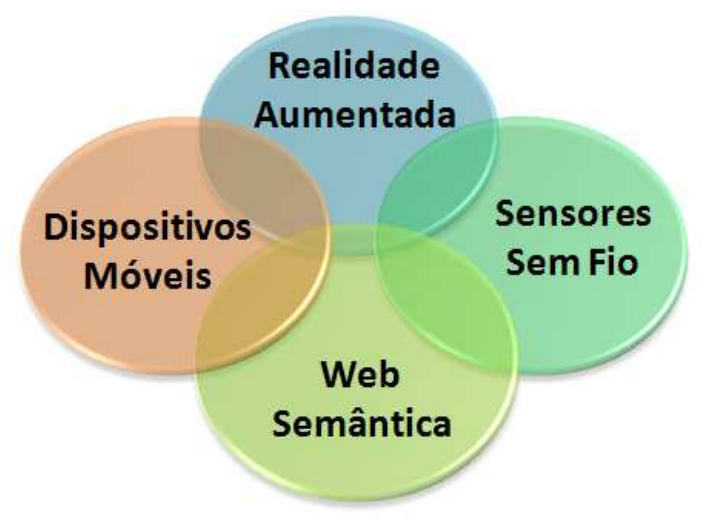

Figura 1.1: Temas de Pesquisa Estudados nesta Dissertação.

\subsection{Motivação}

As motivações deste trabalho são sumarizadas a seguir:

- Interesse do PAD (Grupo de Sistemas Pervasivos e de Alto Desempenho) em desenvolver pesquisas sobre Realidade Aumentada, Computação Móvel e Ubíqua, para analisar como estas pesquisas interagem com as linhas de pesquisa tradicionais do PAD, como Redes de Sensores, Ambientes Inteligentes, Computação Ciente ao Contexto $^{4}$ (Context Awareness) e Computação de Alto Desempenho;

- Explorar e superar os desafios relacionados ao desenvolvimento de aplicações que combinam técnicas de RA, dados obtidos por dispositivos sensores e dispositivos móveis, em especial aplicações que possam servir e ajudar no âmbito social e nas atividades diárias das pessoas;

- Crescimento da indústria, tecnologia e usuários de telefones celulares, especialmente no Brasil, assim como os novos usos que os usuários podem dar a estes dispositivos nas suas atividades diárias.

\footnotetext{
${ }^{4}$ Contexto: é um termo utilizado na computação ciente ao contexto que descreve qualquer informação que pode ser utilizada por um sistema computacional para caracterizar a situação de uma entidade que é considerada relevante entre o usuário e o sistema.
} 


\section{$1.2 \quad$ Justificativas}

O crescimento no desenvolvimento de aplicações de sensoriamento e monitoramento utilizando dispositivos sensores com interfaces de comunicação sem fio e o uso de dispositivos móveis para a coleta, processamento, interação e visualização das informações, inclusive utilizando técnicas de RA, fazem destas tecnologias tópicos interessantes de pesquisa. Portanto, a necessidade de uma metodologia que ajude para um rápido e simples desenvolvimento deste tipo de aplicações justifica o desenvolvimento da presente dissertação.

O interesse em visualizar os dados obtidos pelos dispositivos sensores (instalados em diversos ambientes) com técnicas de RA justifica-se pelas potencialidades do sistema visual humano para analisar e entender informações (RAUHALA; GUNNARSSON; HENRYSSON, 2006). Além disso, pessoas com deficiências poderiam utilizar este modo de visualização e outros modos de interação (efeitos de vibração efeitos sonoros) (TORI; KIRNER; SISCOUTTO, 2006) como formas de incrementar a análise e entendimento das informações (LóPEZ; RODRIGUEZ; VáZQUEZ, 2004).

A escolha do telefone celular como plataforma de desenvolvimento na presente pesquisa é justificada pelas atuais características de hardware, software e design que apresenta este dispositivo (BILLINGHURST; HENRYSSON, 2006). Além disso, o telefone celular não tem o problema da aceitação social que tem os dispositivos de RA tradicionais (DANADO, 2005).

A necessidade de facilitar a aquisição, processamento, gerenciamento e armazenamento dos dados obtidos pelos dispositivos sensores justifica o uso de técnicas da web semântica para estes processos (TOLKSDORF et al., 2005) (LEWIS et al., 2006), isto porque a web semântica permite associar descrições às informações geradas, permitindo aos computadores interpretar e realizar inferências sobres estas informações (NETO; PIMENTEL, 2003).

A escolha do RDF (KLYNE; CARROLL; MCBRIDE, 2007) e RDF Schema (BRICKLEY; GUHA; MCBRIDE, 2007) na modelagem e processamento semântico dos dados justificam-se pelas características do RDF que permitem criar um modelo simples de dados, com uma semântica formal (MEDINA; SANCHEZ; CHAVEZ, 2007) e porque o RDF permite descrever recursos (ambientes, usuários, dispositivos sensores, aplicações e dados) com metadados relevantes, o que é útil para aplicações cientes ao contexto (FORSTADIUS; LASSILA; SEPPäNEN, 2005). Já a estrutura do RDF Schema ou vocabulário permite modelar propriedades, relações e valores para descrever os recursos de forma clara, o que permite implementar restrições, evitando diversas interpretações de uma propriedade ou relação para distintos recursos, garantido uma única interpretação semântica dos dados (MEDINA; SANCHEZ; CHAVEZ, 2007). 


\subsection{Descrição do Problema}

Além dos desafios gerados na implementação de aplicações que combinam técnicas de RA, dados obtidos por dispositivos sensores e dispositivos móveis (descritos na introdução do presente trabalho), nós identificamos alguns problemas específicos para aplicações do tipo Handheld $A R$ e dispositivos sensores com interfaces de comunicação sem fio programáveis como as RSSF, que são descritos a seguir.

\subsubsection{Handheld AR}

- A carência de documentação e a complexidade no desenvolvimento de aplicações do tipo Handheld $A R$, gera a necessidade de metodologias e ferramentas que ajudem a um desenvolvimento rápido e simples (NETO et al., 2006);

- Necessidade de novas interfaces de interação intuitivas ou interfaces intuitivas ${ }^{5}$ que permitam apresentar as informações obtidas pelos dispositivos sensores como objetos virtuais da forma mais adequada e personalizada (BILLINGHURST; HENRYSSON, 2006);

- Necessidade de técnicas de desenvolvimento, implementação e avaliação da usabilidade dos dispositivos móveis, interfaces de interação e aplicações do tipo Handheld $A R$ (BILLINGHURST; HENRYSSON, 2006).

\subsubsection{Dispositivos Sensores}

- A aquisição dos dados é feita por dispositivos sensores heterogêneos com algoritmos de processamento complexos, proprietários e com projetos específicos, dificultando a reutilização e entendimento destes mecanismos de aquisição de dados para sistemas de análise e apresentação em dispositivos móveis (PETERSON, 2007);

- A grande quantidade de dados que podem ser gerados por diversos tipos de dispositivos sensores e a necessidade pela disponibilidade imediata destes dados, gera a necessidade de mecanismos de armazenamento e gerenciamento adequados, isto para facilitar a análise e a apresentação das informações, em tempo real (LEWIS et al., 2006) e utilizando técnicas de RA (GUNNARSSON et al., 2006).

\footnotetext{
${ }^{5}$ Uma "interface intuitiva" é imediatamente compreensível pelo usuário, sem a necessidade de nenhum conhecimento especial ou inicio (execução) do sistema. Estes conceitos são detalhados no capítulo 6.
} 


\subsection{Objetivos}

\subsubsection{Objetivo Geral}

- Criar uma "Metodologia de Desenvolvimento" para aplicações de realidade aumentada em dispositivos móveis, a qual visa ajudar no projeto e facilitar o processo de desenvolvimento de aplicações do tipo Handheld $A R$, em especial as aplicações que utilizem telefones celulares e dispositivos sensores com interfaces de comunicação sem fio, apresentando uma documentação bem definida e um roteiro claro sobre os requisitos e características no desenvolvimento de aplicações deste tipo.

\subsubsection{Objetivos Específicos}

- Analisar e descrever as características, vantagens e limitações dos dispositivos móveis e dispositivos sensores a serem aproveitados pelo presente trabalho de mestrado;

- Analisar, descrever e definir conceitos, tecnologias, ferramentas, dispositivos e processos que se deve seguir para desenvolver sistemas de RA para dispositivos móveis (aplicações do tipo Handheld $A R$ );

- Analisar e descrever as vantagens, limitações e desafios de utilizar técnicas da web semântica para modelar e processar os dados obtidos por dispositivos sensores. Também é analisada e descrita a utilização destes dados como fonte de entrada de informações para as aplicações tipo Handheld $A R$;

- Apresentar a metodologia proposta, e nessa abordagem descrever um cenário geral de aplicação e orientações teóricas (guidelines) relativas ao processo de planejamento e elaboração de uma aplicação do tipo Handheld $A R$, em especial aplicações que utilizam telefones celulares e dispositivos sensores. Nesse sentido, são descritas as características e requisitos relevantes na escolha dos elementos e dispositivos a serem utilizados;

- Desenvolver a modelagem conceitual e semântica das informações, criando $R D F$ Schemas ou vocabulários e arquivos RDF para armazenar os dados ${ }^{6}$ gerados pelos dispositivos sensores, facilitando assim sua disponibilização e apresentação;

- Criar e modelar perfis de usuário (user profiles) para descrever as suas preferências, isto para dar suporte às interfaces de interação intuitivas;

\footnotetext{
${ }^{6}$ Entenda-se por modelagem semântica dos dados ao processo de etiquetado (tagging) destes dados com informações semânticas, este processo é detalhado no Capítulo 4, na seção 4.2.
} 
- Descrever e desenvolver mecanismos para a aquisição dos dados obtidos pelos dispositivos sensores e para o processamento semântico dos dados, permitindo assim seu posterior armazenamento e gerenciamento como recursos em arquivos RDF;

- Analisar, descrever e desenvolver mecanismos para a renderização e apresentação de objetos virtuais ${ }^{7}$ (imagens virtuais, efeitos de vibração e efeitos sonoros);

- Desenvolver um estudo de caso baseado no sensoriamento e monitoramento de um ambiente controlado (neste caso a sala de servidores do PAD), para isto, utiliza-se uma RSSF, para o sensoriamento do ambiente, e telefones celulares para a apresentação das informações ao usuário;

- Avaliar o estudo de caso, analisando-se a efetividade (desempenho) do reconhecimento dos marcadores e renderização dos objetos virtuais. Além disso, analisa-se o desempenho da aplicação na transmissão dos dados obtidos pelos dispositivos sensores.

\subsection{Metodologia}

Como etapa inicial desta pesquisa, foi realizada uma ampla revisão bibliográfica dos principais conceitos, técnicas e ferramentas utilizadas no desenvolvimento de aplicações de RA e do estado da arte da Handheld $A R$, para determinar os requisitos e ferramentas adequadas para o desenvolvimento de nossa pesquisa.

Também foi objeto desta revisão: os tipos de dispositivos sensores com interfaces de comunicação sem fio e sua utilização em diversas áreas de aplicação; conceitos e técnicas para o processamento e gerenciamento dos dados obtidos pelos dispositivos sensores utilizando técnicas da web semântica.

Portanto, com a análise deste levantamento bibliográfico foi possível definir os objetivos da dissertação e estabelecer as bases conceituais para o desenvolvimento da metodologia proposta.

Já para definir uma prova de conceito que demonstrasse a viabilidade e aplicabilidade da metodologia proposta é desenvolvido um estudo de caso. Nesse sentido, foram estudados conceitos, técnicas, linguagens de programação, plataformas de desenvolvimento e ferramentas de software utilizadas no desenvolvimento de aplicações para telefones celulares. Além disso, algumas aplicações exemplo e bibliotecas de software foram desenvolvidas como parte do processo de compreensão das tecnologias e ferramentas disponíveis.

\footnotetext{
${ }^{7}$ Uma definição formal para o termo "Objeto Virtual" na presente dissertação é apresentada no Capítulo 3, na subseção 3.3.3.
} 


\subsection{Organização da Dissertação}

A dissertação está organizada em oito capítulos, descritos a seguir:

- Capítulo 1: Apresentou a introdução, motivação, justificativas, descrição do problema e objetivos da presente pesquisa;

- Capítulo 2: Apresenta os conceitos referentes à Computação Móvel e Ubíqua, sendo apresentada a plataforma Handheld para descrever as características de hardware, software e design dos dispositivos móveis ou handheld devices a utilizar. Além disso, neste capítulo também são apresentados conceitos sobre sensores com interfaces de comunicação sem fio como dispositivos da computação ubíqua;

- Capítulo 3: Apresenta os conceitos referentes à Realidade Aumentada, Realidade Aumentada Móvel e o estado da arte da Handheld Augmented Reality, que descreve os conceitos, técnicas, tecnologias e ferramentas para o desenvolvimento de aplicações do tipo Handheld $A R$;

- Capítulo 4: Apresenta os conceitos sobre técnicas da web semântica, descrevendo o RDF e o RDF Schema como ferramentas para facilitar a aquisição, processamento, gerenciamento, armazenamento e interoperabilidade dos dados gerados pelos dispositivos sensores. Além disso, é apresentado o conceito de perfis para descrever as preferências dos usuários;

- Capítulo 5: Apresenta os grupos de pesquisa e trabalhos relacionados relevantes para o desenvolvimento do presente trabalho de mestrado;

- Capítulo 6: Apresenta a "Metodologia de Desenvolvimento" proposta, a qual é composta pelas: orientações (guidelines) para a implementação de aplicações do tipo Handheld $A R$; a modelagem conceitual e semântica dos dados e do usuário; e o projeto e desenvolvimento das bibliotecas de software para processar e apresentar as informações geradas pela aplicação como objetos virtuais na plataforma Java para dispositivos móveis (J2ME);

- Capítulo 7: Apresenta a implementação do estudo de caso baseado na metodologia de desenvolvimento proposta, apresentando as ferramentas, algoritmos e desafios encontrados na implementação, além da avaliação do protótipo;

- Capítulo 8: Apresenta as contribuições atingidas pela presente pesquisa, as conclusões geradas e os trabalhos futuros a serem desenvolvidos. 


\section{Computação Móvel e Ubíqua}

As seções principais deste capítulo apresentam conceitos sobre computação móvel e ubíqua. Estes conceitos visam apresentar a plataforma Handheld para descrever a classificação, características e usos dos handheld devices ou dispositivos móveis. Além disso, tipos de sensores com interfaces de comunicação sem fio são apresentados como dispositivos ubíquos a serem aproveitados pela presente pesquisa. No final do capítulo é apresentada a relação entre os conceitos da computação móvel, computação ubíqua e a realidade aumentada.

\subsection{Computação Móvel}

A computação móvel é um termo genérico que descreve a convergência da computação com as tecnologias de comunicação sem fio. Caracteriza-se pelo uso de um "computador móvel" para conectar-se, processar, utilizar e executar informações em qualquer lugar e em qualquer momento (TAURION, 2002).

Nesse sentido, define-se um "computador móvel" como qualquer dispositivo de computação portátil com a capacidade de comunicação sem fio e que pode movimentar-se enquanto mantém sua funcionalidade. Independentemente do tipo de dispositivo de computação portátil a utilizar, este deve ter a capacidade de se comunicar com a parte fixa da rede e com outros computadores móveis, além de suportar: comunicação sem fio, portabilidade e mobilidade (FORMAN; ZAHORJAN, 1994).

O avanço da tecnologia e o aumento da capacidade de processamento dos componentes eletrônicos permitiram o surgimento de novas concepções do computador móvel ou computador portátil. Nesse sentido, segundo Weiss (2002) o computador pessoal se classifica em quatro plataformas ou categorias principais: computadores de mesa ou Desktops, computadores portáteis ou Laptops, computadores portáteis de tamanho reduzido ou Palmtops, e Handhelds ou dispositivos computacionais pequenos. Estas plataformas e sua relação com a portabilidade são apresentadas na figura 2.1. 


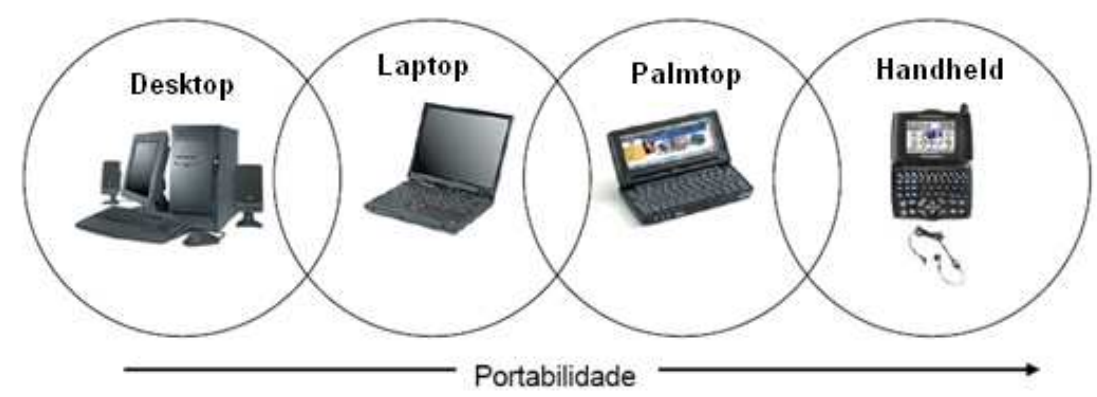

Figura 2.1: Classificação do Computador Pessoal Portátil (Weiss, 2002).

As laptops são os primeiros computadores pessoais portáteis, dotados de bateria e com monitor plano e teclado acoplado a um gabinete compacto, próprio para uso em situações de locomoção, como durante viagens. Já os Palmtops ou Portable Devices são menores que as laptops e podem ser levados dentro do bolso, porém, sendo mais facilmente operados quando apoiados sobre uma superfície (WEISS, 2002). Finalmente, os Handheld Devices ou dispositivos móveis convergem em algumas características que podem ser encontradas em dispositivos como os telefones celulares e PDAs, características como o pequeno tamanho destes dispositivos, permitindo ser usados apenas com uma mão.

\subsubsection{Plataforma Handheld}

Rukzio et al. (2005) propõem uma taxonomia que classifica os dispositivos computacionais de tamanho médio e pequeno em Portable Devices e Handheld Devices respectivamente. Alguns tipos de Portable Devices são os consoles de jogos portáteis, as câmeras digitais, tocadores de musica portáteis, etc. Já os Handheld Devices incluem telefones celulares, Smartphones, Personal Digital Assistants (PDAs) e UMPCs. Esta classificação é apresentada na figura 2.2 .

Além da taxonomia apresentada por Rukzio et al. (2005), para ser considerado um Handheld Device, os dispositivos devem apresentar as seguintes características:

- Deve prover suporte para o processamento e comunicação de dados por uma rede sem fio;

- Deve funcionar sem cabos, exceto temporariamente para a recarga ou para sincronizações com o computador de mesa;

- Deve ser operado facilmente com as mãos sem a necessidade de estar apoiado sobre uma mesa;

- Deve permitir a adição de novos aplicativos ou suportar conexão à Internet. 


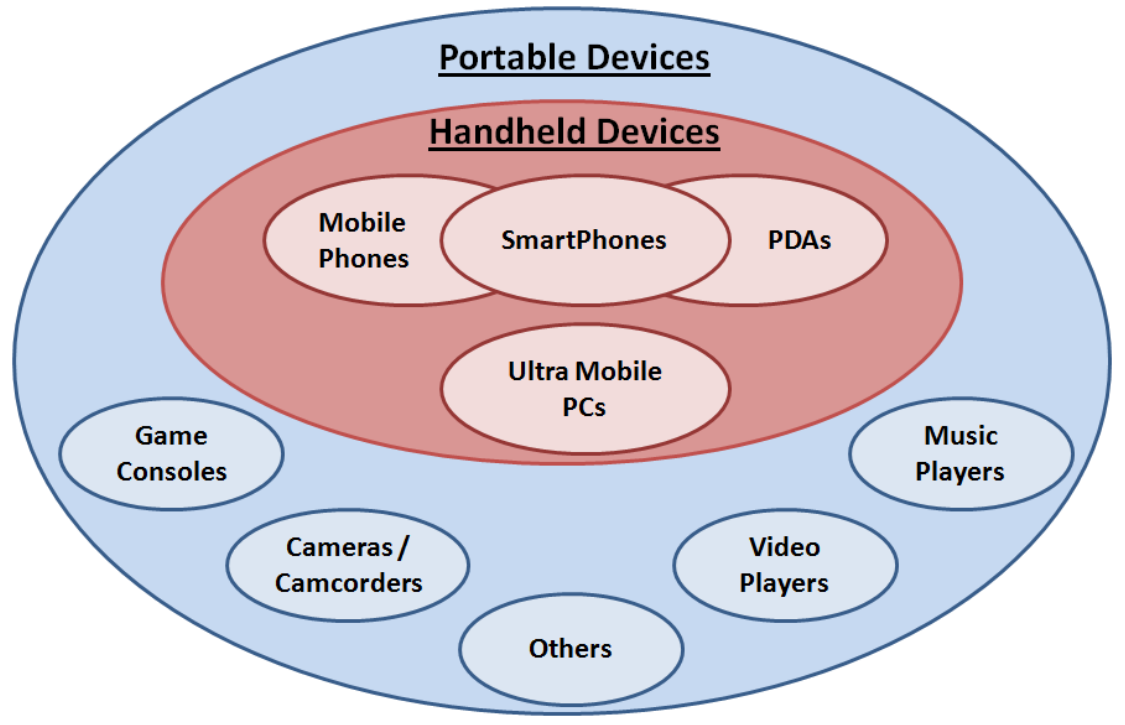

Figura 2.2: Taxonomia dos Dispositivos Computacionais de Tamanho Médio e Pequeno (Rukzio et al., 2005).

Características gerais da Plataforma Handheld são sumarizadas a seguir na tabela 2.1 (RUKZIO et al., 2005).

\section{Tabela 2.1: Características da Plataforma Handheld}

\begin{tabular}{|l|l|}
\hline Uso & Comunicação, processamento e entrada de dados \\
\hline Tamanho do dispositivo & Tamanho $(<10 ” \times 12 ")$ \\
\hline Tela (Display) & $<640 \times 320$ pixels \\
\hline Entrada & Teclado, caneta digital \\
\hline Conectividade & Interfaces sem fio \\
\hline
\end{tabular}

Portanto, baseados na taxonomia e características apresentadas para a plataforma Handheld, a presente dissertação considera como Handheld Devices ou dispositivos móveis os telefones celulares, Smartphones, PDAs e UMPCs. Porém, sendo o foco da presente pesquisa o uso de telefones celulares e Smartphones, a tabela 2.2 apresenta as principais características de hardware e a tabela 2.3 apresenta as principais características de software destes dispositivos (JANSEN; AYERS, 2007). 
Tabela 2.2: Características de Hardware dos Telefones Celulares e Smartphones

\begin{tabular}{|c|c|c|}
\hline & Telefone Celular & Smartphone \\
\hline Processador & Bom desempenho & Desempenho superior \\
\hline Memória & Boa capacidade & $\begin{array}{l}\text { Capacidade superior, } \\
\text { Possibilidade de HD embutido }\end{array}$ \\
\hline Tela (Cores) & 256 cores & $\begin{array}{l}16 \text { bit (65536 cores) ou } \\
\text { superior }\end{array}$ \\
\hline Tela (Tamanho) & $\begin{array}{l}>96 \times 65 \text { pixels } \\
<176 \times 208 \text { pixels }\end{array}$ & $\begin{array}{l}>176 \times 208 \text { pixels } \\
<640 \times 320 \text { pixels }\end{array}$ \\
\hline Card Slots & MiniSD ou MMCmobile & MiniSD ou MMCmobile \\
\hline Câmera & Fotografar & Fotografar, Video \\
\hline Entrada de Dados & Teclado & $\begin{array}{l}\text { Teclado, Toque ao tato, } \\
\text { Caneta digital }\end{array}$ \\
\hline Interface & Voz, Comunicação sem fio & $\begin{array}{l}\text { Voz, Comunicação sem fio } \\
\text { (Vários) }\end{array}$ \\
\hline Bateria & $\begin{array}{l}\text { Removível, Recarregável, } \\
\text { Lithium Ion, Polymer }\end{array}$ & $\begin{array}{l}\text { Removível, Recarregável, } \\
\text { Lithium Ion }\end{array}$ \\
\hline
\end{tabular}

Tabela 2.3: Características de Software dos Telefones Celulares e Smartphones

\begin{tabular}{|c|c|c|}
\hline & Telefone Celular & Smartphone \\
\hline Sistema Operacional & Proprietário, Symbian & $\begin{array}{l}\text { Linux, Windows Mobile } \\
\text { Symbian }\end{array}$ \\
\hline Informação Pessoal & Agenda, Calendário & $\begin{array}{l}\text { Recordatório associado com } \\
\text { a agenda e calendário }\end{array}$ \\
\hline Aplicações & Tocador de MP3 & $\begin{array}{l}\text { Tocador de MP3, Visualizador de } \\
\text { de documentos de Office }\end{array}$ \\
\hline Mensagens & $\begin{array}{l}\text { Mensagens de texto com } \\
\text { imagens e sons simples }\end{array}$ & Mensagens Multimídia \\
\hline Chat & SMS Chat & $\begin{array}{l}\text { Transferência de mensagens } \\
\text { ao instante }\end{array}$ \\
\hline Email & Gateway da Operadora Celular & POP ou IMAP \\
\hline Web & WAP & HTTP \\
\hline Comunicações & Infravermelho, Bluetooth & $\begin{array}{l}\text { Infravermelho, Bluetooth, } \\
W i \text {-Fi, GPS }\end{array}$ \\
\hline
\end{tabular}


Note-se, que mesmo tendo uma classificação e características de hardware, software e design diferenciadas entre os telefones celulares e os Smartphones, diversos fabricantes (Nokia, Motorolla, Sony Ericsson, etc.) chamam de telefones celulares a diversos dispositivos com as capacidades e características dos Smartphones. Portanto, no titulo da presente dissertação se faz referência ao termo "Telefones Celulares" como os dispositivos móveis que cumprem com pelo menos as seguintes capacidades e características:

- Uma interface de comunicação sem fio, por exemplo: Bluetooth, ZigBee, Wi-Fi, etc;

- Uma câmera embutida no dispositivo, preferencialmente uma câmera VGA ${ }^{1}$ de 1,3 Megapixels;

- Capacidades de execução e apresentação de gráficos 3D, reprodução de streams de áudio e efeitos de vibração.

\subsection{Computação Ubíqua}

Weiser define a computação ubíqua como a "tecnologia integrada ao ambiente, porém, de forma não intrusiva" (WEISER, 1991). O objetivo principal da computação ubíqua é permitir que a tecnologia seja integrada ao ambiente que cerca o usuário sem fazer com que ele modifique seu comportamento natural (WEISER, 1993). Assim, recursos computacionais são incorporados aos ambientes sem alterar o comportamento das pessoas, provendo facilidades como informações e serviços em qualquer momento e em qualquer lugar para auxiliar as atividades humanas.

A aplicação da computação ubíqua pode ser encontrada em diversos cenários, como em residências, meios de transporte e ambientes de trabalho, entre outros. Estas aplicações oferecem diversos serviços para estes cenários, como: segurança, comodidade, informação, entretenimento, etc. Para isto, precisa-se de diversos tipos de dispositivos para suportar e prover estes serviços. Exemplos de dispositivos utilizados nestes tipos de aplicações ubíquas incluem: sensores e atuadores para residências e automóveis, eletrodomésticos, ar-condicionado, aquecedor, relógios e etiquetas inteligentes (RFID tags), TVs, telefones celulares, Smartphones, PDAs, consoles de jogos, etc. (WEISER, 1993) (MONTEIRO, 2006).

Portanto, baseados no objetivo e na utilização da computação ubíqua, a metodologia proposta nesta pesquisa pretende implementar diversos recursos computacionais, como dispositivos sensores com interfaces de comunicação sem fio e dispositivos móveis como os telefones celulares, para adquirir e processar informações do ambiente e do usuário

\footnotetext{
${ }^{1}$ VGA: padrão de vídeo que aceita uma resolução de até 800x600 pixels para até 256 cores simultâneas. $<$ www.atlab.com/viewArticle.aspx >
} 
continuamente, para logo (em tempo real) apresentar estas informações para o usuário utilizando técnicas de RA. Nesse sentido, a seguinte subseção (2.2.1) descreve os tipos de dispositivos sensores com interfaces de comunicação sem fio, que podem ser utilizados na implementação de uma aplicação baseada na metodologia proposta.

\subsubsection{Dispositivos Sensores com Interfaces de Comunicação Sem Fio}

Define-se como um dispositivo sensor um dispositivo eletrônico que implementa a monitoração física de um fenômeno ${ }^{2}$ ambiental que produz uma resposta mensurável (medidas) a mudanças em condições físicas, tais como temperatura, campo magnético, luminosidade, umidade, entre outras (MEGERIAN et al., 2002). Um dispositivo sensor, tipicamente, consiste de cinco componentes: detector de hardware, memória, bateria, processador embutido e transmissor receptor (MEGERIAN et al., 2002). Portanto, a função de um dispositivo sensor é coletar, armazenar e em alguns casos processar dados produzidos na monitoração de fenômenos em um determinado ambiente.

Já dispositivos sensores com capacidades de comunicação sem fio, permitem criar redes de sensores atuadores distribuídas para diversos tipos de aplicações de monitoração biológica e ambiental em ambientes marinhos, terrestres e atmosféricos (PEREIRA; AMORIM; STELLING, 2004). Isto porque os dispositivos sensores com interfaces de comunicação sem fio permitem transmitir os dados coletados, armazenados ou processados através de protocolos de comunicação sem fio como Bluetooth, Zigbee, etc. Alguns destes tipos de sensores com interfaces de comunicação sem fio que podem ser aproveitados pela presente pesquisa são descritos a seguir.

\subsubsection{Redes de Sensores Sem Fio (RSSF)}

Uma RSSF é um tipo de rede ad hoc composta por dispositivos sensores independentes chamados de "nós sensores", os quais têm uma série de características e requisitos específicos. O principal objetivo das RSSF é realizar tarefas de sensoriamento de forma distribuída. Estas redes funcionam como sistemas distribuídos para a aquisição de dados. Os dados são coletados através de chips sensores que estão acoplados em cada nó sensor que pertence à rede; estes nós sensores transmitem os dados coletados para um nó sensor especifico que é chamado de "Estação Base" (EB). A EB é o dispositivo encarregado de coletar todas as informações da rede e transmitir estas informações para um computador (ROCA, 2008). A figura 2.3 apresenta uma RSSF com uma EB conectada a uma laptop.

\footnotetext{
${ }^{2}$ Fenômeno: Fato, aspecto ou ocorrência de interesse científico passível de observação e suscetível de descrição, explicação e medição.
} 


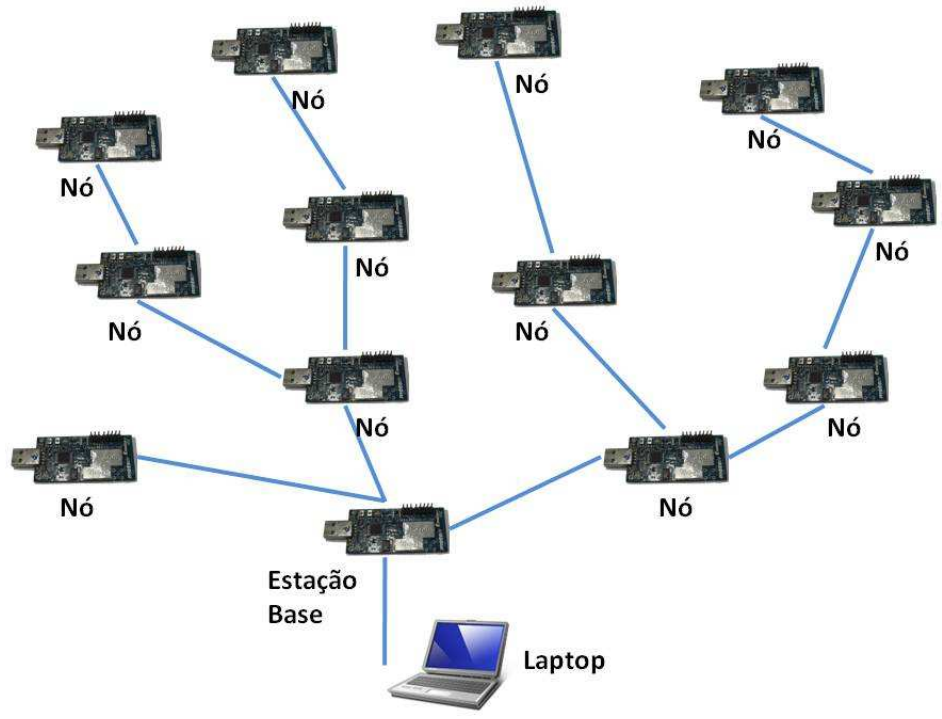

Figura 2.3: Rede de Sensores Sem Fio (Roca, 2008).

A estrutura de uma RSSF é composta por: uma infra-estrutura de hardware; uma pilha de protocolos; e a aplicação. A infra-estrutura refere-se aos nós sensores físicos (suas características físicas e capacidades de sensoriamento), ao número de nós sensores e à sua estratégia de instalação (como e onde eles são alocados). A pilha de protocolos refere-se ao software que implementa as diversas camadas de protocolos existentes em cada nó sensor da rede. O componente de aplicação representa os programas (aplicações) instalados nos nós sensores, os quais executam tarefas especificas de sensoriamento. Portanto, uma RSSF é um tipo de sistema dependente da aplicação. Qualquer projeto ou solução proposta que implementa uma RSSF deve levar em consideração os requisitos da aplicação a ser desenvolvida, as características e restrições dos componentes dos nós sensores e as características do ambiente a ser monitorado (RUIZ et al., 2004).

Novos padrões para RSSF com baixo consumo de energia utilizam o padrão ZigBee como interface de comunicação sem fio. A tecnologia ZigBee é baseada no padrão IEEE 802.15.4 e garante teoricamente uma taxa de transmissão de dados igual a $250 \mathrm{kbps}$ na camada de comunicação sem fio. Três bandas de transmissão são permitidas nesta tecnologia. A primeira é de $2.4 \mathrm{GHz}$, a segunda é de $868 \mathrm{MHz}$ e a terceira é de 916 MHz. O uso da primeira banda de transmissão é permitido para todo o mundo sem restrições, a segunda e a terceira para a Europa e os Estados Unidos respectivamente. Note-se que na presente dissertação é utilizada uma RSSF baseada no padrão ZigBee para a implementação do estudo de caso. 


\subsubsection{RFID Tags and Readers}

RFID é um acrônimo do Radio-Frequency IDentification; em português significa Identificação por Rádio Freqüência. Trata-se de um método de identificação automática através de sinais de rádio, recuperando e armazenando dados remotamente utilizando uma interface de comunicação sem fio e dispositivos chamados de RFID tags e RFID readers. Uma RFID tag é um circuito integrado de silício combinado com uma antena em um empacotamento compacto. A antena da RFID tag pega sinais de um RFID reader ou scanner, e em seguida volta o sinal, geralmente com alguns dados adicionais (Por exemplo: um número de série ou outras informações personalizadas) (FINKENZELLER, 2003). Estas RFID tags por serem objetos pequenos podem ser colocados em pessoas, animais ou produtos.

As RFID tags são usadas para a coleta de informações de recursos móveis e de processos de negócios não estruturados e caóticos, em ambientes como hospitais, dando a esses ambientes (com falta de planejamento sofisticado de processos ou controle) a possibilidade de serem controlados sistematicamente (KHOSLA; CHOWDHURY, 2008). Já aplicações que combinam RFID tags e dispositivos móveis, como os telefones celulares estão sendo utilizados em aplicações de interação em função do contexto (HäKKILä et al., 2005), (FUKAZAWA et al., 2006). A integração de RFID readers em telefones celulares permite adquirir e processar os dados da RFID tag de forma direta, fornecendo rapidamente as informações e serviços presentes no ambiente como é apresentado na figura 2.4.

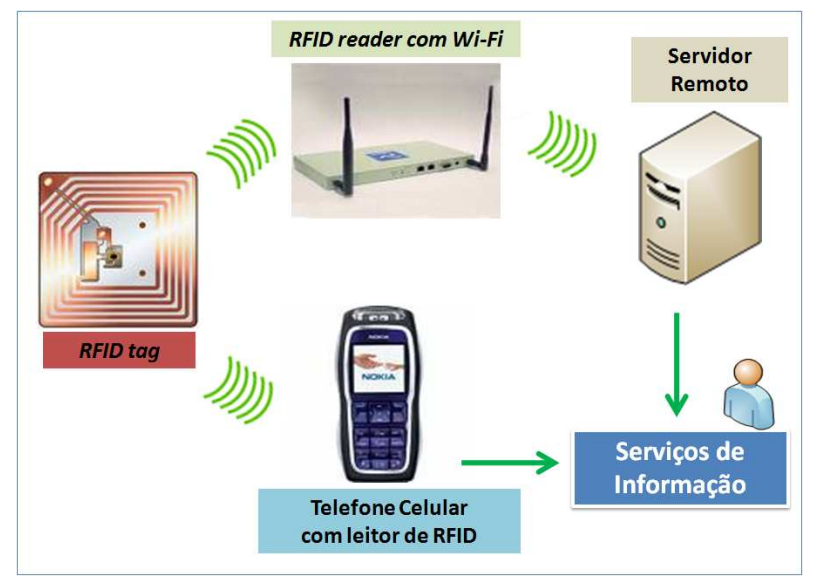

Figura 2.4: Sistemas RFID.

\subsubsection{Bluetooth Sensors and Tags}

O padrão de comunicações sem fio Bluetooth ou IEEE 802.15.1 foi desenvolvido como uma especificação aberta para comunicação de voz e dados. Bluetooth trabalha na freqüência não licenciada de $2.4 \mathrm{GHz}$. Atualmente Bluetooth provê velocidades de rede de até $3 \mathrm{Mbps}$ 
(Bluetooth 2.0). O Bluetooth foi originariamente desenvolvido para um posicionamento estratégico no mercado de Personal Area Networks (PAN) com baixo custo, baixo consumo de energia e para uma curta faixa de interconexões.

Portanto, RSSF e dispositivos sensores independentes podem implementar o padrão Bluetooth como interface de comunicação sem fio para transmitir os dados coletados. Já as Bluetooth Tags cumprem as mesmas funções que as RFID tags, porém, baseadas nas características de comunicação do padrão Bluetooth.

\subsubsection{Wi-Fi}

O padrão IEEE 802.11, também conhecido como Wi-Fi é uma tecnologia de transmissão de dados por rádio. Uma especificação deste padrão é conhecida como 802.11b, trabalha na faixa de $2.4 \mathrm{GHz}$, e permite taxas de dados até $11 \mathrm{Mbits}$, mas com valores médios reais entre $4 \mathrm{Mbits}$ e $6 \mathrm{Mbits}$, na transferência dos dados em ambientes internos, e taxas bem menores que $4 \mathrm{Mbits}$, em ambientes externos. Outra especificação que também está presente na freqüência de $2.4 \mathrm{GHz}$, é o IEEE $802.11 \mathrm{~g}$, que alcança uma taxa de 54Mbits. As principais vantagens deste padrão estão relacionadas com o aumento da eficiência espectral, minimização das interferências e baixa distorção (ROCA, 2008).

Portanto, dispositivos móveis como os telefones celulares com capacidades de acesso $W i$-Fi, geram a possibilidade de conectar estes dispositivos móveis com WLANs (Wireless Local Area Network) e PWLANs (Public Wireless Local Area Network), isto para acessar informações e serviços de interesse comercial ou publico proporcionados por dispositivos sensores remotos (a longas distâncias). Nesse sentido, as WLANs e PWLANs são utilizadas como ponte de conexão com as informações e serviços.

\subsubsection{GPS e Sensores Embutidos}

O Sistema de Posicionamento Global conhecido como GPS (Global Positioning System), é um sistema de posicionamento por satélite, utilizado para a determinação da posição de um receptor na superfície da Terra ou em órbita. Os receptores GPS decodificam as transmissões do sinal de múltiplos satélites e calculam a sua posição com base nas distâncias a estes. A posição é dada por latitude, longitude e altitude, coordenadas geodésicas (PEñAFIEL; ZAYAS, 2001). Com a inclusão de receptores GPS nas arquiteturas de hardware dos telefones celulares, Smartphones e PDAs, estes dispositivos permitem oferecer a seus usuários serviços de localização e rastreamento. Nesse sentido, telefones celulares com receptores GPS embutidos, poderiam ser utilizados para o sensoriamento e monitoração em ambientes dinâmicos (KäHäRI; MURPHY, 2006). 
Nessa mesma convergência, atualmente os telefones celulares de diversas marcas e modelos, além dos receptores GPS, também implementam nas suas arquiteturas de hardware sensores embutidos como por exemplo: acelerômetros, magnetômetros, etc. Já a Sensor Api (SENSORAPI, 2008) é uma biblioteca Java que da suporte para o acesso aos sensores embutidos nos telefones celulares. Portanto, os telefones celulares com sensores e receptores GPS embutidos, transformam-se em dispositivos sensores com a possibilidade de se associar como um tipo de RSSF (KANSAL; GORACZKO; ZHAO, 2007).

\subsection{Sinergia entre a Computação Móvel, Ubíqua e a Realidade Aumentada}

A computação móvel e a computação ubíqua têm claras conexões com a realidade aumentada (KJELDSKOV, 2002). A computação ubíqua procura o desaparecimento da interação consciente e intencional com o usuário de um sistema de informação, enquanto a RA procura que a interação com o usuário seja o mais natural possível, isto é, que perceba e sinta os elementos virtuais como naturais, o que mostra uma clara relação. Já segundo (AZUMA et al., 2001) a computação ubíqua é um subconjunto da meta original da RA. Já o desenvolvimento das capacidades e características da computação móvel permitem a implementação de sistemas de RA em dispositivos que permitem aos usuários se movimentar livremente por diversos ambientes (urbanos ou naturais). A figura 2.5 apresenta a sinergia entre a computação móvel, ubíqua e RA .

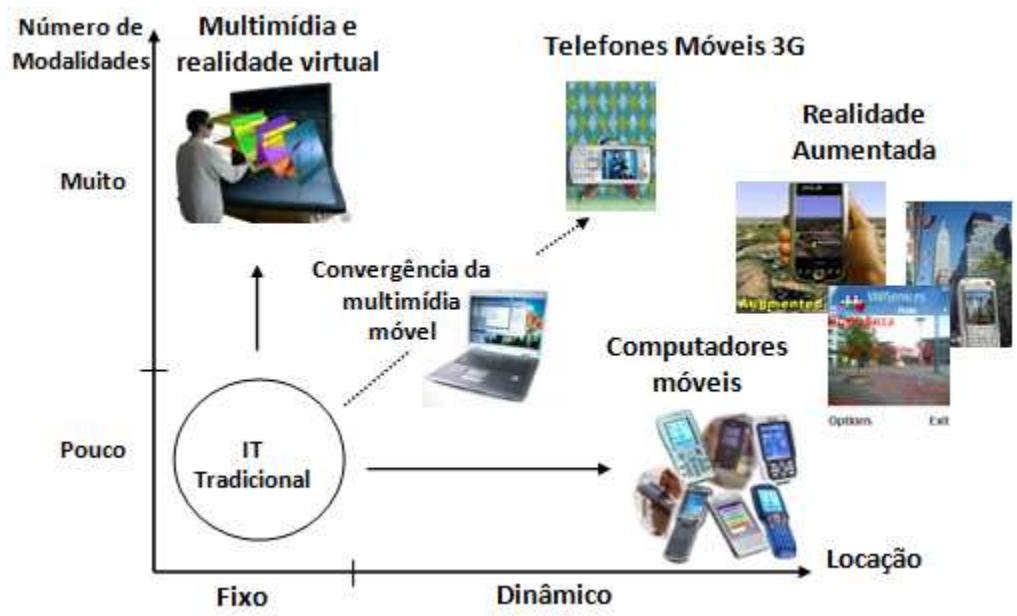

Figura 2.5: Sinergia entre a Computação Móvel, Ubíqua e RA (Kjeldskov, 2002).

Portanto, este capítulo apresentou as características e tipos de dispositivos sensores e dispositivos móveis a serem aproveitados pela presente pesquisa. 


\section{$3 \quad$ Handheld Augmented Reality}

Este capítulo descreve conceitos referentes à Realidade Aumentada, Realidade Aumentada Móvel e o estado da arte da Handheld Augmented Reality. Nesse sentido, são apresentadas informações sobre as tecnologias e ferramentas para o desenvolvimento de aplicações do tipo Handheld AR. Além disso, as seções deste capítulo incluem adaptações dos conceitos descritos, compondo assim, as bases teóricas para o desenvolvimento da presente dissertação.

\subsection{Realidade Aumentada (RA)}

Milgram propõe uma taxonomia para sistemas de apresentação de realidades misturadas que introduz o conceito de "Virtuality Continuum" que é apresentado na figura 3.1. Ao longo deste conceito se distribuem diferentes tipos de sistemas de realidades misturadas. Um extremo representa o mundo real (esquerda) e o outro um mundo totalmente virtual (direita), no meio desses mundos têm-se: a realidade virtual, mais perto do mundo virtual; e a realidade aumentada (RA), mais perto do mundo real. Nesse sentido, a RA é uma tecnologia através da qual se pretende melhorar ou aumentar a visão que o usuário tem do mundo real com imagens virtuais; para isto são usadas técnicas de visão por computador e de computação gráfica (MILGRAM; KISHINO, 1994).

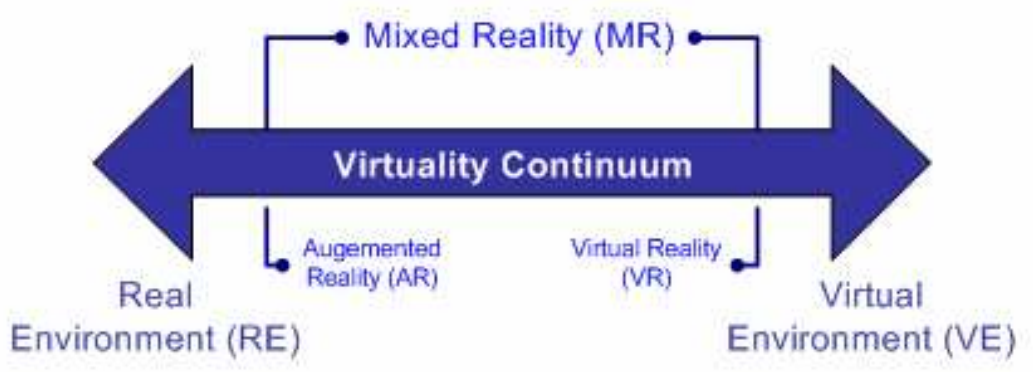

Figura 3.1: Virtuality Continuum (Milgram; Kishino, 1994). 
Aceitando explicitamente o enquadramento da RA proposto por Milgram, Ronald Azuma acaba por definir a RA como:

"Uma variante da Realidade Virtual [...]. As tecnologias de Realidade Virtual submergem completamente ao usuário em um ambiente sintético ou virtual e, enquanto imerso nesse ambiente, o usuário não pode ver o mundo real que o rodeia. Pelo contrário, a RA permite ver o mundo real com objetos virtuais sobrepostos ou integrados nesse mundo real. Desta forma, a RA complementa a realidade em lugar de substituí-la.[...]" (AZUMA, 1997)

Além disso, Azuma (1997) evitando a relação da RA com qualquer tipo de tecnologia para sua implementação, define três características fundamentais e distintivas para um sistema de RA:

- Combinar o mundo real com o virtual;

- Interagir em tempo real;

- Alinhar as imagens reais e virtuais de forma que a visualização esteja sincronizada fisicamente e em tempo real, o que é chamado de "Registro".

\subsection{Realidade Aumentada Móvel}

A Realidade Aumentada Móvel ou RA Móvel explora a sinergia entre os campos da RA, na qual imagens 3D são usadas para revestir o mundo real, e a Computação Móvel, na qual os dispositivos de computação têm acesso a redes de dados sem fio. Esta sinergia permite ter acesso em tempo real a dados e informações virtuais que são inseridas sobre o que nós estamos vendo, enquanto nos movimentamos por ambientes naturais ou urbanos. Para isso a RA Móvel precisa de (CORREIA, 2003):

- Dispositivos de informação de Geo-referência (DGPS - Devices for Global Positioning System) ou simplesmente dispositivos GPS;

- Dispositivos de entrada e saída não intrusivos;

- Mobilidade:

- Redes sem fios (GSM/GPRS, Bluetooth, Zigbee, etc.);

- Dispositivos computacionais portáteis, rápidos (capacidade de processamento) e de melhor resolução; 
- Computação ciente ao contexto (Context Awareness);

- Dispositivos sensores.

Nesse sentido, a figura 3.2 apresenta as características de hardware e design de um sistema de RA móvel projetado pelo Studierstube (STUDIERSTUBE, 2007).
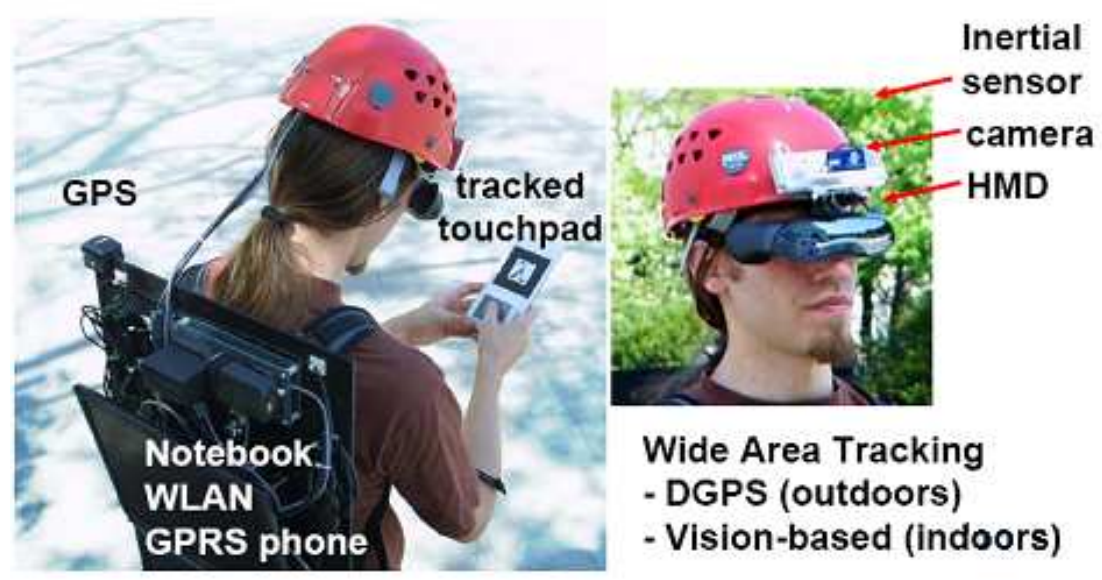

Figura 3.2: Sistema de Realidade Aumentada Móvel (Studierstube, 2007).

\subsection{Handheld Augmented Reality}

A Handheld Augmented Reality ou simplesmente Handheld $A R$ é um subconjunto da RA móvel e é baseada no uso de dispositivos móveis ou Handheld Devices como: PDAs e telefones celulares. Atualmente há quatro tipos distintos de dispositivos móveis comercialmente usáveis e disponíveis como candidatos potenciais para ser o melhor e mais utilizado dispositivo móvel para aplicações do tipo Handheld AR (WAGNER; SCHMALSTIEG, 2003):

- Telefones celulares;

- PDAs;

- Smartphones;

- UMPCs.

O desenho destes dispositivos apresentam características distintivas entre tamanho, peso, poder computacional e custo (WAGNER; SCHMALSTIEG, 2003). Enquanto os telefones celulares são extremamente portáteis e difundidos no mercado, a sua atual falta de poder de processamento e conexão de rede local (Intranet/Internet - WLAN) os faz uma 
plataforma não adequada para aplicações de alto risco (Por exemplo: aplicações onde vidas humanas estejam em risco). Além disso, o tamanho de exibição (tela) pequeno e a limitada capacidade de introduzir dados, torna o telefone celular menos que ideal para interfaces gráficas 3D. Porém, aplicações do tipo Handheld $A R$ para a visualização de informações simples, os telefones celulares são uma boa escolha na implementação deste tipo de aplicações. A figura 3.3 apresenta um telefone celular executando uma aplicação do tipo Handheld $A R$ que reconhece um marcador e insere uma imagem virtual (uma imagem 2D ou bitmap) associada a este marcador (NETO et al., 2006).

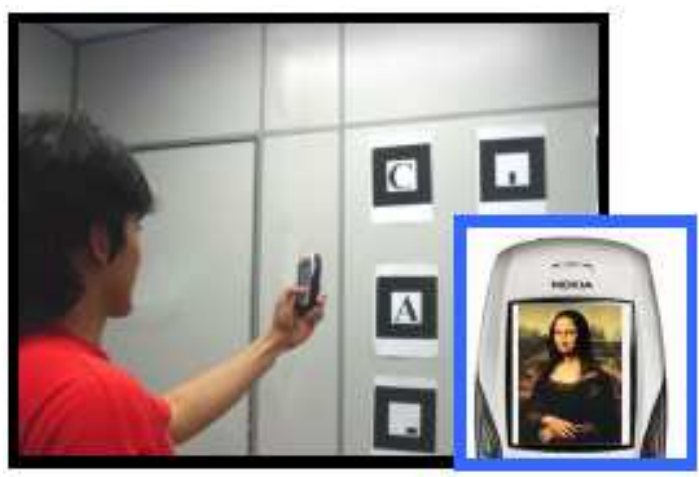

Figura 3.3: Handheld $A R$ on Mobile Phone (Neto et al., 2006).

Já os PDAs são um bom acordo entre capacidades de poder de processamento, tamanho e peso. Eles são socialmente aceitáveis e a sua capacidade de inserir dados através de uma caneta digital, facilita o modo de interação com o dispositivo. Porém, são consideravelmente mais caros, requer o uso das duas mãos para ser operado e têm um maior consumo de bateria. A figura 3.4 apresenta um PDA executando um jogo (aplicação) colaborativo multi-usuário do tipo Handheld AR chamado de "Invisible Train" (WAGNER et al., 2005). Nessa mesma linha, os UMPCs não são muito utilizados em aplicações do tipo Handheld $A R$, principalmente pelo custo destes dispositivos.

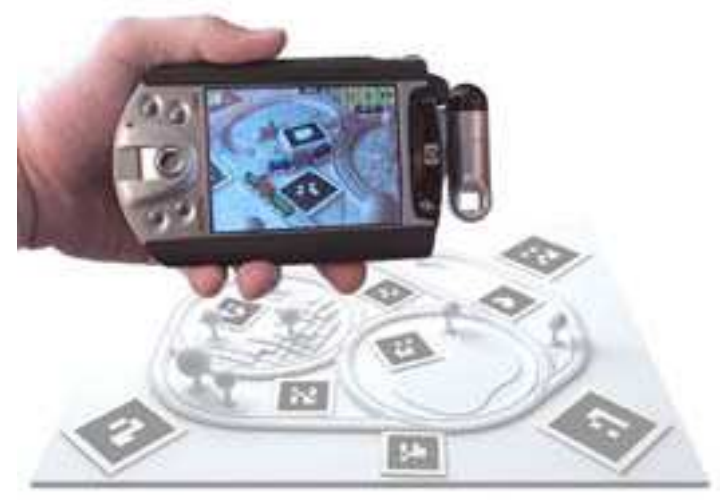

Figura 3.4: Handheld $A R$ on PDA (Wagner et al., 2005). 
Finalmente, os SmartPhones que combinam as melhores características dos telefones celulares e PDAs, parecem ser uma ótima plataforma de desenvolvimento para aplicações do tipo Handheld $A R$ de maior risco e complexidade, por incluir conexão de rede local (Intranet/Internet - WLAN) através de interfaces de comunicação sem fio (Bluetooth, ZigBee e $W i-F i)$. Além disso, processadores gráficos 3D dedicados e interfaces de interação Touch Screen (sensível ao toque), ampliam as possibilidades de desenvolvimento de aplicações do tipo Handheld AR. A figura 3.5 apresenta dois Smartphones executando uma aplicação do tipo Handheld $A R$ que apresenta um jogo de tênis, que utiliza a câmera dos telefones celulares, os marcadores e interface Bluetooth para a comunicação dos dados entre os dispositivos móveis (HENRYSSON; BILLINGHURST; OLLILA, 2006).

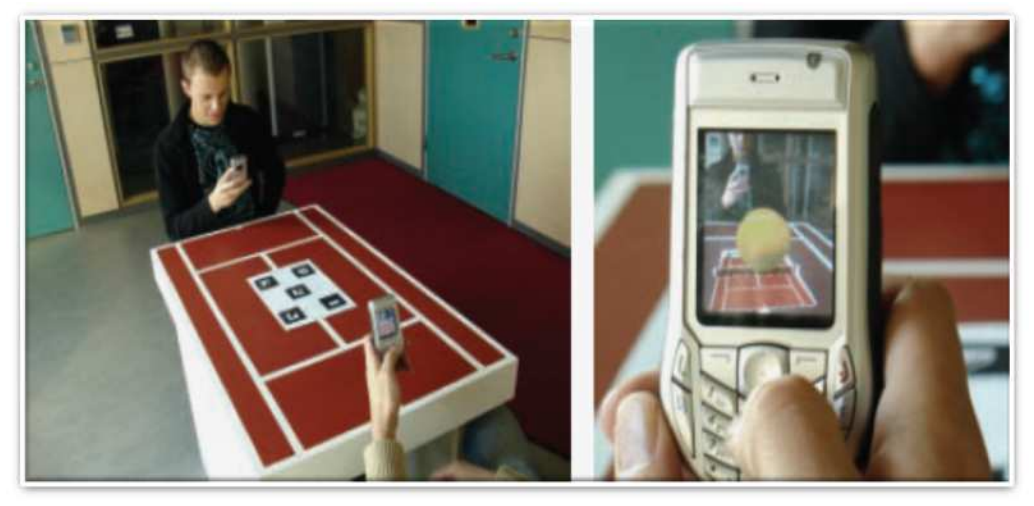

Figura 3.5: Handheld AR on Smartphone (Henrysson; Billinghurst; Ollila, 2006).

Portanto, para definir o uso de algum destes dispositivos na implementação de uma aplicação do tipo Handheld $A R$, têm-se que avaliar fortemente os seguintes aspectos:

- Tipo de aplicação a ser implementada;

- Tipo e quantidade de usuários a atingir;

- Cenário no qual se vai interagir;

- O risco que a aplicação vai abranger.

Porém, independentemente do dispositivo móvel a utilizar, uma aplicação do tipo Handheld $A R$ passa por um fluxo de processamento que pode ser resumido em três fases: (3.3.1) a aquisição de imagens do mundo real (captura de vídeo); (3.3.2) o reconhecimento de marcadores; e (3.3.3) a mistura do mundo real e virtual (renderização e apresentação de imagens virtuais). Como o fluxo de processamento está encapsulado em um sistema, o qual funciona em tempo real, exige deste sistema que apresente um tempo de latência igual ou menor que 100 ms (microsegundos) para um adequado funcionamento da aplicação do 
tipo Handheld AR (TORI; KIRNER; SISCOUTTO, 2006). Nesse sentido, (3.3.4) a forma e estratégias em que é feito o processamento do sistema de RA, também deve ser analisado. Portanto, este fluxo de processamento é apresentado na figura 3.6 e descrito nas seguintes subseções.

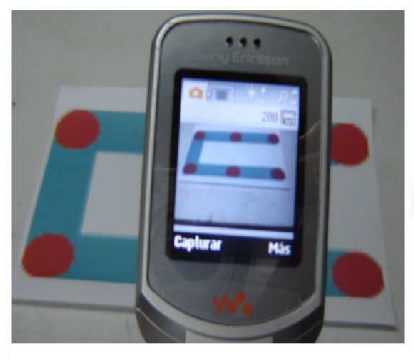

Captura de Vídeo

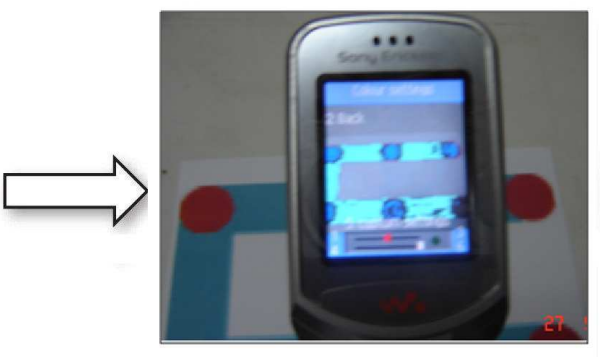

Reconhecimento de Marcadores

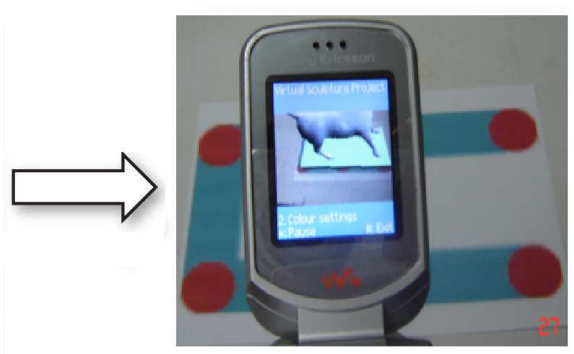

Renderização e Apresentação de Objetos Virtuais

Figura 3.6: Fluxo de Processamento de uma Aplicação do tipo Handheld AR.

\subsubsection{Captura de vídeo}

No ambiente Windows para computadores de mesa (Desktop), a forma mais comum de acessar a câmera é utilizando o DirectShow (DIRECTSHOW, 2007), que é um subconjunto da API DirectX (DIRECTX, 2007). O DirectShow é responsável pela aquisição e manipulação de streams multimídia, manipulando os drivers da câmera e provendo as funções necessárias para adicionar a captura de vídeo à aplicação. Com o intuito de prover uma maneira mais prática de manipular estes streams de vídeo, foi desenvolvido o Ds VideoLib (DSVIDEOLIB, 2007), que é um projeto open source baseado na API do DirectShow.

A captura de streams de vídeo em dispositivos móveis depende da plataforma. Nesse sentido, na plataforma Windows Mobile 5.0, o DirectShow permite o acesso às câmeras dos Smartphones, Pocket PC e PDAs através da Camera Capture API. E pelo mesmo fato que foi criada a DsVideoLib, foi criada a DsVideoCE (STUDIERSTUBE, 2007), isto para melhorar e facilitar o acesso à câmera nos dispositivos móveis.

Já na grande maioria dos telefones celulares, a captura de vídeo é realizada utilizando APIs específicas do sistema operacional instalado no dispositivo (LIMA, 2007). Por exemplo: para a plataforma Symbian é utilizada a biblioteca ECam (HARRISON, 2004). Outras plataformas utilizam $S D K s$ proprietárias dos fabricantes das câmeras.

Finalmente, a plataforma Java provê a Mobile Media API (MMAPI) ou JSR 135 (MMAPI, 2007), que é um pacote opcional do J2ME destinado a fornecer funcionalidades multimídia aos aplicativos. A MMAPI é composta por quatro classes, sendo as duas 
principais: a DataSource e a Player. A DataSource é responsável pela captura dos dados da mídia, que podem ser obtidos de uma câmera embutida no dispositivo, de um sistema de arquivos, de um protocolo padrão, ou de algum mecanismo proprietário. Desta forma, toda a complexidade de acesso à mídia fica encapsulada nesta classe. Através de métodos específicos, a DataSource permite que a classe Player acesse a mídia. A classe Player processa, decodifica e coloca em uma interface de saída (por exemplo: a tela do dispositivo móvel) a mídia adquirida pela DataSource. Ainda, a classe Player atua sobre as classes de controle de mídia, como vídeo e volume, e disponibiliza métodos para o controle da mídia, como play e stop. Portanto, em função da interoperabilidade da plataforma Java, a MMAPI é largamente utilizada para a captura de vídeo utilizando a câmera de diversos modelos e marcas de telefones celulares e Smartphones.

\subsubsection{Reconhecimento de marcadores}

O processo para a criação de um ambiente de RA (misturar imagens reais com objetos virtuais) precisa extrair informações de posicionamento, isto para instruir ao sistema de renderização gráfica, no processo de formação do ambiente aumentado a partir do ponto de vista do usuário (KIRNER; TORI, 2004). Uma das formas para efetuar este processo é utilizando marcadores. Os marcadores são geralmente pedaços de papel com formatos geométricos e marcas fiduciais ou "padrões (patterns)" (LAHR; LOURENçO; DAINESE, 2004). Estes marcadores, chamados também de "2D barcodes" permitem ao sistema de RA, definir um sistema de coordenadas espacial e a orientação dos objetos (do mundo real) a partir do ponto de vista do usuário, para identificar alterações de posicionamento (tracking) e sobrepor as imagens virtuais nos objetos do mundo real de forma adequada.

Atualmente existem mais de trinta tipos de marcadores, porém, apenas seis deles foram projetados ou adaptados para ser utilizados por aplicações em dispositivos móveis. Estes marcadores são divididos em duas categorias (KATO; TAN, 2007):

\subsubsection{Database 2D Barcodes}

Marcadores do tipo Database 2D Barcodes, como por exemplo: QR Code, VSCode e Data Matrix são utilizados junto com as câmeras dos telefones celulares para reconhecer e decodificar dados, funcionando como bases de dados portáteis e permitindo aos usuários acessar informações em qualquer momento e em qualquer lugar, independentemente do tipo de conectividade de rede.

- $\boldsymbol{Q R}$ Code: É uma matriz ou código de barras bi-dimensional, criado no Japão 
em 1994. O QR Code ou Quick Response Code se caracteriza pela detecção rápida da posição (orientação) dos marcadores, robustez no reconhecimento, incluindo erro de correção, mesmo com imagens de baixa resolução feitas por câmeras digitais em formato VGA, como as embutidas nos telefones celulares. Além disso, o $Q R$ Code permite codificar diversos tipos de dados, por exemplo: símbolos, dados binários, códigos de controle, dados multimídia, etc. O QR Code está dividido em 16 áreas de dados e tem uma capacidade máxima de 7089 caracteres para dados numéricos, 4296 caracteres para dados alfanuméricos, 2953 bytes para dados binários, e 1817 caracteres para Japonês Kanji. A figura 3.7.a apresenta a estrutura básica do marcador, a qual determina a orientação do mesmo. Já a figura 3.7.b apresenta a agregação dos dados (codificados como padrões geométricos) para o marcador. Finalmente, o figura 3.7.c apresenta um marcador do tipo QR Code (QRCODE, 2006) (QRCODE, 2007).

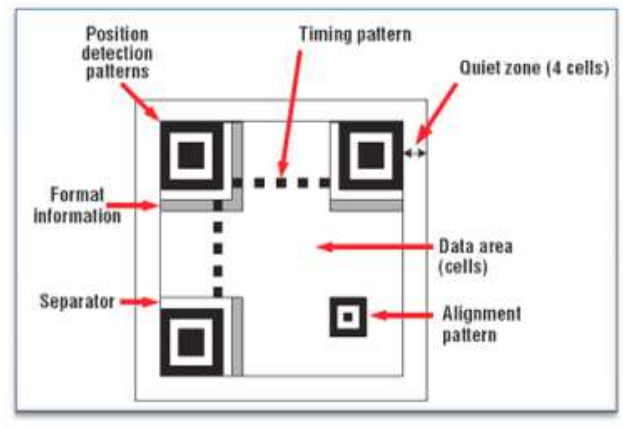

(a) Estrutura do Marcador

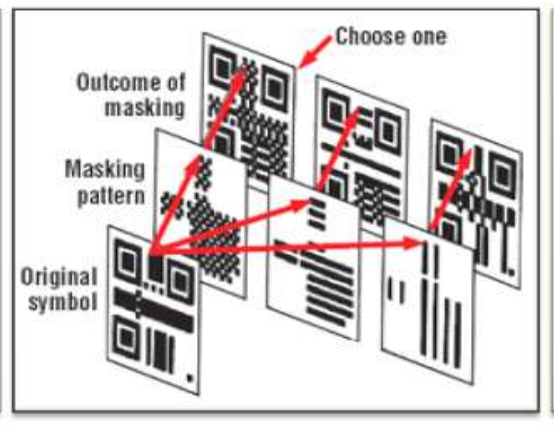

(b) Codificação dos Dados

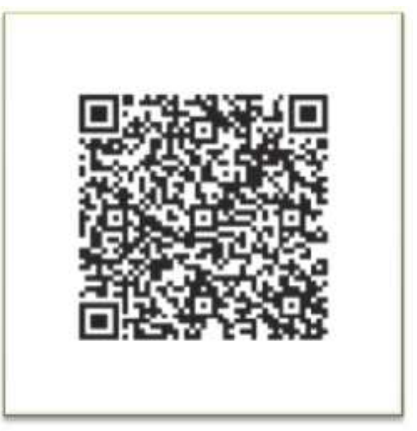

(c) QR Code

Figura 3.7: Marcador do tipo QR Code (QrCode, 2006).

- VSCode: Originalmente chamado de VeriCode, caracteriza-se pela sua alta capacidade de armazenagem de dados, o que lhe permite armazenar dados biométricos para aplicações de controle de acesso. Também oferece opções adicionais de segurança utilizando técnicas criptográficas (Reed-Solomon) e uma alta taxa (15\% - 25\%) de detecção e correção de erros. O VSCode está composto pela: margem preta (solid border frame), a área de dados (data field), e uma margem invisível chamada de quiet zone como é apresentado na figura 3.8. A área de dados é composta por células (cell data) pequenas, o que permite armazenar até 4151 bytes, permitindo ajustar o tamanho e forma (quadrado ou retângulo) do marcador em função do espaço disponível (VSCODE, 2007). 


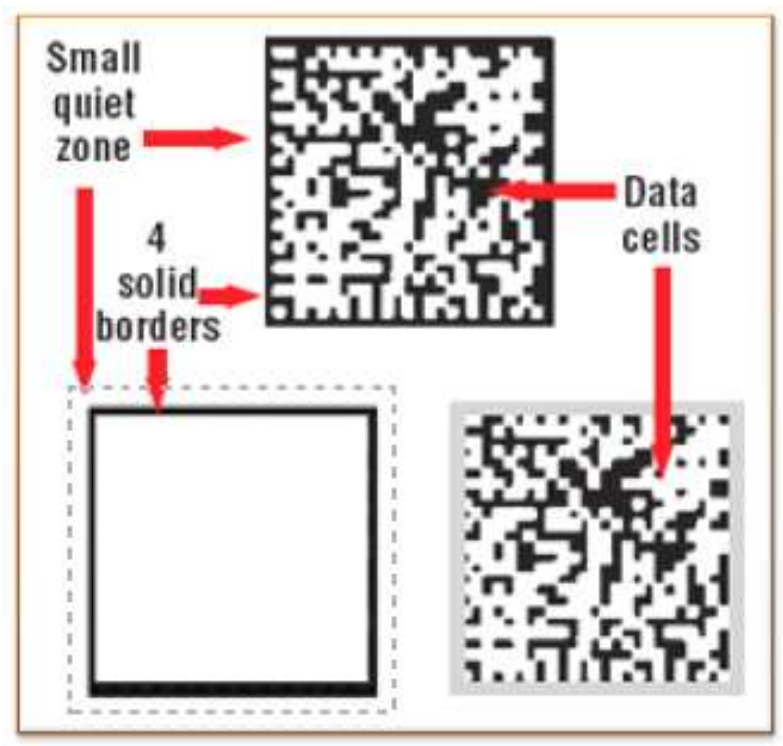

Figura 3.8: Marcador do tipo VSCode (VSCode, 2007).

- Data Matrix: Tem uma estrutura compreendida por dois linhas sólidas (solid border) e duas linhas alternadas (broken border) como perímetro, o que define o tamanho físico, a orientação e símbolo de distorção do marcador, o que é apresentado na figura 3.9.a. Já na figura 3.9.b, apresenta-se um marcador do tipo Data Matrix. A estrutura deste marcador pode ser quadrada ou retangular e sua capacidade máxima de dados é de 3116 dígitos, 2335 caracteres alfanuméricos, ou 1556 bytes. O tamanho de Data Matrix comparado com QR Code e VSCode é o mais pequeno $(3,3$ x $3,3 \mathrm{~cm})$ ainda mantendo a robustez e taxa de correção de erros (10\% - 15\%). O Data Matrix pode conter como dados um número de identificação entre 1 e 254 (permitindo assim até 254 x $254=64516$ identificadores) (DATAMATRIX, 2006) (DATAMATRIX, 2007). Já o Semacode (SEMACODE, 2007) é um projeto open source, que adotou a estrutura do Data Matrix para codificar web sites (paginas web) para associar fisicamente os marcadores com hiperlinks. O Semacode permite o uso e modificação do sistema de reconhecimento de marcadores para aplicações não comerciais.

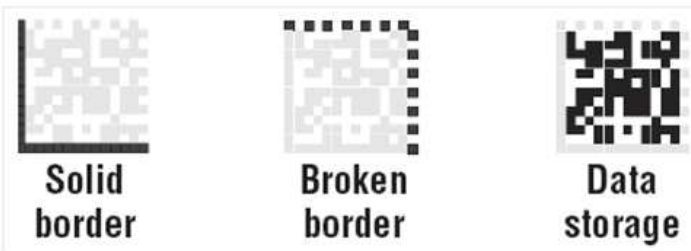

(a) Estrutura do Marcador

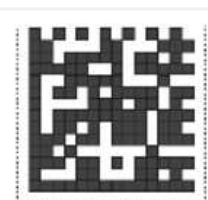

Data matrix symbol shown complete

(b) Data Matrix

Figura 3.9: Marcador do tipo Data Matrix (Data Matrix, 2007). 


\subsubsection{Index-based 2D Barcodes}

Marcadores do tipo Index-based 2D Barcodes, como por exemplo: Visual Code, ShotCode e Color Code foram desenvolvidos tendo em consideração as limitações das câmeras dos telefones celulares. Permitem acessar uma menor quantidade de dados (comparados com os Database 2D Barcodes), porém, oferecem um sistema de reconhecimento mais robusto e confiável. Basicamente estes marcadores funcionam como um hyperlink para alguma página web, fato pelo qual é requerida uma conexão a rede (Internet).

- Visual Code: Este marcador foi desenvolvido para permitir a interação com o usuário utilizando a câmara dos telefones celulares. Para isto, projetou-se um sistema de coordenadas que permite mapear pontos arbitrários em um marcador. Baseados no fato de que os telefones celulares permitem capturar a mesma imagem em diversos modos de orientação (rotação), o Visual Code implementou um algoritmo de deteç̧ão que utiliza a orientação (rotação) e inclinação de uma imagem (capturada) como parâmetros de entrada adicionais. Portanto, os usuários podem obter informações diferentes para o mesmo marcador através da movimentação (rotação e inclinação) do telefone celular. Além disso, o Visual Code tem uma capacidade de armazenamento de dados limitada a 83 bits, porém, pode funcionar como um índice (link) para uma base de dados remota. A figura 3.10.a apresenta o sistema de coordenadas, a figura 3.10.b apresenta os pontos arbitrários que permitem determinar a orientação do marcador, e finalmente, a figura 3.10.c apresenta uma aplicação que utilizando um mesmo marcador, são geradas duas informações distintas, isto pela orientação do marcador em função da câmera (ROHS, 2004) (ROHS, 2005).

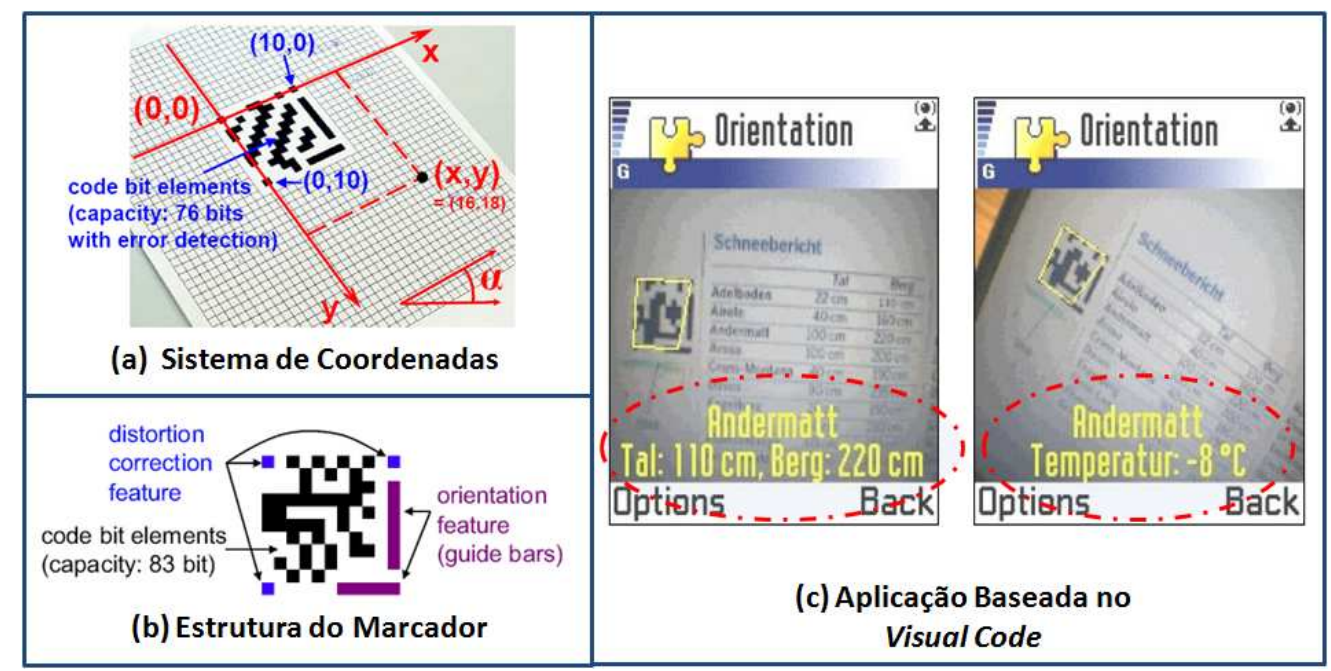

Figura 3.10: Marcador do tipo Visual Code (Rohs, 2004; 2005). 
- ShotCode: Tem como principal característica sua forma circular. Foi desenvolvido pela High Energy Magic que inicialmente o chamou de "SpotCode" (MADHAVAPEDDY et al., 2004) e que foi baseado em um outro circular 2D-barcode conhecido como TRIP (Target Recognition using Image Process) (LóPEZ; MENDONçA; HOPPER, 2002). TRIP foi projetado para câmeras de baixo custo como as Web cams para monitorar dinamicamente um alvo móvel e obter informação da sua localização em tempo real. Nessa evolução, o ShotCode permite codificar um número na faixa de 1 até 19683, utilizando para isso dois anéis concêntricos em torno de um ponto central. A figura 3.11.a apresenta estes dos dois anéis que estão divididos em 16 setores. O primeiro setor (para a sincronização) indica o início (onde começa) do marcador. Os seguintes dois setores são utilizados para a correção de erros. Já os quatro seguintes setores codificam em milímetros o raio do ponto central do marcador. Os restantes nove setores codificam um identificador ternário (sistema numérico com três estados possíveis). Por exemplo, o valor do marcador na figura 3.11.a é 102011221210001. A figura 3.11.b apresenta o marcador do tipo ShotCode. Atualmente o ShotCode é utilizado como hiperlinks para interligar o mundo real com o mundo digital através de acesso remoto de dados, como é apresentado na figura 3.11.c (SHOTCODE, 2007).

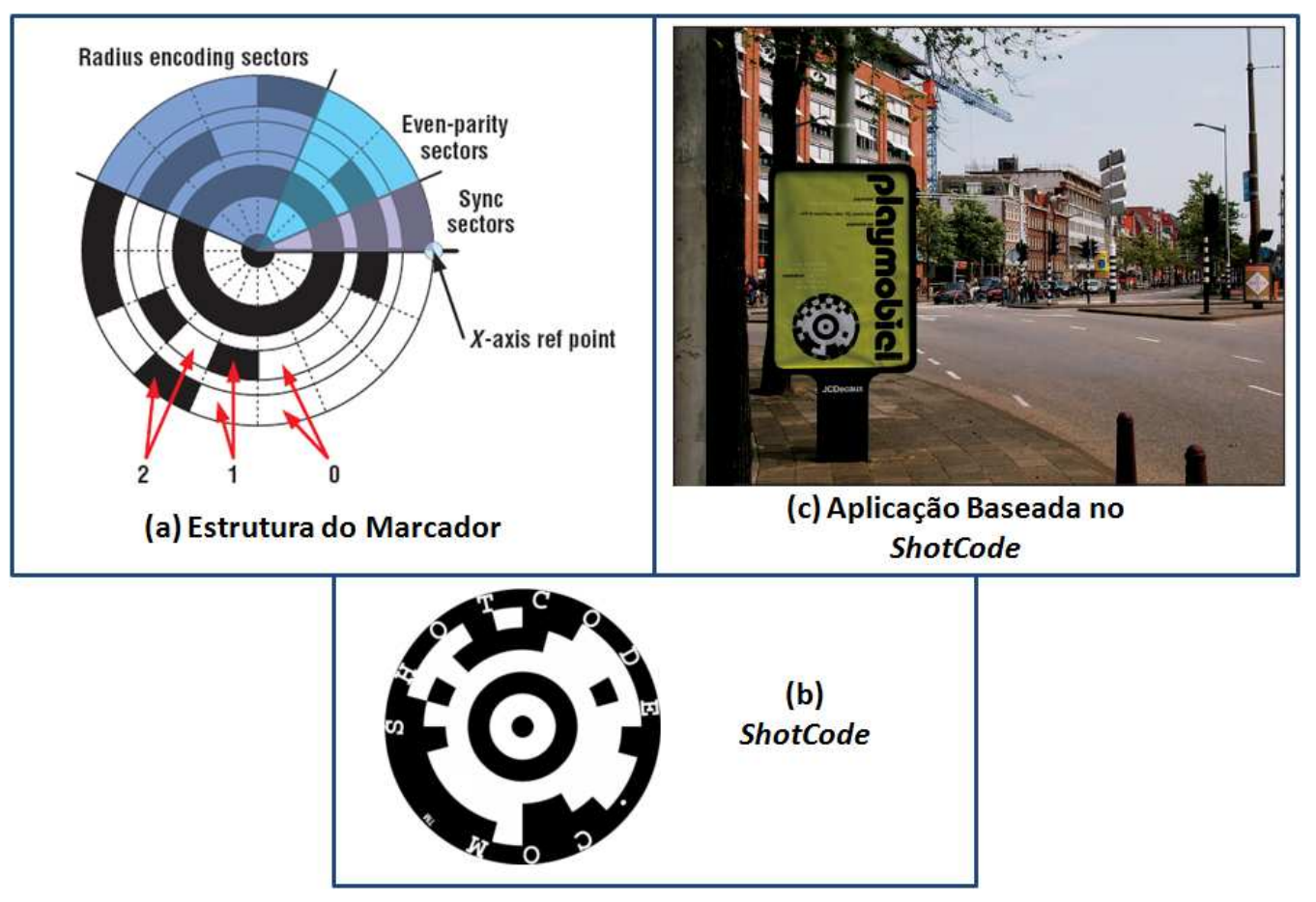

Figura 3.11: Marcador do tipo ShotCode (ShotCode, 2007). 
- ColorCode: Foi desenvolvido pela equipe da Universidade de Yonsei (TACK-DON et al., 2006). As principais características deste marcador são a maior visibilidade que dá o uso de cores e flexibilidade no design de diversas formas e figuras, como é apresentado na figura 3.12.a. ColorCode codifica 10 dígitos e compreende uma matriz de 5 x 5 células, as quais podem ser projetadas até com quatro cores diferentes: preto, azul, verde e vermelho. As células também podem ser círculos, ovóides, ou polígonos, a estrutura do ColorCode é apresentada na figura 3.12.b. A qualidade da impressão, do papel e as condições de iluminação podem afetar a cor da imagem do marcador. Para resolver estes problemas, ColorCode implementa um algoritmo de correção de erro para detetar qualquer reconhecimento incorreto de cor. Além disso, ColorCode requer apenas do $40 \%$ de visibilidade de uma célula individual. Portanto, ColorCode permite incorporar um código de barras, um logotipo ou algum outro desenho gráfico, no restante $60 \%$ do marcador, como é apresentado na figura 3.12.c (COLORCODE, 2007).

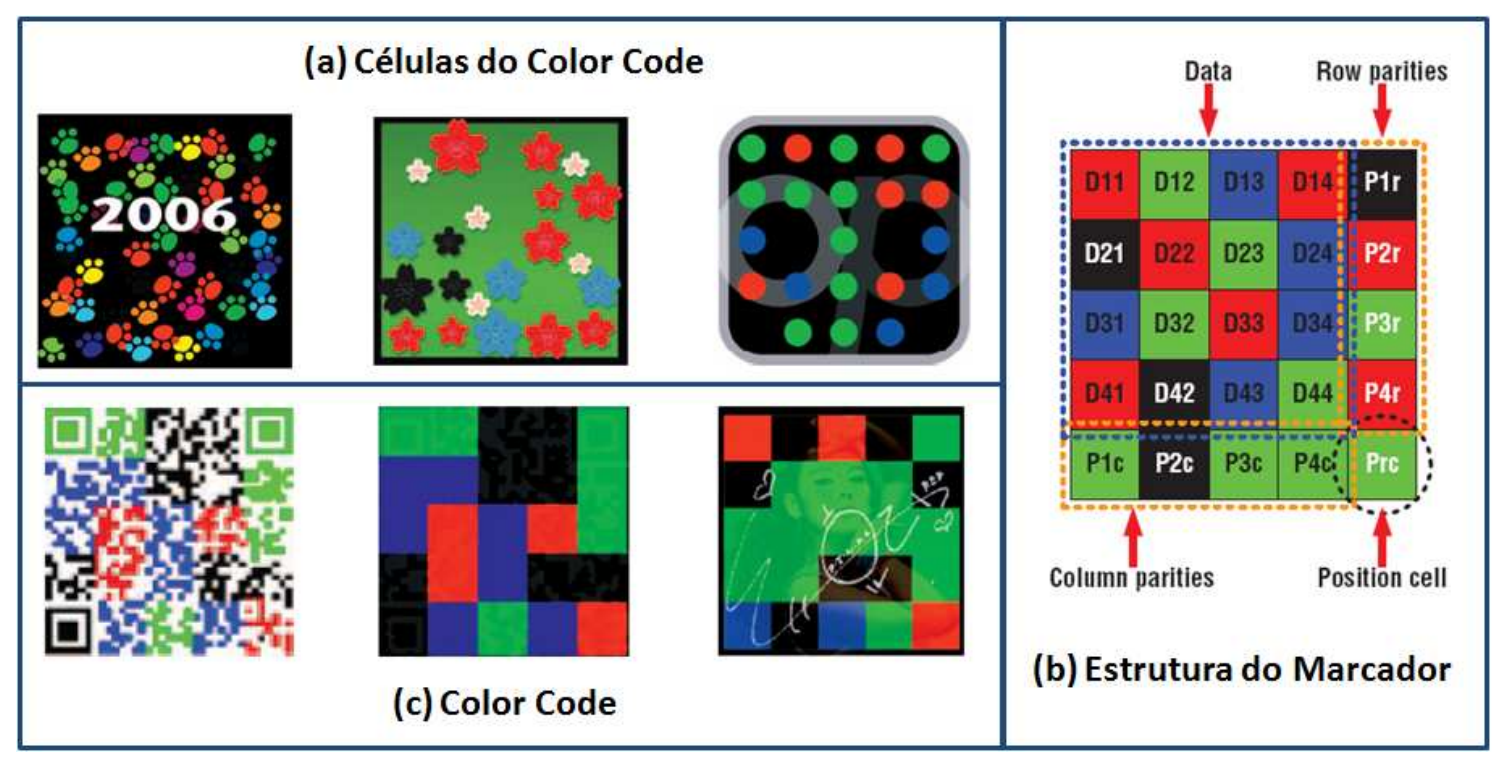

Figura 3.12: Marcador do tipo ColorCode (ColorCode, 2007).

Note-se, que cada tipo de marcador apresentado, provê suas próprias ferramentas e suporte necessário para seu reconhecimento. Porém, todos estes seis tipos de marcadores não tem como objetivo a apresentação de imagens virtuais ou a implementação de aplicações do tipo Handheld AR.

Mas na abordagem da presente pesquisa, nós precisamos que os marcadores utilizados representem suas informações em forma de objetos virtuais, isto é, imagens virtuais, efeitos de vibração e efeitos sonoros. 
Nesse sentido, o ARToolKitPlus (ARTOOLKITPLUs, 2007) é uma biblioteca open source para aplicações do tipo Handheld AR baseada no ARToolKit (ARTOOLKIT, 2007), projetada exclusivamente para a detecção de marcadores, pelo que não oferece suporte para a captura de vídeo ou renderização das imagens virtuais. O ARToolKitPlus foi projetado para as plataformas Windows Mobile (Pocket PCs e Smartphones) e consoles de jogos como o Gizmondo (WAGNER; SCHMALSTIEG, 2007). Os algoritmos do ARToolKitPlus utilizam matemática de ponto fixo, para melhorar o desempenho das aplicações. Já os marcadores utilizados pelo ARToolKitPlus são chamados de ID-based markers (marcadores baseados em identificadores) e estão baseados no Data Matrix. O desenho do marcador utilizado pelo ARToolKitPlus permite codificar até 4096 marcadores diferentes. A figura 3.13 apresenta o ID-based marker. Uma descrição mais detalhada do ARToolKitPlus é apresentada no Capítulo 5, na seção 5.1.

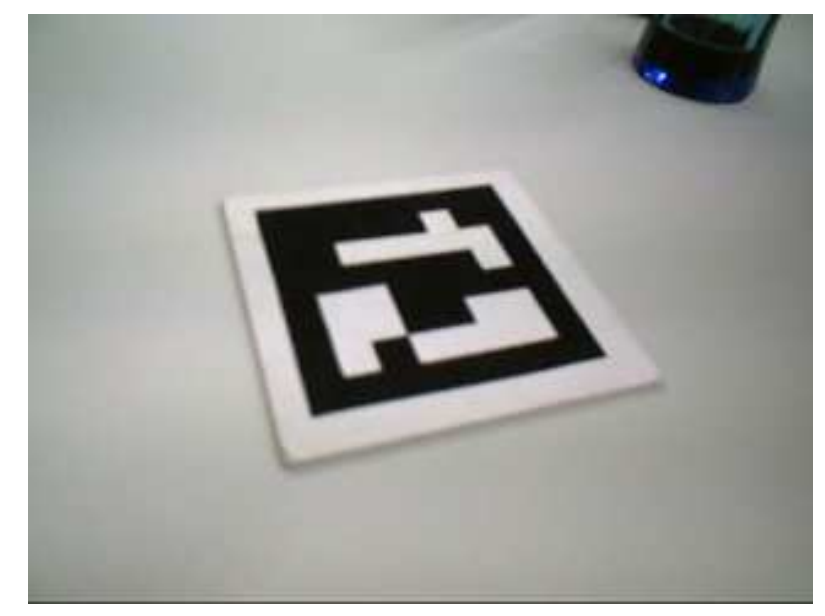

Figura 3.13: Marcador do ARToolKitPlus (ARToolKitPlus, 2007).

Na mesma linha do ARToolKitPlus, Henrysson e Ollila (2004) desenvolveu o ARToolKit for Symbian que é uma biblioteca open source para aplicações do tipo Handheld $A R$, projetada exclusivamente para a detecção de marcadores por telefones celulares que utilizam o sistema operacional Symbian (HENRYSSON; OLLILA, 2004). Esta biblioteca foi desenvolvida em linguagem $\mathrm{C}++$ e implementa suporte para a captura de vídeo. Porém, não tem nenhum mecanismo de renderização de imagens virtuais. Outras desvantagens são os problemas de desempenho, quantidade de marcadores (a ser reconhecidos), documentação e suporte para esta biblioteca.

Finalmente, fatores que afetam a todos os sistemas de reconhecimento de marcadores são: condições de luminosidade, distância entre o marcador e a câmera, resolução da câmera e a quantidade marcadores em cena a serem reconhecidos (KATO; TAN, 2007). 


\subsubsection{Renderização de Objetos Virtuais}

O conceito de "Realidade Aumentada" apresentado neste capítulo, pode ser estendido para:

"Uma mistura do mundo real com o mundo virtual, incluindo neste conceito uma renderização sensorial o que envolve aspectos visuais, auditivos e hápticos."

(TORI; KIRNER; SISCOUTTO, 2006)

Nesse sentido, e em função da abordagem da presente dissertação, define-se:

"Um objeto virtual é a representação de informações do mundo real em aspectos: visuais como imagens virtuais (esquema de cores, gráficos $2 \mathrm{D}$ e gráficos $3 \mathrm{D}$ ), auditivos como efeitos sonoros (efeitos sonoros 3D, reprodução de streams de áudio e Text-To-Speech), e hápticos como efeitos de vibração."

Portanto, a renderização de objetos virtuais é a implementação da representação das informações do mundo real captadas (utilizando a câmera do dispositivos móvel e dispositivos sensores) pela aplicação do tipo Handheld $A R$ em imagens virtuais, efeitos sonoros e efeitos de vibração, isto através das capacidades de hardware e software do dispositivo móvel que é utilizado como interface de interação com o usuário.

\subsubsection{Renderização de Imagens Virtuais}

O interesse em visualizar os dados gerados pelos dispositivos sensores e pela câmera do dispositivo móvel através de imagens virtuais justifica-se pelas potencialidades do sistema visual humano para analisar e entender informações (GUNNARSSON et al., 2006). As imagens virtuais podem ser representadas por gráficos 2D (NETO et al., 2006), esquema de cores (RAUHAla; GUNNARSSON; HENRYSSON, 2006) e gráficos 3D (HENRYSSON, 2007). Nesse sentido, a utilização de gráficos 3D na renderização de imagens virtuais popularizou-se pelo rápido desenvolvimento nas características de hardware nos dispositivos móveis (telefones celulares, Smartphones e PDAs) e pelo desenvolvimento de bibliotecas de software para a implementação de gráficos 3D.

Já a biblioteca mais popular para esta finalidade é o OpenGL ES (OPENGLES, 2007), que é uma versão limitada de OpenGL (OPENGL, 2007) direcionada para sistemas embarcados. Existem basicamente duas versões sendo desenvolvidas em paralelo: a versão 1.x, projetada para trabalhar com hardwares de função fixa, e a versão 2.x, especificada para hardwares programáveis. Uma desvantagem do OpenGL e Open $G L$ ES é que possuem 
uma programação de baixo nível, o que diminui a produtividade do desenvolvedor pela complexidade da implementação.

O Klimt (KLIMT, 2007) é outra biblioteca parecida ao OpenGL. O Klimt também possui algumas otimizações para a plataforma Pocket $P C$. A versão disponível é de código aberto e usa um mecanismo de renderização próprio. Devido à similaridade com OpenGL, o nível de programação é também muito baixo.

Já a plataforma Windows Mobile 5.0 possui o Direct3D Mobile (DIRECT3D, 2007), que é baseado no Direct3D para desktops. O . NET Compact Framework provê um entorno de desenvolvimento seguro e fácil para o Direct3D Mobile, porém, o nível de abstração é quase o mesmo do OpenGL ES (LIMA, 2007).

Finalmente, a plataforma Java provê uma API para renderização 3D chamada Mobile 3D Graphics API for J2ME (M3G) ou JSR 184 (MOBILE, 2007). O M3G é uma biblioteca orientada a objetos que possui dois modos de operação diferentes: o immediate mode, que usa acesso de baixo nível semelhante ao de Open $G L$ e Open $G L E S$, e o retained mode, que usa um grafo de cena, uma estrutura de mais alto nível para renderização 3D, tornando o processo de codificação muito mais intuitivo. A desvantagem das aplicações Java é o baixo desempenho. Entretanto, os dispositivos móveis atuais, vem integrando nas suas plataformas placas de aceleração 3D ou Graphics Processing Unit (GPU), o que apresenta expectativas significantes na melhora do desempenho para esta plataforma.

\subsubsection{Renderização de Efeitos de Vibração}

Efeitos de vibração são um tipo de representação sensorial háptica. Esta representação "háptica" justifica-se pela capacidade dos seres humanos de sentir um ambiente mecânico natural ou sintético através do tato (RODRIGUES, 2006). O tato possui dois componentes independentes, o cutâneo e o cinestésico. O primeiro está ligado aos sensores localizados na superfície da pele, que são responsáveis por sensações tais como temperatura, vibração e dor. O segundo está ligado aos sensores localizados nos músculos e tendões, que são responsáveis por sensações tais como movimento e força (OAKLEY et al., 2000). Ao tocar ou mover um objeto qualquer, a pessoa tem diversas sensações que são convertidas pelo cérebro em informação cutânea e cinestésica (KLATZKY; LEDERMAN, 2000).

Já as interfaces hápticas geram sinais mecânicos que estimulam os componentes cutâneos e cinestésicos do ser humano. Nesse sentido, uma interface háptica pode ser representada pela renderização de efeitos de vibração através de um telefone celular. Esta renderização manipula os transdutores do telefone celular, os quais são programados na sua amplitude e freqüência para representar diversos tipos de informações. 
Na plataforma Windows Mobile 5.0 a manipulação dos efeitos de vibração em Smartphones é feita utilizando o OpenNETCF Smart Device Framework 2.2 (OPENNETCF, 2007) o qual manipula a API chamada Vibrate Class (VIBRATECLASS, 2007). Baseados no fato que não todos os dispositivos móveis têm a capacidade de hardware de representar efeitos de vibração, a implementação de bibliotecas de software que suportam este modo de renderização é feito pelos fabricantes dos dispositivos. Nesse sentido, a Nokia desenvolveu uma API chamada CVibraControl Class Reference (CVIBRACONTROL, 2007) para dar suporte na programação para seus dispositivos da Serie 60 e 40. Além disso, a Nokia também desenvolveu uma API chamada Nokia UI API (NOKIA, 2007c) para prover suporte na programação de efeitos de vibração na plataforma JAVA.

Note-se que em geral é difícil produzir uma interação háptica realista. Porém, mesmo quando um dispositivo háptico imperfeito é usado, o usuário se adapta rapidamente à sua atuação, ignora as suas imperfeições, e naturalmente associa os estímulos mecânicos criados pelo dispositivo às suas experiências do dia-a-dia. Além disso, quando as interfaces hápticas são combinadas com representações gráficas (imagens virtuais), o usuário prontamente associa o estímulo táctil à imagem mostrada na tela (RODRIGUES, 2006).

\subsubsection{Renderização de Efeitos Sonoros}

A renderização de efeitos sonoros como interface de representação de informações justificase porque os ouvidos humanos captam som proveniente de todas as direções e o cérebro recebe estas ondas sonoras e as processa para descobrir de onde vem em tempo real (LóPEZ; RODRIGUEZ; VáZQUEZ, 2004). Nesse sentido, os efeitos sonoros podem ser representados por efeitos sonoros 3D (eco, reverberação, etc.), reprodução de streams de áudio (arquivos mp3, wav, etc.) e reprodução de Text-To-Speech (TTS), isto é, reconhecimento de texto, neste caso dos dados, para sua tradução em fala.

Na plataforma Windows Mobile 5.0 o .NET Framework for Mobile Devices provê suporte para as bibliotecas WindowsMobile.DirectX e WindowsMobile.DirectX.Direct3D, as quais gerenciam: a classe DirectSound para simular efeitos sonoros 3D, como o eco e a reverberação; e a classe AudioVideoPlayback que fornece suporte para controlar a reprodução de áudio e vídeo (WINDOWS, 2007). A reprodução de Text-To-Speech é feito utilizando o Text-To-Speech Core and SDK (SPEECH, 2008) e o Text-to-Speech SDK for Windows Mobile (DIGITAL, 2008).

Já na plataforma JAVA, o suporte para reprodução de streams de áudio e efeitos sonoros 3d utiliza as APIs MIDP 2.0 Sound API e Mobile Media API (MMAPI). Além disso, Flash Lite (NOKIA, 2007b) provê novas funcionalidades que permitem reproduzir 
streams de áudio em diversos formatos suportados por dispositivos da Nokia da Serie 60 e 40, como streams de áudio em formato MIDI. Diferentemente dos formatos de áudio, como WAV e MP3, o formato MIDI contém dados de desempenho, como o pitch (freqüência real de um som), duração (tempo), o volume e timbre de cada nota da composição. A reprodução de Text-To-Speech é feito utilizando a Java Speech API(JSAPI) (JSAPI, 2008).

Nesse sentido, independentemente da tecnologia utilizada, os dispositivos móveis podem reproduzir efeitos sonoros 3D, streams de áudio e Text-To-Speech em função do contexto e do ambiente, isto é, estes sons reproduzidos são associados as informações geradas contextualmente no ambiente. Além disso, os sons reproduzidos podem estar armazenados na memória dos dispositivos ou podem ser transmitidos através de uma interface de comunicação sem fio desde o ambiente ou de um servidor remoto. Finalmente, a figura 3.14 resume as classes, bibliotecas (APIs) e tecnologias disponíveis para o desenvolvimento de aplicações do tipo Handheld $A R$.

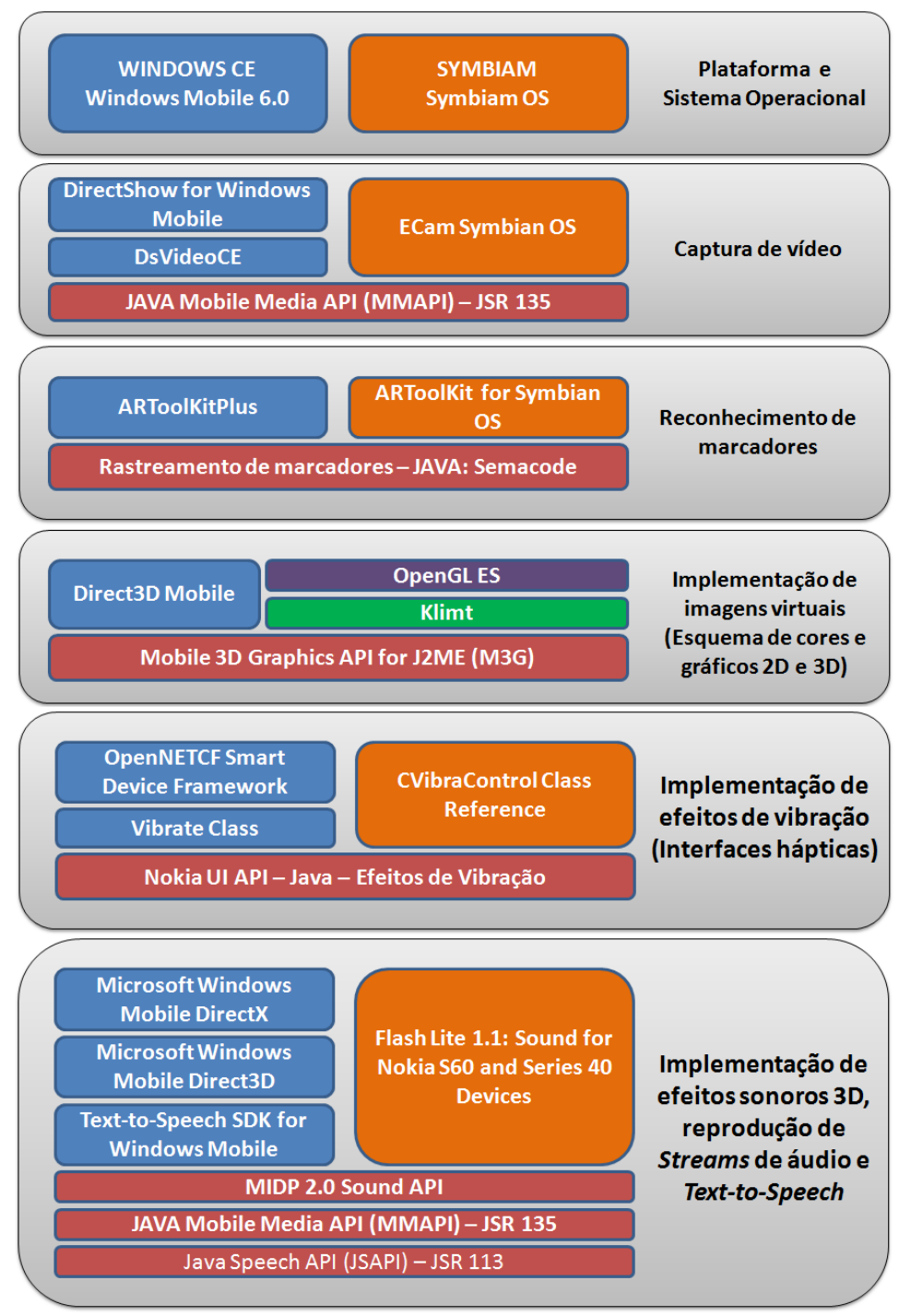

Figura 3.14: Bibliotecas e Tecnologias para Aplicações do tipo Handheld AR. 


\subsubsection{Estratégias de Processamento}

As aplicações de RA em dispositivos móveis se dividem em aplicações distribuídas e aplicações autônomas (LIMA, 2007). Os primeiros trabalhos de RA em telefones celulares eram aplicações distribuídas, devido à escassez de poder de processamento dos dispositivos da época.

Nas aplicações distribuídas, uma parte das tarefas necessárias para aumentar o ambiente é realizada por um servidor, trocando dados com o telefone celular. A detecção de marcadores na imagem capturada e a renderização de imagens virtuais é feita pelo servidor, já o telefone celular é responsável apenas por capturar a imagem, enviá-la para o servidor, receber o resultado final e desenhá-lo na tela. Como o servidor normalmente possui um grande poder de processamento, ele pode executar operações mais complexas de maneira mais rápida que o telefone celular.

Além disso, o servidor pode aproveitar recursos como GPU, melhorando o desempenho da aplicações e permitindo o projetos de objetos virtuais mais complexos. Entretanto, cada frame capturado pelo telefone celular é transferido para o servidor, processado, e os resultados são então enviados de volta para o dispositivo, causando um atraso que impacta no frame rate ou latência das aplicações. Outro problema é relacionado à necessidade de se ter um computador servidor, o que prejudica a mobilidade das soluções. Os trabalhos apresentados em (SINGH et al., 2004) e (WOODWARD, 2006) mostram a utilização de processamento distribuído em aplicações do tipo Handheld AR.

Já com o crescimento do poder de processamento dos dispositivos móveis, surgiram os sistemas autônomos, que não dependem de um servidor para gerar o resultado de RA, implementando todos os procedimentos necessários no mesmo dispositivo. Este fator permite o desenvolvimento de soluções de RA completamente móveis. Os trabalhos apresentados em (HENRYSSON; BILLINGHURST; OLLILA, 2005) e (HENRYSSON; OLLILA; BILLINGHURST, 2005) mostram a utilização de processamento autônomo em aplicações do tipo Handheld $A R$.

Note-se que os dois tipos de aplicações (distribuídas e autônomas) foram projetados em base a utilização de marcadores como única fonte de ingresso de dados no início da execução do sistema de RA.

Já Bertelsen e Nielsen (2000) propuseram estratégias de implementação para aplicações de RA, como sistemas de informação, desenvolvidas utilizando um PDA como dispositivo que interage con diversos objetos físicos (sensores, atuadores e máquinas) instalados no ambiente do mundo real. Estas estratégias são (BERTELSEN; NIELSEN, 2000): 
- Estratégia de aumentar o usuário, isto é, utilizar o PDA como "óculos", permitindo estender as capacidades de percepção dos usuários no ambiente, fazendo que o usuário tenha disponível informações que não percebe naturalmente com seus sentidos. A conexão entre o PDA e os objetos do mundo real é escondida e indireta.

- Estratégia de aumentar os objetos, isto é, conectar o PDA com os objetos inseridos no ambiente do mundo real. O PDA converte os objetos físicos em dispositivos de interação e ao mesmo tempo faz os objetos mais acessíveis para o usuário. A conexão entre o PDA e os objetos é visível e direta, o que permite controlar sem fios alguns tipos de máquinas.

- Estratégia de aumentar o meio ambiente, isto é, conectar o PDA com um sistema central que controla o ambiente, interagindo com códigos de barras, máquinas fotográficas, dispositivos sensores e outros elementos que permitam projetar informações. Neste caso, o PDA poderia acessar bancos de dados gerenciados pelo sistema central para incrementar seu conhecimento do ambiente.

Note-se que estes objetos físicos devem ter uma interface de comunicação sem fio para poder trocar as informações com os dispositivos móveis. Além de isso, todas informações apresentadas nos PDAs foram representadas como texto na tela do dispositivo móvel, como é apresentado na figura 3.15. Nesse sentido, a figura 3.15a apresenta uma sala de máquinas, já a figura 3.15b mostra um PDA como um sistema de informação, o qual permite visualizar o estado de funcionamento dos motores instalados na sala de máquinas.

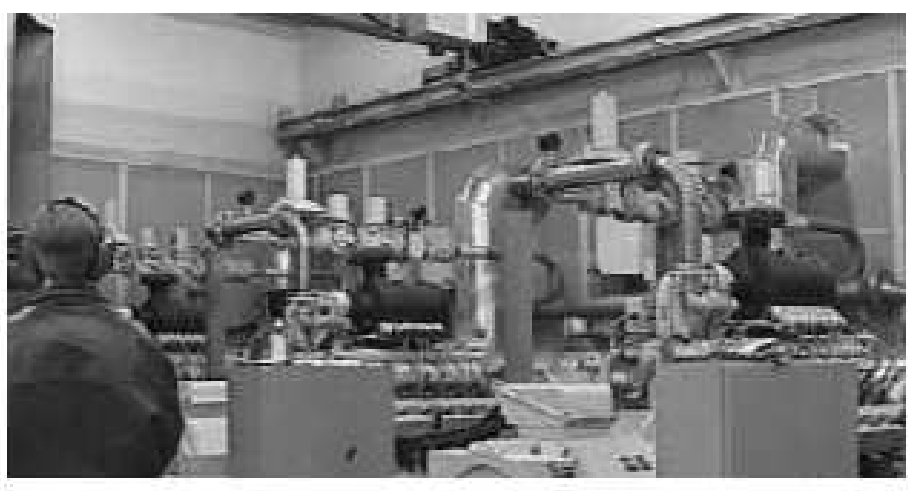

(a) Sala de Máquinas

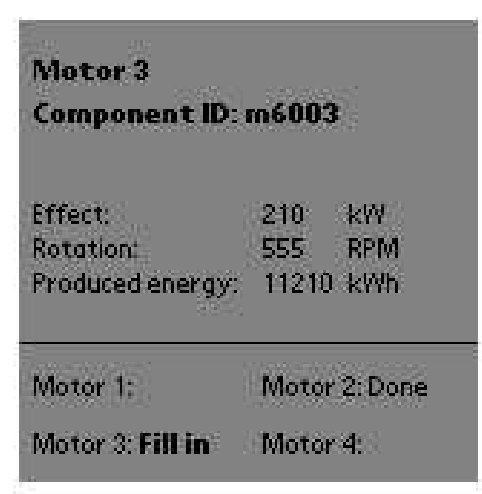

(b) Tela do PDA

Figura 3.15: Aplicações de RA como Sistemas de Informação (Bertelsen; Nielsen, 2000). 
Portanto, baseados nas atuais capacidades dos telefones celulares e as estratégias propostas em (BERTELSEN; NIELSEN, 2000), nós projetamos três cenários de aplicação, para aplicações do tipo Handheld $A R$, baseados nas capacidades de processamento e comunicação do telefone celular e dos diversos objetos físicos (redes de sensores, atuadores, receptores GPS, papel eletrônico, câmeras e telas de vídeo, mesas gráficas e projetores de vídeo) com os quais se pode interagir. Estes cenários são descritos a seguir:

- O dispositivo móvel através de uma interface de comunicação sem fio e a câmera embutida nele, acessa as informações do ambiente, as quais podem ser proporcionadas por diversos objetos físicos (por exemplo: dispositivos sensores) e marcadores. Neste cenário, a capacidade de processamento do dispositivo móvel permite gerar (adquirir, processar e apresentar) as informações do ambiente como objetos virtuais. Esta estratégia está baseada em um processamento autônomo que inclui o uso de dispositivos sensores para a aquisição e o dispositivo móvel para a representação das informações do ambiente.

- Para um cenário, no qual os objetos físicos (dispositivos sensores e atuadores) têm a capacidade de processamento e de atuação (execução de eventos, por exemplo: abrir e fechar portas), a aplicação de RA compartilha o processamento da aplicação entre o dispositivo móvel e os objetos físicos. A estratégia de processamento é distribuído. Além disso, a renderização das informações não só é feita pelos objetos virtuais no dispositivo móvel, se não também pelos dispositivos atuadores que executam eventos físico/mecânicos no ambiente.

- Já um cenário mais distribuído (até ubíquo) é baseado na assistência de outros sistemas computacionais (servidores) com acesso a dados remotos (adquiridos ou gerados em outros ambientes) para processar e transmitir diversas informações para o dispositivo móvel que executa uma aplicação de RA em um determinado ambiente. Neste caso, o dispositivo móvel pode capturar informações do ambiente e através de uma interface de comunicação sem fio conectar-se com um servidor. O servidor pode processar as informações capturadas pelo dispositivo móvel ou pode associar e processar informações remotas relevantes. O sistema de RA não depende de um único servidor para acessar esses dados remotos, já que o sistema de RA pode conectar-se com diversos servidores em diversos ambientes. A renderização das informações do ambiente ou informações remotas são apresentadas como objetos virtuais no dispositivo móvel. 


\subsubsection{Vantagens da Handheld Augmented Reality}

- Alternativa viável para os HMDs em aplicações móveis;

- São dispositivos socialmente mais utilizados e aceitos, e de menor custo;

- Suporte para mobilidade, portabilidade, disponibilidade em tempo real, conexão a rede (telefonia, LAN, Internet);

- Permite gerar novos modelos e serviços baseados em conceitos de RA;

- Suporte para múltiplos usuários;

- Maior interação entre o usuário e o mundo da RA (em qualquer tempo e ambiente).

\subsubsection{Limitações da Handheld Augmented Reality}

- Comparados com os HMDs, não permitem ter as mãos livres para outras tarefas;

- Em dispositivos pequenos (PDAs e telefones celulares) tem displays muito limitados pelo tamanho e resolução;

- Em dispositivos pequenos, limitações no poder de processamento das imagens;

- Complexidade na navegação pela tela do dispositivo, além de só 12 botões para escrever textos e mais alguns outros para a navegação;

- Impossibilidade de utilizar o dispositivo enquanto se dirige.

Nesse sentido, os conceitos apresentados nos capítulos 2 e 3 permitiram atingir os primeiros objetivos específicos da presente dissertação. Além disso, estes capítulos foram resumidos no artigo (ZUñIGA; KOFUJI, 2006), permitindo assim apresentar uma análise e caracterização dos requisitos mínimos de hardware e software para implementar aplicações do tipo Handheld AR em telefones celulares. 


\section{Modelagem e Processamento Semântico de Dados}

Este capítulo apresenta conceitos sobre técnicas da web semântica utilizadas na modelagem e desenvolvimento de processos de aquisição, processamento, armazenamento e gerenciamento de dados gerados por dispositivos sensores. Nesse sentido, nas seções deste capitulo são descritos o RDF e o RDF Schema como ferramentas para utilizadas na modelagem e processamento semântico de dados.

\subsection{Web Semântica}

A Web semântica tem como finalidade conseguir atribuir um significado (sentido) aos conteúdos publicados na Internet (páginas web) de modo que seja perceptível tanto pelo ser humano como pelo computador (BENERS-LEE; HENDLER; LASSILA, 2001). Isto porque tradicionalmente as páginas web são compostas principalmente por informações para a compreensão humana. No entanto, para os computadores é difícil compreender o sentido destas informações apresentadas nas páginas web. Já pesquisas em Web Semântica objetivam associar descrições às informações da Web atual sob uma representação que habilite aos computadores a interpretarem e realizarem inferências sobre essas informações. A implementação da Web semântica gera serviços de recuperação e intercâmbio de dados, garantindo a interoperabilidade das informações (NETO; PIMENTEL, 2003).

Nesse sentido, a infra-estrutura da Web Semântica está construída com base nas especificações: (a) XML (QUIN, 2007) para a estruturação de documentos; (b) o XML Schema (SPERBERG-MCQUEEN; THOMPSON, 2007) para tipagem de dados de elementos XML; (c) o RDF Resource Description Framework (KLYNE; CARROLL; MCBRIDE, 2007) que fornece um modelo genérico de representação de metadados em uma sintaxe XML; e (d) o RDF Schema (BRICKLEY; GUHA; MCBRIDE, 2007) que fornece uma linguagem baseada em hierarquia de classes para descrever relacionamentos semânticos RDF por meio de classes, propriedades e relacionamentos entre classes e restrições (W3C, 2007). 
Portanto, o objetivo principal da Web semântica é desenvolver uma estrutura de tecnologias e linguagens que tornem a informação da Internet (páginas web) legível e compreensível para os computadores. Nesse sentido, o uso de técnicas da web semântica em processos de aquisição, processamento, armazenamento e gerenciamento de dados gerados por dispositivos sensores buscam facilitar a implementação destes processos e permitir aos computadores compreender estes dados de uma forma simples e adequada.

\subsection{Dispositivos Sensores, Dados e Semântica}

O rápido crescimento no desenvolvimento de aplicações de sensoriamento e monitoração em ambientes industriais, agrícolas, urbanos, etc., gerou a necessidade de utilizar diversos tipos de dispositivos sensores para uma mesma aplicação, o que produz uma heterogeneidade nos dados gerados pela aplicação, e que em conseqüência gera uma grande quantidade de dados que precisam ser integrados (NI et al., 2005).

Além disso, os dados são coletados como dados brutos (Raw Data) o que dificulta seu entendimento por parte dos usuários e computadores. Nesse sentido, para tornar estes dados brutos em dados com algum sentido ou significado são aplicados conceitos da Web semântica, isto é, etiquetar (tagging) estes dados com informações semânticas. Estas informações semânticas incluem um padrão ou Schema, metadados e informações contextuais. Sem estas descrições semânticas, os dados brutos não teriam sentido nem significado. Além disso, a coleta, processamento, armazenamento e gerenciamento dos dados se tornaria mais complexa.

Portanto, aplicações como as apresentadas em (TOLKSDORF et al., 2005) e (LEWIS et al., 2006), implementam dispositivos sensores (como uma RSSF), o RDF e o RDF Schema (como técnicas da Web semântica) para tratar os processos de armazenamento e gerenciamento dos dados gerados pelas RSSF em cenários do mundo real, como no controle de tráfego e ambientes industriais.

Nesse sentido, no trabalho de Lewis et al. (2006) é apresentada uma arquitetura para a modelagem e processamento semântico dos dados brutos. Esta modelagem e processamento implementa um processo de etiquetado (tagging) dos dados brutos coletados com informações semânticas (metadados e informações contextuais). Esta implementação é descrita a seguir e apresentada na figura 4.1:

1. Coleta de Dados (Data Collection): A coleta de dados é uma questão importante para aplicações de sensoriamento. Geralmente os dados brutos, gerados por diversos sensores são coletados em arquivos de texto ou planilhas de cálculo (Excel). Para en- 
riquecer semanticamente estes dados e para resolver o problema da heterogeneidade de dados é aplicado o processo de etiquetamento (tagging).

2. Armazenamento em Memória Cache (Memory Caching): Para facilitar e melhorar a eficiência do processo de etiquetamento (tagging), este pode ser feito por dispositivos sensores com capacidades de processamento ou pelos dispositivos (talvez móveis) utilizados para coletar os dados gerados pelos dispositivos sensores. Porém, estes dados etiquetados ou não, deverão ser armazenados permanentemente.

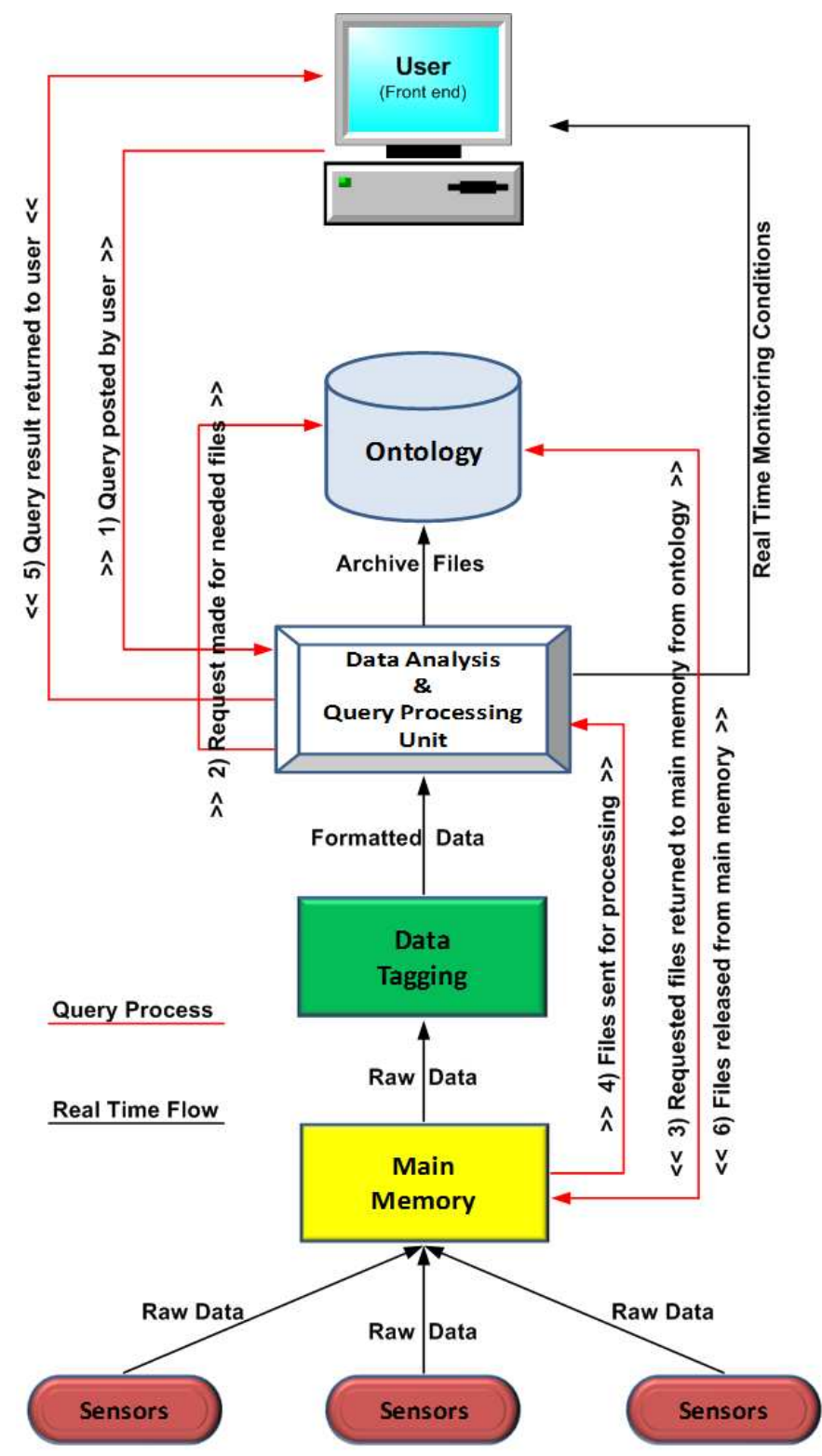

Figura 4.1: A Semantic Approach to Data Management in Sensor Networks (Lewis, 2006).

3. Etiquetamento de Dados (Data Tagging): Inerentemente os dados gerados por diversos tipos de sensores são heterogêneos e representam apenas valores simples (dados 
brutos) dos fenômenos observados ou medidos. O processo de etiquetamento (tagging) representa a modelagem destes dados brutos dentro de etiquetas (tags) que representam informações indexadas e relevantes para possibilitar o entendimento destes dados por sistemas computacionais. Portanto uma tag pode ser utilizada por exemplo para identificar unicamente a um determinado sensor.

4. Representação Ontológica (Ontology Representation): O processo de etiquetamento (tagging) pode ser implementado utilizando os padrões RDF, RDF Schema e OWL (MCGUINNESS; HARMELEN, 2007).

5. Processo de Consulta (Query Processing): Com os dados enriquecidos semanticamente, processos de consulta e gerenciamento são simplificado através de técnicas semânticas para a realização de consultas.

6. Interface de Usuário e Representação de Dados (User Interaction and Data Representation): Diversas ferramentas estão disponíveis para a visualização dos dados. Interfaces baseadas em gráficos, interfaces web, histogramas, tabelas, etc. Estas formas de visualização geralmente dependem do tipo de informações coletadas e dos requisitos do usuário.

Para demonstrar a aplicação da semântica em sistemas de sensoriamento, apresenta-se o seguinte exemplo: suponha que em um prédio, existe um grande número de dispositivos sensores (heterogêneos) instalados para monitorar o ambiente (interior do prédio). Estes dispositivos sensores incluem capacidades para monitorar temperatura, luminosidade e umidade. Agora, imagine-se que acontece um incêndio. Nesse sentido, precisa-se um maior grau semântico que identificação e localização do dispositivo sensor, exatidão e data do dado coletado. Esta maior semântica só pode ser compreendida por seres humanos, isto porque para compreender um incêndio precisa-se, mais ou menos, uma combinação de fatores como detecção de alta luminosidade e temperatura para a mesma área. Nesse sentido, a semântica é convertida para uma consulta que consiga determinar se está acontecendo um incêndio ou não. A consulta teria um formato como: "alta luminosidade (candlepower $)>=10$; e temperatura $>=80$, quando ambos sensores se encontram entre se a uma distância $<=1$ metros, isto durante um período de 10 segundos". Esta consulta é modelada em uma sintaxe adequada como por exemplo: SPARQL (PRUDHOMMEAUX; SEABORNE, 2007), que é uma uma linguagem de consulta baseada no padrão RDF.

Nesse sentido, nós adaptamos a arquitetura proposta por Lewis et al. (2006) em beneficio da metodologia apresentada na presente dissertação. Portanto, a coleta de dados será feita por uma RSSF; os dados serão armazenados e processados semanticamente (etiquetados - tagging) em um dispositivo móvel, neste caso em um telefones celular; já 
para nossa implementação, o processo de etiquetamento será feito utilizando os padrões RDF e RDF Schema; a consulta de dados será feita em função às preferências do usuário; e a apresentação das informações será feita como objetos virtuais utilizando o telefone celular como interface de interação com o usuário.

\subsection{Resource Description Framework (RDF)}

O Resource Description Framework (RDF) (KLYNE; CARROLL; MCBRIDE, 2007) é uma infra-estrutura com uma linguagem de propósito geral para representar informação no contexto da web semântica e para processar metadados, o qual provê interoperabilidade entre aplicações que trocam informações compreensíveis ao nível de máquina (GOMES, 2006). Portanto, o RDF pode ser usado em varias áreas de aplicação:

- Descoberta de recursos, para prover melhores métodos de busca;

- Agentes de software inteligentes, para facilitar o compartilhamento de informações;

- Avaliação de conteúdo, para descrever as preferências de privacidade de um usuário como também as políticas de privacidade em uma página web.

\subsubsection{O Modelo de Dados do RDF}

Tecnicamente, RDF não é uma linguagem, mas sim um modelo de dados para descrição de recursos com maior grau semântico, através da adoção de metadados (MARINO, 2001). O modelo básico de dados é composto por (BECKETT; MCBRIDE, 2007):

- Recursos (Resources): Todas as coisas que podem ser descritas através de expressões na linguagem RDF são chamadas de recursos. Um recurso pode ser uma página web, como por exemplo: http://www.pad.lsi.usp.br/ . Um recurso também pode ser um objeto que não é diretamente acessível pela web, como por exemplo: um livro impresso ou um pequeno sensor. Recursos sempre são nomeados por URIs ${ }^{1}$ mais um $i d$ (identificador) opcional.

- Propriedades (Properties): Uma propriedade é um aspecto específico, característica, atributo, ou relação que descreve um recurso. Cada propriedade tem um significado específico que define seus valores permitidos, os tipos de recursos que pode descrever e sua relação com outras propriedades.

\footnotetext{
${ }^{1}$ URIs: são strings utilizadas para identificar recursos na web como páginas, serviços, documentos, imagens, músicas, arquivos, caixas de e-mail, notícias, entre muitos outros.
} 
- Declaração (Statements): Um recurso específico junto a uma determinada propriedade e ao valor desta propriedade para aquele recurso, criam uma declaração RDF. Estas três partes individuais de uma declaração são chamadas respectivamente, o assunto (subject), o predicado (predicate) e o objeto (object). O objeto de uma declaração ou valor da propriedade pode ser outro recurso ou um simples valor literal.

A representação do modelo de dados é usada para avaliar equivalência de significado. Duas expressões RDF são equivalentes se, e somente se, suas representações de modelo de dados forem a mesma. Esta definição de equivalência permite algumas variações sintáticas nas expressões sem alterar o significado. Considere as duas sentenças da tabela 4.1.

\section{Tabela 4.1: Sentenças Sintaticamente Diferentes com o Mesmo Significado}

\begin{tabular}{|l|l|}
\hline 1 & O dono do sensor TmoteSky é o PAD \\
\hline 2 & O PAD é dono do sensor TmoteSky \\
\hline
\end{tabular}

Para as pessoas, estas declarações levam o mesmo significado (isto é, o PAD é o dono de um sensor em particular nomeado TmoteSky). Para uma máquina, porém, estas são sentenças completamente diferentes. Considerando que as pessoas são extremamente adeptas de extrair significado de diferentes construções sintáticas, máquinas permanecem grotescamente ineptas (MILLER, 1998).

Usando o modelo de dados, RDF tenta prover um método sem ambigüidade, representando uma semântica codificada e legível pela máquina. Portanto, as sentenças da tabela 4.1 são descritas no modelo de dados do RDF, como é apresentando na tabela 4.2.

\section{Tabela 4.2: Partes de uma Declaração RDF}

\begin{tabular}{|l|l|l|}
\hline Assunto (Subject) & Sensor TmoteSky & Recurso \\
\hline Predicado (Predicate) & Dono & Nome da Propriedade \\
\hline Objeto (Object) & PAD & Valor da Propriedade \\
\hline
\end{tabular}

Uma declaração RDF também pode ser visualizada na forma de um grafo, projetada usando diagramas de arcos e nodos como é apresentada na figura 4.2, onde os nodos (desenho oval) representam os recursos, os arcos (setas) representam as propriedades nomeadas e os retângulos representam literais, isto é, o valor da propriedade ou objeto.

Nesse sentido, a tabela 4.2 pode ser representada como um grafo, o que é apresentado na figura 4.3 . 


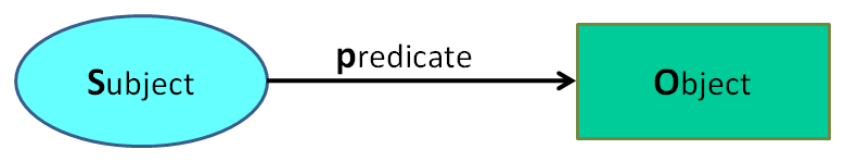

Figura 4.2: Representação Gráfica de uma Declaração RDF.

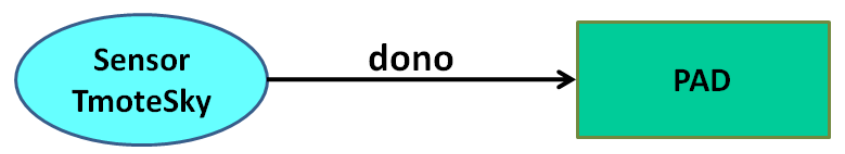

Figura 4.3: Grafo da Declaração RDF da Tabela 4.2.

\subsubsection{Especificação da Sintaxe RDF}

Tecnicamente RDF não é uma linguagem, mas sim um modelo de dados que provê um framework que faz uso de alguma linguagem que consiga expressar este modelo de dados. A sintaxe do RDF utiliza a linguagem de marcação XML (Extensible Markup Language) para representar seu modelo de dados, sendo o RDF e XML complementares. A sintaxe de XML é só uma possível forma sintática para RDF, outras formas de sintaxe poderiam ser usadas para representar o mesmo RDF (BECKETT; MCBRIDE, 2007).

A figura 4.4 ilustra como a declaração da tabela 4.2 pode ser expressada na sintaxe XML.

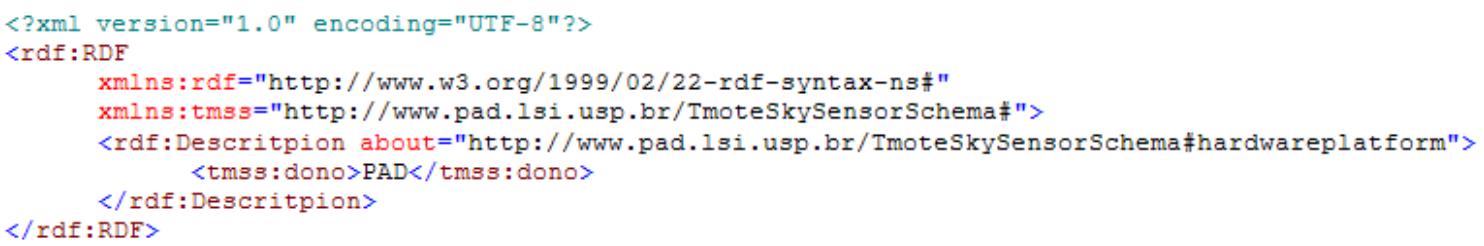

Figura 4.4: Sintaxe XML da Declaração RDF para o Sensor TmoteSky do PAD.

A primeira linha do código indica o documento XML e a versão da linguagem. A segunda e terceira linhas demarcam o trecho RDF do documento e identifica, com os prefixos "rdf:" e "tmss:" a localização dos vocabulários que definem os elementos utilizados. As demais linhas representam a declaração RDF que descreve o documento, com etiquetas (tags) precedidos dos prefixos "rdf:" e "tmss:", cuja semântica é descrita no vocabulário associado ao prefixo. Assim, o marcador "rdf:Description about" indica que haverá uma descrição referente ao documento identificado pela URI: 
A semântica do elemento Description encontra-se definida no vocabulário associado ao prefixo "rdf:" 2 . O marcador "tmss:dono" indica que o documento tem uma propriedade chamada "dono", cujo valor é "PAD" e cuja semântica está definida no vocabulário associado ao prefixo "tmss:" 3 .

Cada vocabulário no RDF recebe o nome de Schema e contém a declaração das propriedades (com a respectiva semântica) utilizadas na descrição do recurso. Os prefixos "rdf:" e "tmss:" representam namespaces utilizados na composição da descrição. Namespaces e Schemas serão descritos na seção RDF Schema.

Um indicador de fragmento "\#” foi incluído na referência about do recurso. Isso implica que todas as propriedades se referem somente a um componente contido no recurso, e não a todo o recurso, isto é, a propriedade dono encontra-se no componente HardwarePlatform e não nos componentes SoftwarePlatform e SensorDataCharacteristics.

Portanto, mesmo que as propriedades do RDF permitam representar relações entre recursos, RDF não provê nenhum mecanismo para descrever semanticamente estas propriedades, nem provê qualquer mecanismo para descrever as relações entre estas propriedades e outros recursos. Isso é o papel do RDF Schema.

\subsection{Resource Description Framework Schema (RDF Schema)}

Já o RDF Schema é um linguagem de representação de conhecimento, provendo elementos básicos para a descrição de vocabulários RDF, o que permite definir a semântica de um domínio de aplicação em específico. Isto é, um RDF Schema documenta vocabulários, definições e restrições para um conjunto de propriedades com a semântica correspondente para um recurso (BRICKLEY; GUHA; MCBRIDE, 2007).

O objetivo do RDF Schema é evitar confusões entre independentes e possivelmente conflitantes definições do mesmo termo para uma propriedade, para isso, RDF utiliza XML Namespaces. Namespaces são simplesmente um modo de ligar um uso específico de uma palavra dentro de um contexto, para o vocabulário onde a propriedade está definida. Em um arquivo RDF, cada predicado usado em uma declaração deve ser identificado por um namespace ou vocabulário (GOMES, 2006).

\footnotetext{
${ }^{2} \mathrm{O}$ vocabulário associado ao namespace "rdf:" contém a descrição dos elementos (e a correspondente semântica) que definem o modelo de dados RDF especificado pelo World Wide Web Consortium - W3C.

${ }^{3} \mathrm{O}$ vocabulário associado ao namespace "tmss:" contém a descrição do modelo de dados RDF para o sensor TmoteSky especificado na presente dissertação
} 
O vocabulário associado ao namespace "rdfs:" contém a descrição dos elementos (e a correspondente semântica) que definem o RDF Schema, especificado pelo World Wide Web Consortium - W3C na URI:

$$
\text { http : //www.w3.org/2000/01/rdf - schema } \sharp
$$

O RDF Schema define classes e propriedades que podem ser usadas para descrever classes, propriedades e outros recursos nos vocabulários. As classes são organizadas em uma hierarquia, o que o faz extensível por refinamento de subclasses.

\subsubsection{Definição de Classes}

Uma classe é algum recurso que tem uma propriedade rdf:type cujo valor é o recurso rdfs:Class. Os recursos que pertencem a uma classe são chamados de suas instâncias. Então, toda classe é um recurso e está identificada através de uma URI. As instâncias são indicadas através da propriedade rdf:type. (BRICKLEY; GUHA; MCBRIDE, 2007).

Classes RDF podem ser usadas para representar quase todas as coisas, tais como páginas Web, pessoas ou conceitos abstratos. Dentre os tipos de classes do RDF Schema destacam-se:

- rdfs:Resource, todas as coisas descritas por um RDF são chamadas de recursos, e são instâncias da classe rdfs:Resource. Esta é a classe genérica no modelo RDF Schema. Todas as outras classes são subclasses da classe rdfs:Resource.

- rdfs:Class, é subclasse de rdfs:Resource e representa o conceito genérico de tipo ou categoria, similar à noção de classe em orientação a objetos.

- rdfs:Literal, é subclasse de rdfs:Resource e representa os valores de uma propriedade como strings e integers.

- rdf:Property, é subclasse de rdfs:Resource e representa um aspecto ou característica do recurso sendo descrito por uma propriedade, similar à noção de atributo em orientação a objetos.

\subsubsection{Definição de Propriedades}

Propriedades permitem expressar relações entre classes e suas instâncias. Também são permitidas relações entre propriedades, criando uma hierarquia de propriedades (BRICKLEY; GUHA; MCBRIDE, 2007). Todas as propriedades em RDF são descritas utilizando- 
se a classe rdf:Property, e as propriedades do RDF Schema usam rdfs:subPropertyOf, rdfs:range e rdfs:domain (GOMES, 2006).

- rdf:type, é uma instância de rdf:Property e denota que um recurso é instância de uma classe, isto é, um recurso "Y" é do tipo da classe "X", possuindo todas as suas características. Um recurso pode ser instância de mais de uma classe. Nota-se que "rdf:type" foi definido no modelo de dados RDF e só é utilizado pelo RDF Schema.

- rdfs:subClassOf, é uma instância de rdf:Property e define uma relação entre classes e subclasses. Esta propriedade é transitiva. Somente instâncias de rdfs:Class podem ter a propriedade rdfs:subClassOf e seu valor é sempre do tipo rdfs:Class. Uma classe pode ser subclasse de mais de uma classe. Uma classe nunca pode ser declarada subclasse dela mesma, nem de alguma de suas subclasses.

- rdfs:subPropertyOf, é uma instância de rdf:Property e é utilizada para especificar que uma propriedade é uma especialização de outra. Uma propriedade pode ser especialização de zero, uma ou mais propriedades. Se uma propriedade P2 é subpropriedade de P1, e se um recurso A tem uma propriedade P2 com o valor B, implica que A tem também uma propriedade P1 com o valor B.

- rdfs:domain, é uma instância de rdf:Property e especifica por qual classe uma propriedade pode ser usada. Isto é, rdfs:domain limita as instâncias de classes que podem utilizar uma determinada propriedade. Uma propriedade pode ter zero, uma ou várias classes como seu domínio. Se uma propriedade não possui a propriedade rdfs:domain ela pode ser usada com qualquer recurso. Se há somente uma propriedade rdfs:domain, uma propriedade pode ser usada apenas nas instâncias dessa classe.

- rdfs:range, é uma instância de rdf:Property, e que é usada para declarar que os valores de uma propriedade são instâncias de uma ou mais classes. Isto é, a restrição rdfs:range limita os valores que podem ser aplicados a uma determinada propriedade.Por exemplo, indicar que a propriedade "tmss:AntennaRangeIndoor" tem valores do tipo integer. Uma propriedade pode ter somente uma propriedade range ou nenhuma, nesse caso, a classe de valores da propriedade é irrestrita.

Um RDF Schema tem outras propriedades que podem ser usadas para documentação e outras informações sobre o próprio vocabulário ou sobre suas instâncias. As principais são: (BRICKLEY; GUHA; MCBRIDE, 2007) 
- rdfs:comment, pode ser usada para descrever um recurso em formato adequado para ser lido por seres humanos.

- rdfs:label,pode ser usada para indicar a versão do nome de um recurso em formato adequado para ser lido por seres humanos.

- rdfs:seeAlso, pode ser usada para indicar um recurso que contém informações adicionais a respeito do recurso em questão.

- rdfs:isDefinedBy, é uma sub-propriedade da propriedade rdfs:seeAlso que indica o recurso que define o recurso em questão.

Portanto, nós utilizamos o RDF Schema para criar vocabulários RDF para descrever as classes a serem utilizadas no processamento semântico dos dados coletados no ambiente pela RSSF implementada na presente dissertação. Além disso, o RDF também é utilizado para criar os perfis de usuário. Nesse sentido, conceitos sobre personalização das informações são apresentadas na seguinte subseção.

\subsection{Personalização de Informações}

A personalização das informações constitui-se em um mecanismo da tecnologia necessário para adaptar o acesso e apresentação das informações para o usuário final. Esta personalização pode ser definida como o ajuste automático do conteúdo da informação, da sua estrutura e da sua apresentação ao usuário (PERUGINI; RAMAKRISHNAN, 2003). Nesse sentido, a personalização implementa técnicas que descrevem o comportamento, interesses, necessidades e limitações do usuário, dispositivos, sistemas, situações e ambientes. Estas técnicas permitem facilitar a adaptação de serviços personalizados.

Os Perfis ou Profiles são uma técnica utilizada para representar as características e capacidades dos dispositivos, dados pessoais e preferências dos usuários, condições da rede de comunicação, características dos conteúdos requisitados, e situações, eventos e períodos em função dos ambientes (FORTE, 2006). Duas implementações de perfis, muito utilizadas, para dispositivos móveis são apresentadas a seguir:

- O Composite Capability / Preferences Profile (CC/PP): Recomendação do W3C, é um método para comunicar (descrever) as capacidades (de hardware e software) de dispositivos como os telefones celulares em recursos e documentos. O $\mathrm{CC} / \mathrm{PP}$ foi desenvolvido utilizando o RDF. O CC/PP não define um vocabulário para especificar as capacidades dos dispositivos, mas sim uma linguagem genérica para construir tais vocabulários (KLYNE et al., 2007). 
- O User Agent Profile (UAProf): Definido pela Open Mobile Alliance (OMA) é uma complementação do CC/PP para dispositivos móveis que utilizam tecnologia Wireless Application Protocol (WAP) para acessar a Internet. O WAP definiu o protocolo Wireless Session Protocol (WSP) para suportar a comunicação entre o dispositivo móvel e o gateway WAP, uma de suas funções é transportar os perfis UAProf. Estes perfis são utilizados para negociar a forma como os conteúdos da Internet serão apresentados, isto é, tamanho, cores e gráficos das páginas web acessadas, isto porque o UAProf informa ao gateway WAP as características do dispositivo. Portanto, o UAProf, ao contrário do CC/PP, define um vocabulário para especificar capacidades de dispositivos (OMA, 2007).

Já duas linguagens formais, além do RDF, para a implementação de perfis de usuários são descritos a seguir:

- HumanML (Human Markup Language): é uma especificação que descreve as características das pessoas como descrições físicas (preferências estéticas), descrição de emoções (interpretar gestos), de ações (hábitos) e descrições culturais (interesses) através da sintaxe XML e outros esquemas apropriados (BROOKS; CAGLE, 2002).

- UserML (User Model Markup Language): é uma plataforma de comunicação sobre modelos parciais do usuário para aplicações da computação ubíqua. Esta plataforma estabelece uma taxonomia que é apresentada na figura 4.5. O UserML a diferença do HumanML, descreve principalmente preferências e políticas de privacidade do usuário. Nesse sentido, o UserML é utilizado como base para a criação dos perfis de usuário na presente dissertação (HECKMANN, 2005).

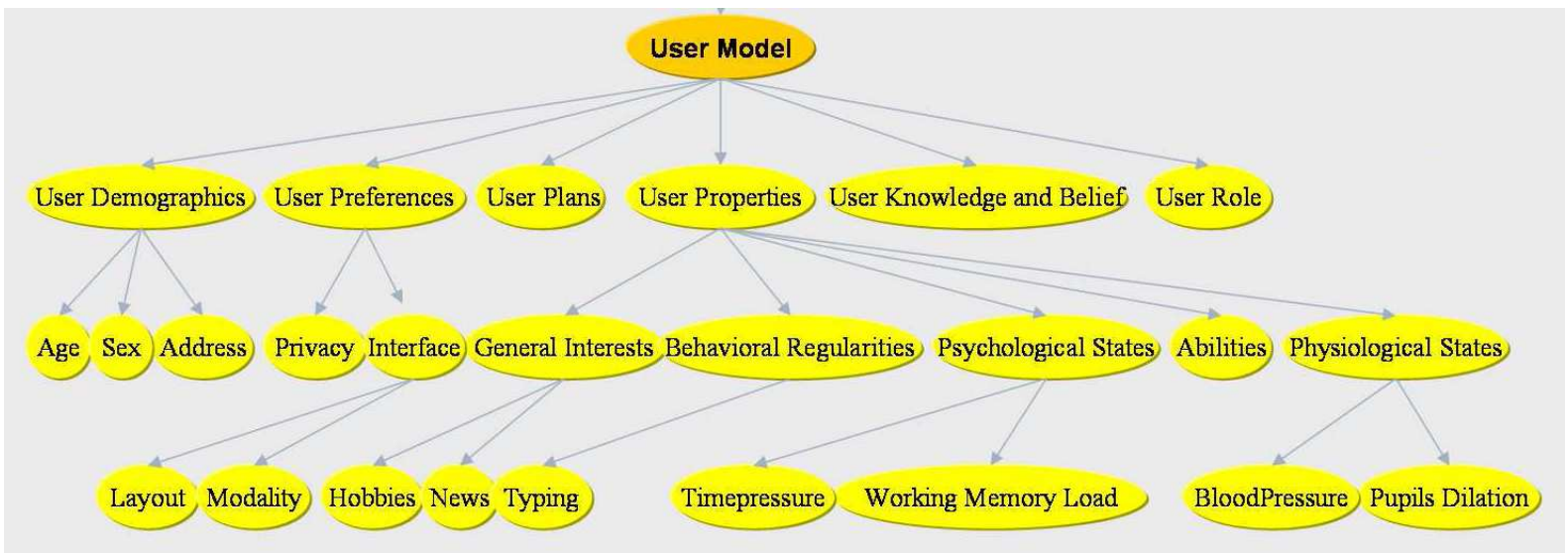

Figura 4.5: Uma Taxonomia Parcial do UserML (Heckmann, 2005). 


\section{Grupos de Pesquisa e Trabalhos Relacionados}

Neste capítulo são apresentados os grupos de pesquisa e trabalhos relacionados relevantes para o desenvolvimento da presente pesquisa.

\subsection{Studierstube}

O Studierstube (STUDIERSTUBE, 2007) é um grupo de pesquisa composta por pesquisadores da Graz University of Technology e Vienna University of Technology. As linhas de pesquisa deste grupo são:

- Localização, interação e disponibilização de serviços de RA em tempo real para ambientes urbanos e ao ar livre;

- Geração de imagens 3D estéreo gráficas, para incrementar a sensação de interação com imagens virtuais;

- Manipulação e interação direta com imagens virtuais;

- Colaboração em tempo real com outros usuários em diferentes ambientes;

- Implementação de sistemas de RA utilizando a plataforma Windows Mobile para dispositivos móveis como: PDAs, UMPCs e Smartphones;

- Implementação de agentes de software para sistema de RA, como uma forma de comunicação homem-máquina devido ao comportamento autônomo e afetivo dos agentes.

Os principais trabalhos desenvolvidos por este grupo de pesquisa são descritos a seguir:

1. ARToolKitPlus, é uma versão otimizada e estendida do ARToolKit, a qual acrescenta características para o uso de PDAs, UMPCs e Smartphones. A compatibilidade 
com algumas características do ARToolKit é quebrada devido a que é implementa uma nova API Base (WAGNeR; SCHMALSTIEG, 2007). O ARToolKitPlus foi desenvolvido como parte do Handheld AR Project (HANDHELD, 2007). Já na tabela 5.1 são apresentadas as mais relevantes e novas características do ARToolKitPlus (WAGNER; SCHMALSTIEG, 2007).

\section{Tabela 5.1: Características da Implementação do ARToolKitPlus}

\begin{tabular}{|c|c|}
\hline $\begin{array}{l}\text { Ponto Fixo } \\
\text { (Fixed Point) }\end{array}$ & $\begin{array}{l}\text { Implementação de bibliotecas em } \mathrm{C}++ \text { com aritmética de ponto } \\
\text { fixo para emular as operações nativas em ponto flutuante. }\end{array}$ \\
\hline $\begin{array}{l}\text { Formato de Pixels } \\
\text { (Pixel Formats) }\end{array}$ & $\begin{array}{l}\text { Suporte para } 6 \text { formatos de pixels: ABGR, BGRA, RGBA, } \\
\text { RGB, RGB565 e GRAY. }\end{array}$ \\
\hline $\begin{array}{l}\text { Identificação de } \\
\text { Marcadores } \\
\text { (Id-markers) }\end{array}$ & $\begin{array}{l}\text { Suporte para } 3 \text { modos de identificação de marcadores: Template } \\
\text { Matching compara o marcador com as imagens na base de dados; } \\
\text { Simple ID é um algoritmo que identifica } 512 \text { marcadores; } \\
\text { e Advanced } B C H \text { é um algoritmo que identifica } 4096 \text { marcadores. }\end{array}$ \\
\hline $\begin{array}{l}\text { Limiar Automático } \\
\text { (Automatic } \\
\text { Thresholding) }\end{array}$ & $\begin{array}{l}\text { Devido as mudanças na luminosidade, uma escolha automática } \\
\text { para os valores mínimo e máximo aceitos para a distorção de } \\
\text { luminosidade (limiar) é implementada. }\end{array}$ \\
\hline $\begin{array}{l}\text { Compensação } \\
\text { (Vignetting) }\end{array}$ & $\begin{array}{l}\text { Para evitar que o borde do marcador se sobrepor, é implementada } \\
\text { uma compensação na qual é especificado numericamente um } \\
\text { limite entre o centro da imagem para os cantos. }\end{array}$ \\
\hline $\begin{array}{l}\text { Calibração da } \\
\text { Câmera } \\
\text { (Camera Calibration) }\end{array}$ & $\begin{array}{l}\text { Usa o GML MatLab Camera Calibration Toolbox (GML, 2007), } \\
\text { para calibrar a câmera do telefone celular o usuário tem que } \\
\text { tirar várias fotos de uma tábua de xadrez, o que } \\
\text { permite a calibração semi-automática da câmera. }\end{array}$ \\
\hline $\begin{array}{l}\text { Portabilidade } \\
\text { (Portability) }\end{array}$ & $\begin{array}{l}\text { ARToolKitPlus é implementado em } \mathrm{C}++ \text { e é altamente portátil. } \\
\text { Roda sobre Windows XP, Windows CE, Symbian e Linux. }\end{array}$ \\
\hline $\begin{array}{l}\text { Memória } \\
\text { (Memory) }\end{array}$ & ARToolKitPlus faz uma distribuição standard de memória. \\
\hline $\begin{array}{l}\text { Otimização } \\
\text { (Optimizations) }\end{array}$ & $\begin{array}{l}\text { Uso do ponto fixo para simular operações em ponto flutuante } \\
\text { e uso de técnicas de pre-processamento. }\end{array}$ \\
\hline $\begin{array}{l}\text { Algoritmo de } \\
\text { Rastreamento } \\
\text { (Robust Planar } \\
\text { Pose Tracking) }\end{array}$ & $\begin{array}{l}\text { Implementa um algoritmo robusto para a otimização do rastreamento } \\
\text { (SCHWEIGHOFER; PINZ, 2006). O algoritmo foi portado em } \mathrm{C}++ \text {, } \\
\text { porem só é suportado em computadores e não em PDAs ou } \\
\text { telefones celulares. }\end{array}$ \\
\hline
\end{tabular}

O modo no qual o ARToolKitPlus detecta o código de identificação dos marcadores (Id-markers), é baseado no trabalho de Fiala (2004), o qual apresenta um sistema de marcadores 2D de padrão plano que codifica 36 bits de dados, os quais contém um único código de identificação por marcador para evitar erros de detecção (ARTOOLKITPLUS, 2007). 
O ARToolKitPlus pode reconhecer um marcador ou um conjunto de marcadores, o que é interpretado como um único marcador, isto aumenta a complexidade do sistema, porém, melhora a precisão e robustez do reconhecimento.

Antes do processo de reconhecimento de marcadores, ARToolKitPlus executa um pré-processamento para calibrar a câmera, este pré-processamento gera como resultado uma matriz de projeção da perspectiva e os parâmetros de distorção da imagem, os quais são armazenados em um arquivo e carregados no sistema quando ele começa o processo de reconhecimento dos marcadores. Depois, o fluxo de reconhecimento segue por 6 etapas como é descrito e apresentado pela figura 5.1 (WAGNER; SCHMALSTIEG, 2007).

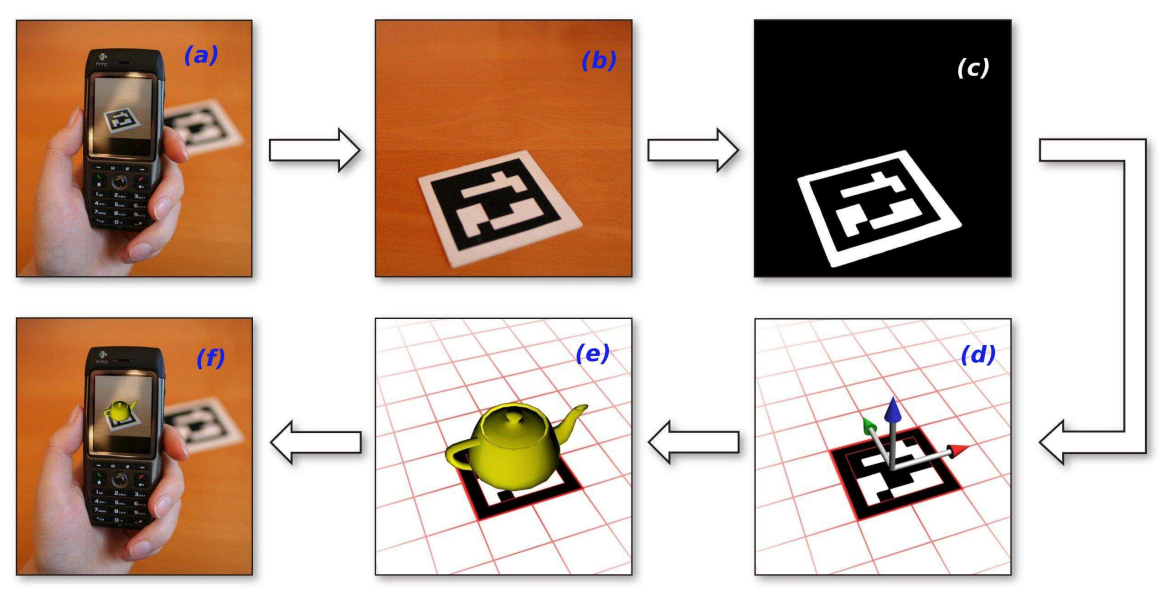

Figura 5.1: Fluxo de Processamento de uma Aplicação do Tipo Handheld AR que utiliza Marcadores (Wagner, 2007).

(a) A câmera captura um stream de vídeo;

(b) O stream de vídeo é enviado para o sistema de reconhecimento o qual executa um processo de compensação ( Thresholding ${ }^{1}$ ) para separar o que é fundo de um eventual marcador;

(c) O processo de compensação permite a identificação da área interior do marcador. Esta área é analisada e as imagens resultantes são comparadas com os padrões conhecidos;

(d) Quando um padrão é detectado, um processo iterativo calcula e refina a posição e orientação ou direção, resultando uma transformada do plano da câmera para um sistema de coordenadas no centro do marcador;

\footnotetext{
${ }^{1}$ Thresholding: A menor intensidade da um luminosidade que pode ser percebido pelo olho de um observador.
} 
(e) Ferramentas para o desenvolvimento gráfico usam esta matriz para criar as imagens virtuais como gráficos 3D. No caso do ARToolKitPlus as imagens virtuais são criadas com o OpenGL ES e Klimt;

(f) Estas imagens virtuais são sobrepostas no marcador. Finalmente a imagem é exibida na tela do dispositivo móvel.

2. AR on Smartphone, é uma extensão do Handheld AR Project para Smartphones. Em março de 2006 foi publicada uma demonstração simples em um i-mate SP5 Smartphone, o qual reconhece um marcador e insere uma imagem virtual na tela do aparelho. Esta aplicação apresenta uma freqüência entre 11-12 frames por segundo e precisa dos seguintes componentes de software (HANDHELD, 2007):

- DSVideoCE: aplicação que captura o fluxo de video da câmera, além de converter o formato nativo dos telefones celulares YV12 para RGB565 e cinza (não disponível para seu estudo);

- ARToolKitPlus: para o rastreamento de reconhecimento dos marcadores;

- Klimt: biblioteca 3D de código aberto, projetada para PDAs e telefones móveis. Solução baseada em OpenGL e OpenGL ES;

- FPK: pacote de animação proprietário para PDAs e SmartPhones (não disponível para seu estudo).

3. AR on the Gizmondo, é uma extensão do Handheld $A R$ Project e do $A R$ on Smartphone Project para consoles móveis de jogos comerciais. Em julho de 2006 foi publicada uma demonstração simples num console Gizmondo ${ }^{2}$, o qual reconhece um marcador e insere uma imagem virtual na tela do aparelho. Esta aplicação apresenta uma freqüência de 25 frames por segundo e precisa dos seguintes componentes software (HANDHELD, 2007):

- ARToolKitPlus: para o rastreamento de reconhecimento dos marcadores;

- OpenGL: biblioteca 3D de código aberto, projetada para PDAs, SmartPhones, telefones celulares e consoles móveis de jogos. O Gizmodo contém um acelerador gráfico GeForce 4500 e uma biblioteca que administra os fluxos de vídeo da câmera;

- FPK: pacote de animação proprietário para PDAs e SmartPhones (não disponível para seu estudo).

\footnotetext{
${ }^{2}$ Gizmondo: <http://en.wikipedia.org/wiki/Gizmondo>
} 


\section{$5.2 \quad$ VITA}

O VITA (Visual Information Technology and Applications) (VITA, 2007) é um grupo de pesquisa composta por pesquisadores da Linköping University. As linhas de pesquisa deste grupo são:

- Desenvolvimento de técnicas e ferramentas para visualização científica;

- Desenvolvimento de técnicas e ferramentas para sistemas de informação e visualização geográfica;

- Desenvolvimento de métodos para computação gráfica, RV e RA.

Os principais trabalhos desenvolvidos por este grupo de pesquisa são descritos a seguir:

1. UMAR - Ubiquitous Mobile Augmented Reality, é um framework que propõe uma ponte entre o mundo real e o domínio digital. Para um contexto arbitrário o framework deve exibir informações relevantes que dependem do contexto. Se há uma relação direta entre contexto e informação relevante, a técnica apropriada para representar a informação seria RA. Se a relação é mais fraca, nós poderíamos usar um mapa 2D como técnica de representação. Se não há nenhuma relação entre contexto e as informações, então nenhuma informação é representada. Como parte deste trabalho foi portado o ARToolKit para a plataforma Symbian (HENRYSSON; OLLILA, 2004).

2. CMAR - Collaborative Mobile Augmented Reality, é uma plataforma para realidade aumentada móvel colaborativa que permite a vários usuários interagir e manipular uma cena e uma imagem virtual compartilhada, utilizando para isto a interface Bluetooth e seus telefones celulares como interfaces de interação em tempo real. O CMAR permite que até oito usuários possam participar deste ambiente colaborativo de realidade aumentada (ANDEL; PETROVSKI, 2006).

\section{Visualization of Sensor Data Using Mobile Phone Augmented Reality,} protótipo para visualização de umidade nas estruturas, utilizando para isto: telefones celulares, RSSF e técnicas de RA. Os dados são coletados em uma matriz e são usados para sintetizar um gráfico em tempo real (RAUHALA; GUNNARSSON; HENRYSSON, 2006). Este gráfico apresenta um esquema de cores que permite perceber facilmente a quantidade de umidade presente no ambiente, já o marcador é utilizado para determinar a localização do dispositivo sensor, como é apresentado na figura 5.2. 


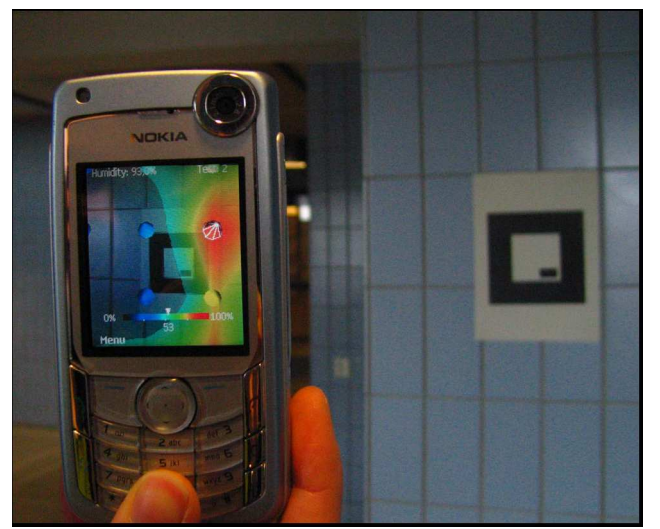

Figura 5.2: Visualization of Sensor Data Using Handheld AR (Rauhala, 2006).

\subsection{Nokia Center Research}

O Nokia Center Research (NOKIA, 2007a) é o centro de pesquisas da Nokia Corporation para áreas como Digital Services, Physical Touch - Digital Match, Human Interaction, Data and Content Technologies, e Device Architecture. Já as linhas de pesquisa deste grupo que são de interesse para este trabalho de mestrado exploram:

- Aplicações de Realidade Aumentada Móvel que exploram o uso de telefones celulares e sensores integrados, criando novas e excitantes aplicações, soluções e paradigmas.

- Uso de tecnologias da Web Semânticas não só para prover interoperabilidade em aplicações ubíquas, mas também outros problemas mais complexos, como aplicações cientes ao contexto e políticas de contexto, que são tecnologias necessárias para implementar ambientes inteligentes.

O trabalho desenvolvido por este grupo de pesquisa que é de nosso interesse é:

1. MARA - Mobile Augmented Reality Applications, é um sistema que inclui diversos sensores como: um receptor GPS, para prover informações sobre posicionamento; acelerômetros para prover orientação relativa; e um magnetômetro que é utilizado para determinar a direção. O sistema utiliza a câmera do celular para adquirir imagens e apresentar na tela do dispositivo as informações virtuais geradas em função dos dados adquiridos pelos dispositivos sensores integrados. Informações adicionais de serviços externos são enviados para o sistema através da Internet por conexão da rede celular (KäHäRI; MURPHY, 2006). A figura 5.3 apresenta esta aplicação na cidade de New York. 


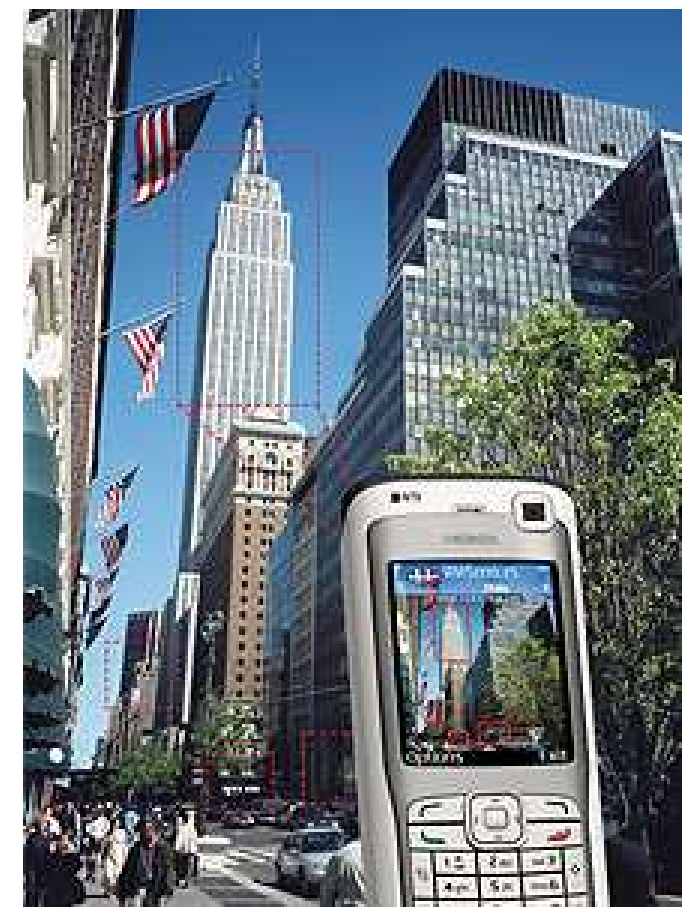

Figura 5.3: Mobile Augmented Reality Systems (Kahari;Murphy, 2006).

\subsection{Trabalhos Relacionados (Individuais)}

O objetivo do artigo apresentado por Neto et al. (2006) é descrever as experiências vivenciadas na implementação de uma aplicação de Realidade Aumentada para dispositivos móveis baseados na plataforma Symbian. Já no trabalho de formatura apresentado por Lima (2007) é desenvolvido um framework que facilita o desenvolvimento de aplicações de realidade aumentada para a plataforma Pocket PC. Este framework implementa uma biblioteca chamada OGRE4PPC para renderização de gráficos 3D em tempo real baseada na biblioteca OGRE ${ }^{3}$.

Propostas mais formais para direcionar a implementação de aplicações de RA são apresentadas no trabalho de mestrado de Nilsen (2006) e no artigo apresentado por Dunser et al. (2007). Nesse sentido, Nilsen desenvolveu um jogo de estratégia baseado em realidade aumentada chamado "AR Tankwar"; este jogo permitiu direcionar aspectos tecnológicos, de interação e de design, gerando algumas orientações (guidelines) para o desenvolvimento de jogos baseados em RA. Já Dunser utilizou o conhecimento derivado da Realidade Virtual (RV) existente na literatura e princípios gerais das Interfaces Homem-Computador (IHC) aplicáveis no projeto de sistemas de RA. Este conhecimento e princípios procuram minimizar o esforço físico e incrementar a satisfação do usuário, ao mesmo tempo que incrementa a flexibilidade e adaptabilidade do sistema de RA.

\footnotetext{
${ }^{3}$ OGRE: <http://www.ogre3d.org/>
} 
Finalmente, no trabalho de doutorado de Henrysson (2007) concluído em dezembro de 2007, é apresentado o estado da arte da RA em telefones celulares. Este trabalho inclui a descrição das limitações computacionais dos telefones celulares e da possibilidade de adicionar novos recursos de hardware para superar estas limitações. Também são apresentadas limitações e iniciativas das interfaces de entrada e saída que implementam gráficos 3D.

\subsection{Comparação com os Trabalhos Relacionados}

O avanço das capacidades de hardware dos dispositivos móveis, permitiu a evolução da RA e RA Móvel para plataformas como os PDAs, smartphones e telefones celulares. Nessa evolução, o Studierstube adaptou o ARToolKit na sua solução chamada ARToolKitPlus, para PDAs e smartphones que rodam sobre Windows Mobile. Na mesma linha, o VITA adaptou o ARToolKit para a plataforma Symbian o que denominaram de ARToolKit for Symbian. Nesse sentido, como prova de conceito da metodologia proposta, nós portamos e adaptamos uma solução para o reconhecimento dos marcadores e renderização de objetos virtuais na plataforma Java para dispositivos móveis (J2ME).

O código fonte do ARToolKitPlus e do ARToolKit for Symbian estão disponíveis para seu estudo e aproveitamento, porém, a documentação quase não existe. Nesse sentido, a presente pesquisa não só busca proporcionar uma documentação do código fonte desenvolvido no estudo de caso, se não também, apresentar uma base conceitual e um roteiro claro para a elaboração e desenvolvimento de aplicações do tipo Handheld AR.

Além disso, o projeto CMAR introduz o conceito de "interação com imagens virtuais", o que leva o marcador e a imagem virtual a ser uma interface de interação com o ambiente e não só uma forma de representação aumentada. Nesse sentido, nós propomos interfaces de interação que incluem renderização de efeitos de vibração e efeitos sonoros. Já os projetos que utilizam dispositivos sensores com interfaces de comunicação sem fio como Visualization of Sensor Data Using Mobile Phone Augmented Reality e MARA, são o tipo de aplicações que a metodologia proposta pretende direcionar.

Finalmente, os trabalhos relacionados denominados de "individuais" são a literatura base com respeito ao desenvolvimento de metodologias, orientações (guidelines) e arquiteturas para desenvolver nossa metodologia. Porém, estes trabalhos não consideram a utilização de dispositivos sensores como fontes de entrada de dados para os sistemas de RA. Nesse sentido, a presente pesquisa desenvolve o processo de conceitualização metodológica para o desenvolvimento de aplicações do tipo Handheld $A R$ que utilizam dispositivos móveis e dispositivos sensores com interfaces de comunicação sem fio. 


\section{Metodologia de Desenvolvimento}

O objetivo desta dissertação é criar uma "Metodologia de Desenvolvimento" para aplicações de realidade aumentada em dispositivos móveis, a qual visa ajudar no projeto e facilitar o processo de desenvolvimento de aplicações do tipo Handheld $A R$, em especial as que utilizam telefones celulares e dispositivos sensores com interfaces de comunicação sem fio.

Nesse sentido, neste capítulo nós apresentamos um cenário geral de aplicação, uma arquitetura e orientações (guidelines) de desenvolvimento para aplicações do tipo Handheld AR. Além disso, é apresentada uma modelagem semântica de dados como parte da solução para facilitar a aquisição, armazenamento e gerenciamento de dados e à criação de perfis de usuário. Também, são apresentadas implementações, na plataforma Java para dispositivos móveis (J2ME), dos mecanismos de aquisição de dados, componente lógico da aplicação e mecanismos de apresentação das informações para uma aplicação do tipo Handheld $A R$ que utiliza dispositivos sensores.

\subsection{Cenário Geral de Aplicação}

O cenário geral de aplicação descreve o ambiente físico, os dispositivos móveis, os dispositivos sensores e os mecanismos de visualização das informações que podem ser utilizados na implementação de uma aplicação do tipo Handheld AR. Este cenário geral de aplicação é apresentado na figura 6.1 e está dividido em três perspectivas: usuário, dispositivos móveis e ambiente.

A perspectiva do Ambiente está composta por três camadas. A primeira é chamada de "Camada de Ambientes" e define o tipo de ambiente no qual a aplicação vai ser implantada, podendo ser um ambiente Outdoor ou Indoor. Já a "Camada de Serviços" define o tipo de serviços e informações que são apresentadas aos usuários. Finalmente, a "Camada de Aquisição de Dados" descreve os dispositivos utilizados para adquirir dados e registrar informações do ambiente. Além disso, o "Sensor and Data Schemas - RDF" define os vocabulários RDF que descrevem o Sensor Schema, o Ambient Schema, o Application 
Schema e Sensor Data Schema, que são utilizados no processamento semântico dos dados coletados.

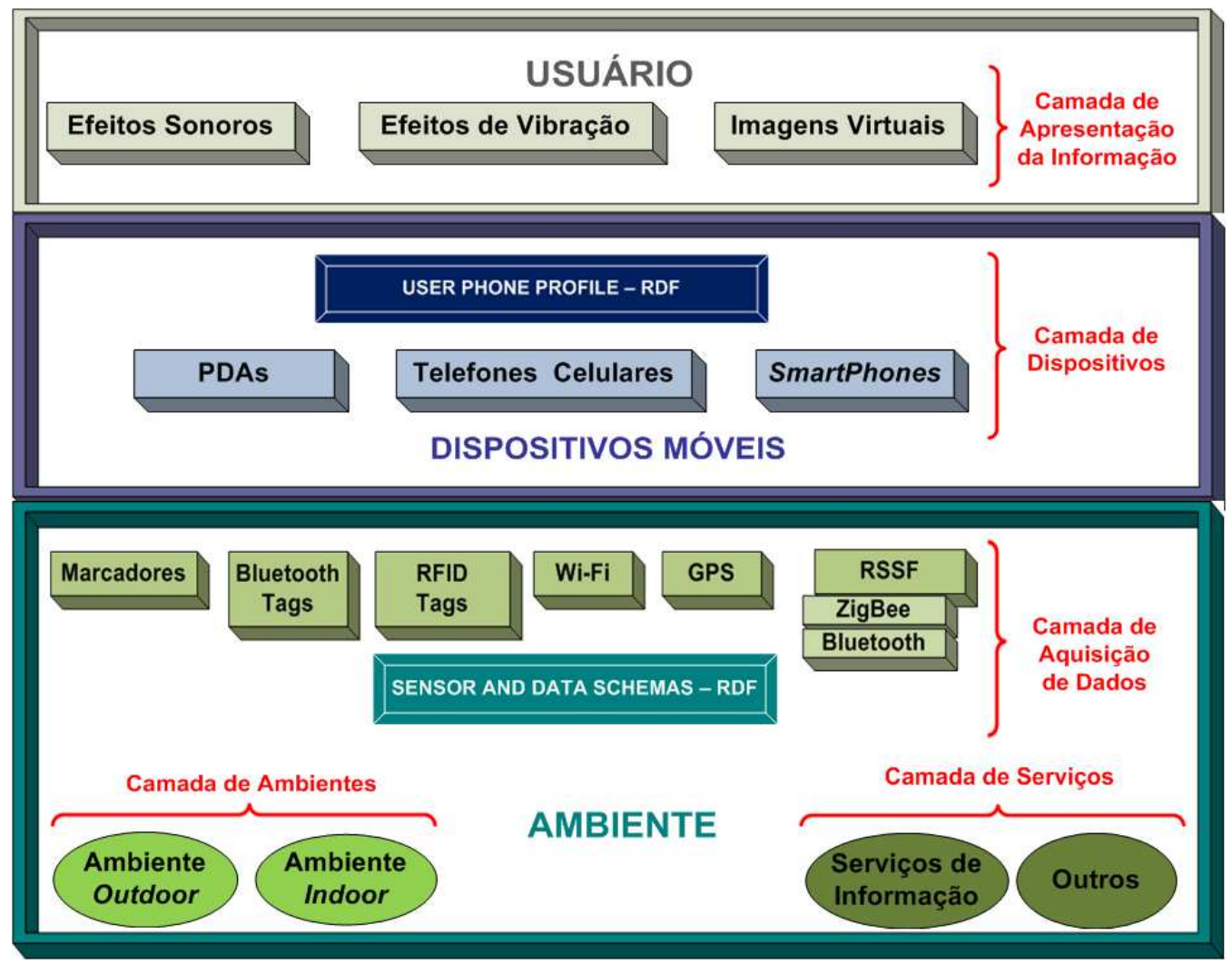

Figura 6.1: Cenário Geral de Aplicação da Nossa Metodologia de Desenvolvimento.

A segunda perspectiva baseada nos Dispositivos Móveis descreve a "Camada de Dispositivos" e o "User Phone Profile - RDF". A camada de dispositivos permite definir o tipo de dispositivo móvel a ser utilizado na aplicação em função dos requerimentos e características da aplicação e do usuário. Já o "User Phone Profile - RDF" é um arquivo RDF armazenado na memória do dispositivo móvel, que descreve as preferências do usuário. Estas informações são utilizadas para prover interfaces de interação intuitivas.

Finalmente, a perspectiva baseada no Usuário apresenta a "Camada de Apresentação da Informação" que define a forma como as informações são representadas por objetos virtuais, incluindo imagens virtuais, efeitos sonoros e efeitos de vibração. Estas formas de representação das informações dependem das preferências dos usuários e das características de hardware e software dos dispositivos móveis.

Portanto, o cenário de aplicação e as perspectivas apresentadas, descrevem de forma geral os dispositivos e cenários a serem utilizados por aplicações do tipo Handheld $A R$, especialmente em aplicações de sensoriamento, monitoração e visualização de ambientes inteligentes e ubíquos. 


\subsection{Arquitetura}

A característica principal das aplicações desenvolvidas em função da metodologia proposta é a interação direta com o mundo real, isto porque são adquiridas informações em tempo real utilizando dispositivos sensores e a câmera do dispositivo móvel.

Nesse sentido, uma aplicação do tipo Handheld $A R$ tradicional, propriamente dito, não precisa de suporte para aquisição de dados que provém de dispositivos sensores. Já aplicações como a apresentada em (RAUHALA; GUNNARSSON; HENRYSSON, 2006) precisa deste tipo de suporte. Porém, este trabalho não apresenta uma arquitetura clara para o suporte dos dados obtidos pelos dispositivos sensores, sendo a arquitetura proposta nesta dissertação uma contribuição para este tipo de aplicações.

A arquitetura proposta é apresentada na figura 6.2 e contempla: a aquisição de informações obtidas pelas câmeras embutidas nos dispositivos móveis e pelos dispositivos sensores espalhados pelo ambiente; o reconhecimento de marcadores e o processamento semântico dos dados respectivamente; o componente lógico da aplicação; e a renderização de objetos virtuais como forma de representação das informações para o usuário.

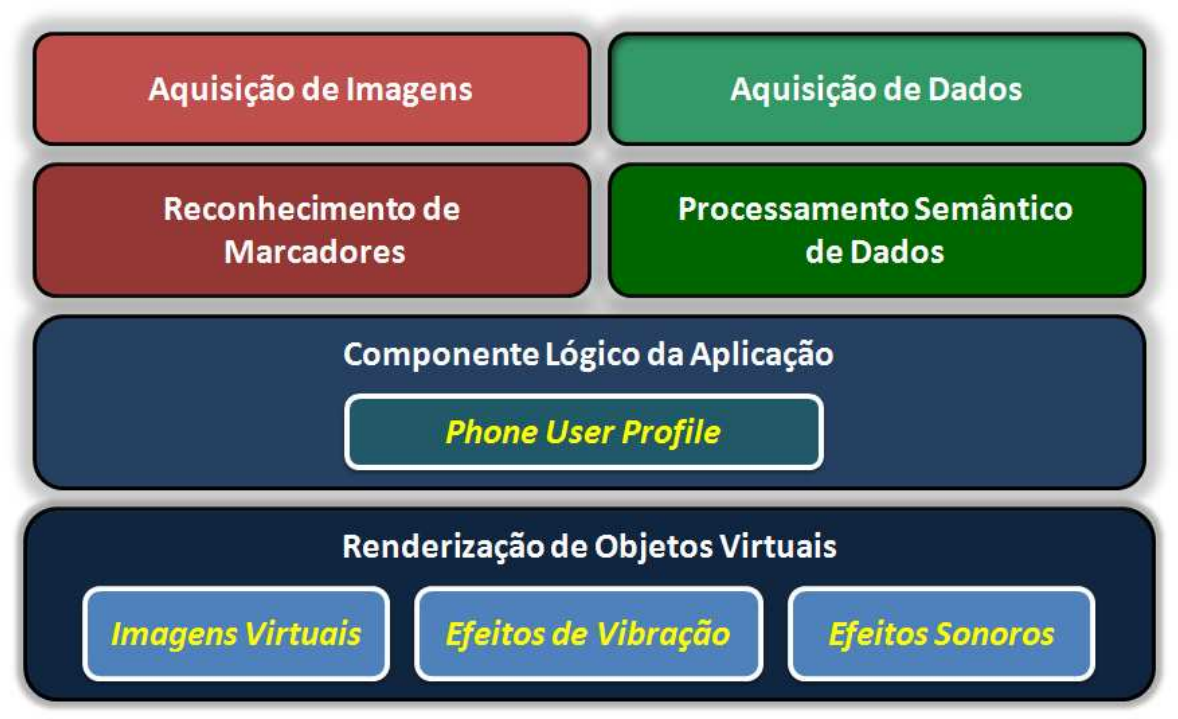

Figura 6.2: Arquitetura para Aplicações do Tipo Handheld AR que Utilizam Dispositivos Sensores com Interfaces de Comunicação Sem Fio.

Nesse sentido, a aquisição de informações pela câmera dos dispositivos móveis referese ao processo de captura de imagens em um stream de vídeo, o qual pode incluir alguma imagem relevante para a aplicação, como por exemplo um marcador. O sistema de reconhecimento de marcadores analisa o stream de vídeo capturado. No caso de encontrar uma imagem relevante (marcador), a imagem é reconhecida e decodificada. 
Já o processo de aquisição de informações pelos dispositivos sensores, deve estabelecer um caminho de conexão com os dispositivos sensores para receber os dados. Este caminho deve utilizar algum protocolo de comunicação sem fio, como por exemplo: Bluetooth. Com os dados no dispositivo móvel, o componente de processamento semântico está encarregado de atribuir um significado (sentido) a estes dados, isto para facilitar processo de consultas ou inferências (ver seção 6.4 e subseção 6.5.2 do presente capítulo).

Note-se que as informações podem ser adquiridas pela câmera e pelos dispositivos sensores ao mesmo tempo (simultaneamente) ou só por um destes mecanismos.

O "componente lógico da aplicação" está encarregado de receber os dados adquiridos (pela câmera e dispositivos sensores) e processados (pelo sistema de reconhecimento de marcadores e processamento semântico), para analisar as preferências do usuário e determinar a representação das informações como objetos virtuais em função do tipo de aplicação implementada. Além disso, este componente pode implementar alguma lógica de inferência, isto é, regras necessárias para determinar um tipo de alerta, por exemplo, determinar se a temperatura de um ambiente é a adequada ou não para o funcionamento dos equipamentos instalados nesse ambiente.

Portanto, baseados no cenário de aplicação e na arquitetura apresentada, definem-se as seguintes orientações para ajudar ao desenvolvedor no planejamento e elaboração de uma aplicação do tipo Handheld AR.

\subsection{Orientações (Guidelines) de desenvolvimento para aplicações do tipo Handheld $\boldsymbol{A R}$}

Esta subseção apresenta um roteiro que descreve os principais tópicos que devem ser considerados na implementação de uma aplicação do tipo Handheld AR.

\subsubsection{Definição da Aplicação}

Precisa-se entender e definir o tipo de aplicação e o cenário no qual será implantada a aplicação do tipo Handheld $A R$.

- Tipo de aplicação de RA a ser implementada: As aplicações do tipo Handheld $A R$ mais comuns são: jogos (games), sistemas de informação para turismo, localização e colaboração. Já esta pesquisa apresenta um suporte especial para aplicações do tipo Handheld $A R$ de sensoriamento, monitoramento e sistemas de informação baseados na aquisição de dados gerados por dispositivos sensores. A definição do 
tipo de aplicação inclui a definição da lógica da aplicação (jogos, sensoriamento, etc.), a qual influenciará o projeto geral do sistema. No caso de sistemas de sensoriamento, também é preciso definir os tipos de fenômenos (por exemplo: temperatura, umidade, etc.) a serem monitorados.

- O risco que a aplicação vai atingir: O maior risco que pode atingir uma aplicação deste tipo é colocar vidas humanas em perigo, como por exemplo: casos de monitoramento de pessoas doentes. Para aplicações com este grau de risco, a precisão das informações coletadas pelos sensores, a tolerância a falhas na conexão com os dispositivos sensores, a perda de pacotes de dados, a capacidade de processamento dos dispositivos móveis e a clareza e rapidez com que estas informações são apresentadas, têm um valor fundamental no projeto do sistema. O tipo de aplicação junto ao risco que vai atingir determina o tipo de informações que se pretende proporcionar aos usuários.

- Ambiente no qual a aplicação vai interagir: No cenário geral (apresentado na figura 6.1), a "Camada de Ambientes" apresenta 2 tipos de ambientes: (Outdoor e Indoor). Entenda-se por ambiente Indoor a um ambiente fechado, no qual temos um maior ou até absoluto controle das pessoas, das situações e demais eventos em geral, como por exemplo: em um escritório ou em um dormitório. Já um ambiente Outdoor é entendido como um ambiente público e geralmente ao ar livre, no qual temos pouco controle, como por exemplo: um restaurante ou uma estação de metrô. A definição do ambiente é importante para a definição do tipo e quantidade de dispositivos sensores a serem utilizados.

No final deste ponto, definem-se o ambiente no qual vai se interagir ("Camada de Ambientes") e o tipo de informações a serem apresentadas pela aplicação ("Camada de Serviços"), como é resumido na figura 6.3 .

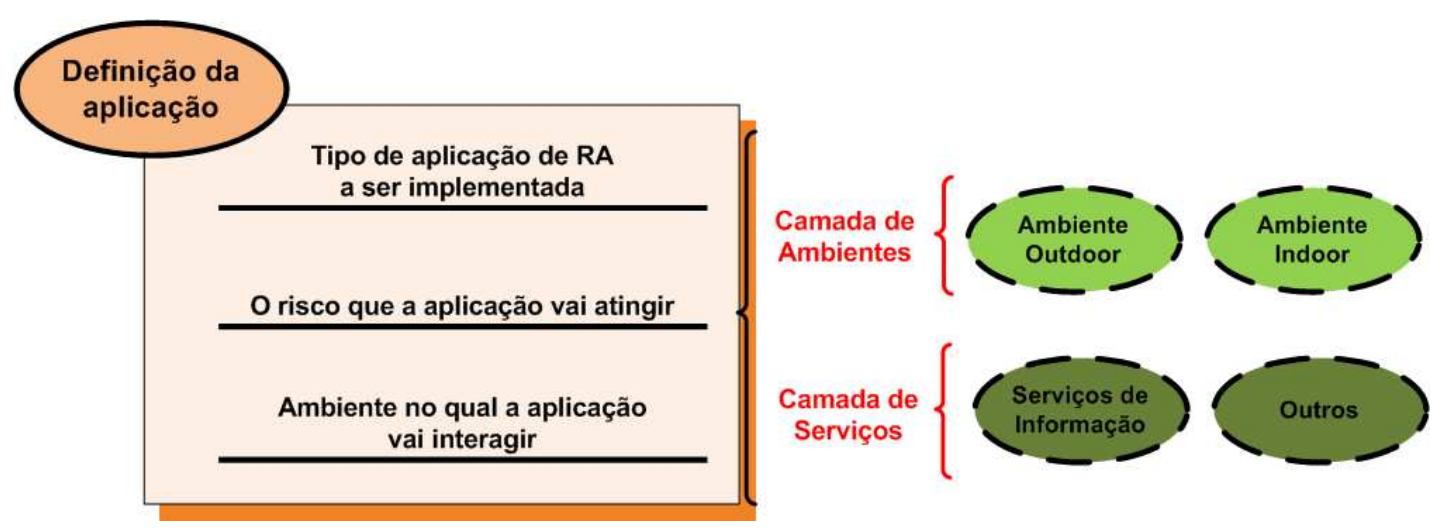

Figura 6.3: Guidelines - Definição da Aplicação. 


\subsubsection{Definição dos Dispositivos Sensores para a Aquisição de Dados}

Os dispositivos sensores são escolhidos em função do tipo de aplicação a ser implementada e dos fenômenos que são monitorados pela aplicação.

- Escolha dos elementos e dispositivos sensores: O termo "elemento" é utilizado pelo fato que os marcadores não são um tipo de dispositivo sensor, mas sim simples elementos de papel que permitem a interação com um determinado ambiente, proporcionando à aplicação uma informação fixa e previamente definida. Já os Bluetooth Tags e RFID Tags são dispositivos sensores que através das suas interfaces de comunicação sem fio transmitem as informações previamente armazenadas neles, geralmente códigos ou dados pequenos. Alguns tipos de Bluetooth Tags e RFID Tags permitem também gravar novas informações processadas pelo sistema ou dados gerados pelo usuário. Dispositivos com acesso a sistemas de GPS e acesso a rede local $(W i-F i)$ permitem obter informações atualizadas e dinâmicas sobre o ambiente, gerando um maior grau de interação e informação entre o ambiente e o usuário. Finalmente, as RSSF são compostas por dispositivos eletrônicos chamados de "nó sensores" capazes de abstrair os fenômenos físicos do ambiente em sinais elétricas, permitindo o sensoriamento dos ambientes para diversos fenômenos (temperatura, umidade, etc.). A escolha e uso dos marcadores está associado ao fato de poder utilizar a câmera do dispositivo móvel para reconhecer dito marcador. Já a escolha de qualquer um dos outros dispositivos sensores está associada às necessidades da aplicação a ser implementada.

- Localização dos elementos e dispositivos sensores: Os marcadores, por serem elementos geralmente feitos de papel, devem estar alocados em lugares: secos, bem iluminados e totalmente visíveis para que o usuário possa, com a câmera do dispositivo móvel, fazer o reconhecimento sem maiores dificuldades. Já no caso dos dispositivos sensores, as suas interfaces de comunicação sem fios permitem que sejam alocados em função da distância máxima de alcance e dos lugares específicos que se deseja monitorar. No caso das RSSF como a plataforma TmoteSky (MOTEIV, 2007), as características da própria rede (topologia, interface de comunicação, etc.) recomenda o uso de uma topologia estrela (WAH; LI, 2007), especialmente para ambientes pequenos e justifica-se pelo fato que esta plataforma tem uma estação base, a qual coleta os dados dos nós sensores de forma centralizada e os transmite para seu processamento no dispositivo móvel. Além disso, a alocação destes dispositivos sensores não deve atrapalhar as atividades dos usuários. 
No final deste ponto, definem-se os elementos e dispositivos sensores que são utilizados para a aquisição de dados ("Camada de Aquisição de Dados"), como é resumido na figura 6.4 .

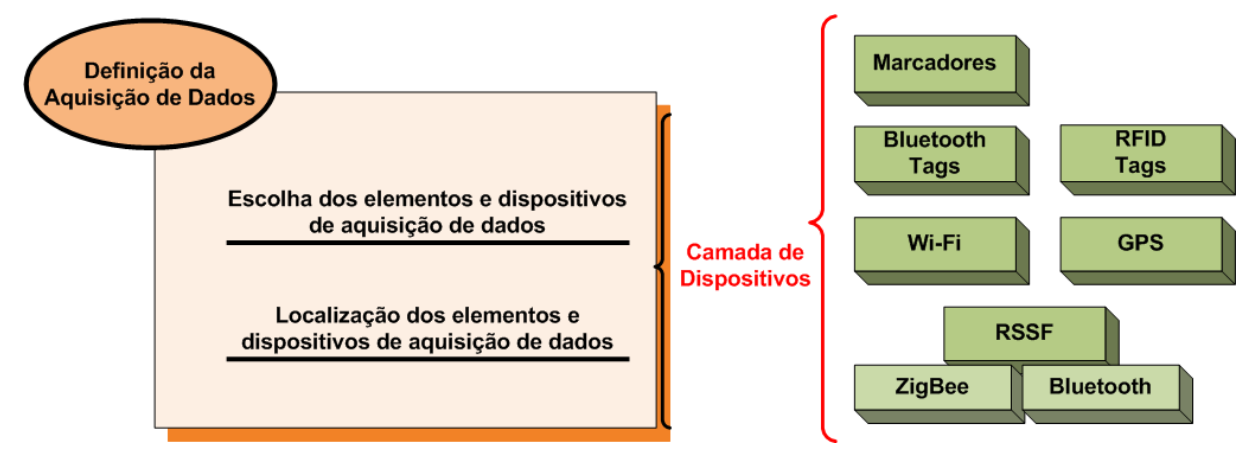

Figura 6.4: Guidelines - Definição da Aquisição de Dados.

\subsubsection{Definição da Modelagem Semântica}

Para facilitar o processo de aquisição e processamento dos dados, e prover suporte para a implementação de consultas ou inferências, utiliza-se $R D F$ Schemas ou vocabulários para modelar semanticamente os seguintes elementos:

- Dispositivos sensores: Os RDF Schemas permitem descrever através de metadados as características de hardware e software relevantes dos dispositivos sensores utilizados pela aplicação de sensoriamento do tipo Handheld AR. A heterogeneidade dos dispositivos sensores gera a necessidade de criar RDF Schemas específicos para cada tipo de dispositivo sensor.

- Ambiente: Os RDF Schemas permitem descrever através de metadados as informações relevantes sobre o ambiente, o que permite gerar um maior grau de informação para o usuário. Estes metadados são utilizados para descrever a localização dos dispositivos sensores em um determinado ambiente.

- Aplicação de sensoriamento: Os RDF Schemas permitem descrever através de metadados as informações relevantes das aplicações de sensoriamento e fenômenos monitorados. Estes metadados são utilizados para decodificar e calcular os dados coletados pelos dispositivos sensores.

- Dados obtidos: Os RDF Schemas permitem armazenar semanticamente através de metadados as informações processadas pelas aplicações de sensoriamento. Estas informações são armazenadas em arquivos RDF e utilizadas para a representação de objetos virtuais. 
- Perfil de usuário: Os RDF Schemas permitem armazenar semanticamente através de metadados as informações das preferências do usuário. Estas informações são armazenadas na memória do dispositivo móvel e são utilizadas para determinar como os objetos virtuais serão apresentados.

No final deste ponto, definem-se os os vocabulários RDF que compõem o "Sensor and Data Schemas - RDF" na "Camada de Aquisição de Dados" e o "User Phone Profile - RDF" na "Camada de Dispositivos", como é resumido na figura 6.5. A descrição detalhada destes RDF Schemas é apresentada na seção 6.4.

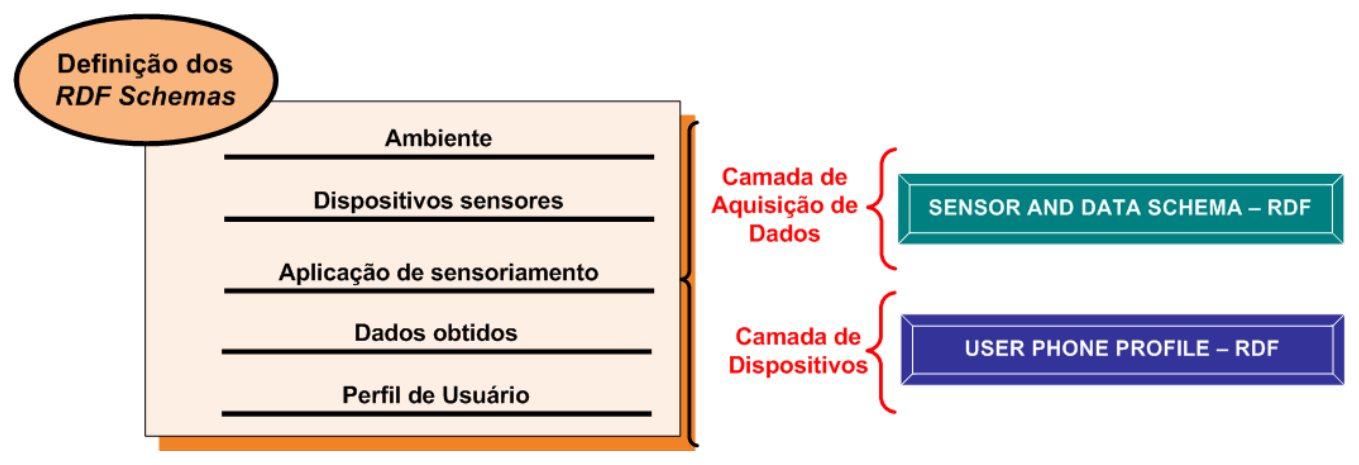

Figura 6.5: Guidelines - Definição dos vocabulários RDF.

\subsubsection{Definição do Dispositivo Móvel}

A escolha do dispositivo móvel depende de:

- Tipo e quantidade de usuários a atingir: Geralmente os dispositivos móveis são projetados para uso pessoal. Porém, para alguns tipos de aplicações, um mesmo dispositivo pode ser utilizado por diversos usuários, ou vários usuários podem estar observando e manipulando um único dispositivo móvel ao mesmo tempo. Estes fatores são elementos a considerar no projeto da aplicação, em especial a forma como as informações são apresentadas. Outro fator é a quantidade de usuários que suportará a aplicação do tipo Handheld $A R$ a ser implementada.

- Forma de processar as informações: Definidos o ambiente e a quantidade de usuários a utilizar a aplicação, define-se como será feito o processamento dos dados e a renderização dos objetos virtuais. Na seção "3.3.4 Estratégias de Processamento", foram descritas as estratégias de processamento estudadas e propostas pela presente pesquisa. Estas estratégias foram baseadas nas capacidades de processamento dos dispositivos móveis e na distribuição do processamento para outros dispositivos inseridos no ambiente (sistemas embarcados) ou fora dele (servidores dedicados). 
Também se deve considerar as características de hardware dos dispositivos móveis (descritas nas tabelas 2.2 e 2.3) na hora de escolher o dispositivo móvel a utilizar.

No final deste ponto, define-se o dispositivo móvel a utilizar ("Camada de Dispositivos"), como é resumido na figura 6.6. Note-se que para aplicações que coletam dados de dispositivos sensores, um requisito obrigatório para a escolha do dispositivo móvel é possuir uma interface de comunicação sem fio (Bluetooth, ZigBee ou Wifi) e uma câmera integrada.

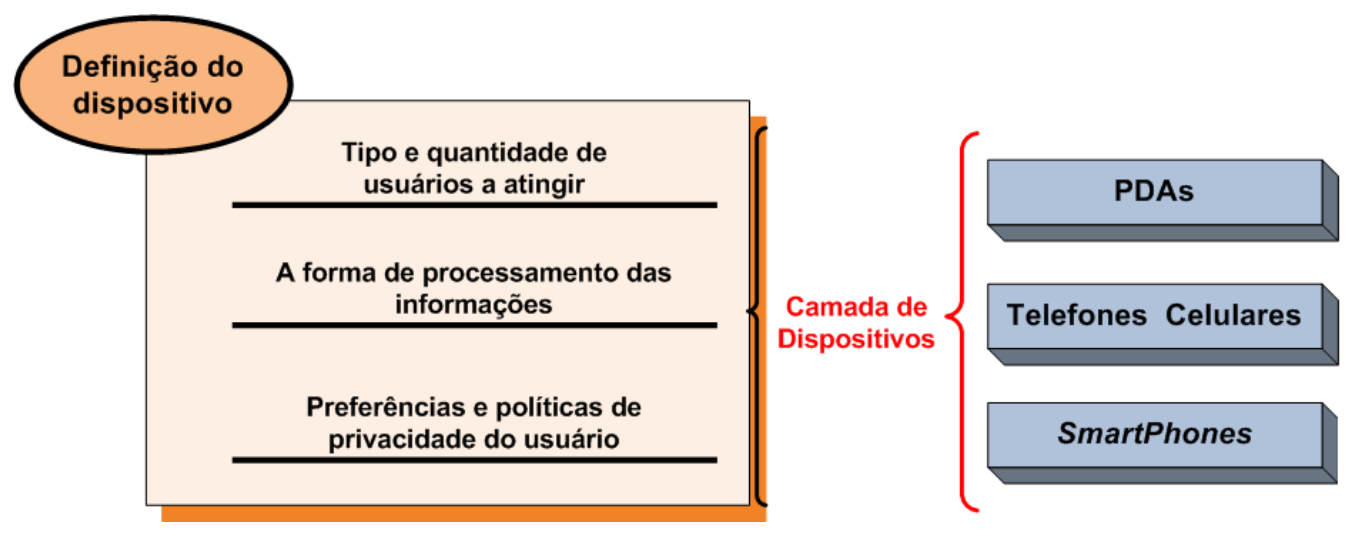

Figura 6.6: Guidelines - Definição do dispositivo.

\subsubsection{Disponibilização das Informações}

A disponibilização das informações como objetos virtuais dependem de:

- Características do dispositivo móvel: Com o dispositivo móvel definido, as características de hardware e software como: tamanho da tela (display), quantidade de cores, recursos de aceleração gráfica, suporte para imagens 3D, capacidade para reprodução de arquivos de áudio (mp3, midi, etc.), capacidade de vibração e outro tipo de interfaces que possam ser utilizadas como formas de apresentar as informações são avaliadas na procura pela melhor interface de interação que atenda os requisitos desejados. As plataformas de software que atualmente têm suporte para desenvolvimento de aplicações do tipo Handheld $A R$ em telefones celulares são os sistemas operacionais Symbiam, para os aparelhos da serie 60 (S60) ou superior e a plataforma Windows Mobile 5.0 ou superior para Smartphones, PDAs e PocketPCs. Além destas duas plataformas, a plataforma Java também provê suporte para aplicações deste tipo para dispositivos móveis de outros fabricantes, porém, na têm-se implementações avaliáveis nesta plataforma. 
- Preferências e requerimentos do usuário: Usuários com necessidades especiais (por exemplo: pessoas cegas) podem exigir algum requisito especial na apresentação das informações geradas pela aplicação. Por exemplo: para pessoas surdas a apresentação das informações só seria útil como imagens virtuais e efeitos de vibração, porém, precisaria-se um estudo mais profundo de como as pessoas surdas interpretariam os efeitos de vibração. Já para usuários sem necessidades especiais, os fatores que determinam a forma de apresentar as informações dependem das preferências do usuário, que são modeladas em um perfil.

No final deste ponto, define-se a forma como as informações são apresentadas ao usuário ("Camada de Apresentação da Informação"), como é resumido na figura 6.7.

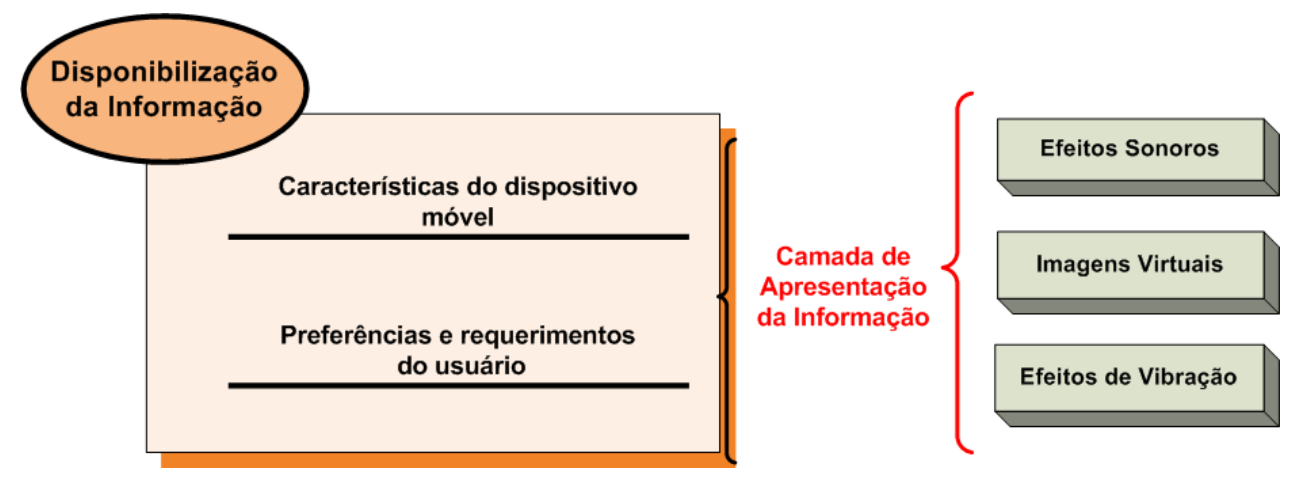

Figura 6.7: Guidelines - Disponibilização da Informação.

Portanto, com todos os elementos claramente definidos a implementação da aplicação do tipo Handheld $A R$ fica muito mais clara simplificando o processo de desenvolvimento. Note-se também que estas orientações não dependem de nenhuma plataforma de software em especifico para sua implementação.

\subsection{Modelagem Semântica de Dados}

O processamento semântico de dados é o processo de etiquetamento (tagging) dos dados brutos (raw data) obtidos pelos dispositivos sensores (ver seção 4.2 do capítulo 4). Este processamento é feito para resolver o problema da heterogeneidade de dados e a complexidade no desenvolvimento nos mecanismos de aquisição, armazenamento e gerenciamento de dados (LEWIS et al., 2006). Porém, para este processamento semântico precisa-se (previamente) de uma modelagem semântica que proporcione as tags ou informações contextuais a serem adicionadas aos dados brutos. Além disso, esta modelagem também é utilizada para descrever as preferências dos usuários. 
Nesse sentido, nesta seção são apresentados os RDF Schemas desenvolvidos para modelar conceitual e semanticamente os dados, os dispositivos sensores, o ambiente, as aplicações de sensoriamento e o usuário. Esta modelagem é feita para garantir a integridade, usabilidade e interoperabilidade das informações geradas pelos dispositivos sensores.

\subsubsection{Sensor Schema}

O Sensor Schema é o vocabulário que descreve as características de hardware, software e de comunicação dos dispositivos sensores em propriedades, relações e valores. Para projetar o nosso Sensor Schema, nós fizemos um estudo e análise do SensorML (BOTTS, 2003) e do Sensor Description proposto em (JURDAK; LOPES; BALDI, 2004). O SensorML é um modelo padrão baseado na sintaxe XML que descreve dispositivos sensores e os processos que convertem fenômenos reais em dados (medições feitas por estes sensores). Porém, o SensorML não provê suporte para uma modelagem semântica, o que é uma das contribuições da presente dissertação.

Portanto, o Sensor Schema provê um modelo semântico para descrever e caracterizar as capacidades do dispositivo sensor. A caracterização destas informações podem ser relevantes para múltiplos casos, por exemplo: para processo de manutenção e reparação preventiva dos dispositivos sensores ou dos ambientes que os sensores monitoram. O nosso Sensor Schema está composto pelas classes:

- HardwarePlatform: Caracteriza as capacidades de hardware do dispositivo sensor, definindo propriedades que agrupam-se por características como: identificação (SensorID, Model, Vendor); processamento (ModelMicroprocessor, TypeMicroprocessor, VendorMicroprocessor); memória (RAM, ExternalFlash); fonte de poder (Voltage, BatterySupplyType); conexão com o computador (PcCommunication, ExpansionConnector, ExpansionConnectorUse); programação (Programming, SoundOutputCapable, TextInputCapable).

- SoftwarePlatform: Caracteriza as capacidades de software do dispositivo sensor, definindo propriedades que agrupam-se por características como: aplicações instaladas no dispositivo sensor (ApplicationInstalled); sistema operacional (OSName, OSVendor, OSVersion); plataforma de programação (JavaEnabled, JavaPlatform, JVMVersion, AcceptDownloadableSoftware, ProgrammingLanguage); armazenamento (ProgramSpace, InformationStorage); segurança (FccCertification).

- NetworkCharacteristics: Caracteriza as capacidades de comunicação do dispositivo sensor, definindo propriedades que agrupam-se por características como: 
hardware de comunicação (ModelRadioChip, VendorRadioChip, AntennaType, SerialCommunications); freqüências de comunicação (RadioFrequency, RadioStandard); protocolos de comunicação (SupportedBearers, SupportedBearersVersion); alcance (AntennaRangeIndoor, AntennaRangeOutdoor).

- SensorChipCharacteristics: Caracteriza as capacidades dos chips sensores, isto é, o hardware encarregado de abstrair os fenômenos monitorados, definindo propriedades que agrupam-se por características como: hardware do chip (ModelSensorChip, VendorSensorChip, SensorDirectlyMounted); taxa, entrada e saída de dados (DataRate, DataInputSignal, DataOutputSignal); características dos fenômenos monitorados (SensorCapables, HumidityAccuracy, TemperatureAccuracy, LightSensorChipModel, VendorLightSensorChip).

Note-se que as classes HardwarePlatform, SoftwarePlatform, NetworkCharacteristics e SensorChipCharacteristics foram projetadas para descrever de forma geral os componentes de diversos tipos de dispositivos sensores. Porém, as propriedades descritas para cada uma destas classes foram projetadas especificamente em função da plataforma TmoteSky, que são os dispositivos sensores a serem utilizados na presente pesquisa.

Portanto, todas ou algumas classes e propriedades podem ser reutilizadas para outros tipos de dispositivos sensores. Em trabalhos futuros, serão projetadas novas classes e propriedades que descrevam de melhor forma outros tipos de dispositivos sensores descritos no cenário geral.

\subsubsection{Ambient Schema}

O Ambient Schema é o vocabulário que descreve informações de localização em propriedades, relações e valores. O Ambient Schema provê um modelo que descreve ambientes, lugares e equipamentos onde podem ser alocados os dispositivos sensores, gerando assim um mapa do ambiente que permite descrever informações operacionais destes ambientes. Por exemplo: se nós alocamos um dispositivo sensor perto do motor de um veículo para monitorar a temperatura, além dos dados que o sensor coleta, nós podemos modelar informações relevantes para esta peça, como as temperaturas adequadas nas quais deve trabalhar o motor. Então, com os dados coletados e metadados acrescentados para esta peça, a aplicação poderia determinar se o veículo está funcionando adequadamente ou advertir ao usuário que precisa fazer algum tipo de manutenção para essa peça em específico. 
Já o uso de RDF Schemas para modelar informações em ambientes veiculares é apresentado em (SERVANT, 2007a) e (SERVANT, 2007b). Estes trabalhos baseados no padrão RDF podem ser utilizados para mapear e descrever um veículo, utilizando estas informações para processos de documentação, treinamento e manutenção do veículo. Nesse sentido, o nosso Ambient Schema está composto pelas classes:

- AmbientCharacteristics: Descreve de forma geral as características do ambiente. As propriedades definidas para esta classe agrupam-se para: descrever o tipo de ambiente no qual nos encontramos (AmbientType, AmbientName, AmbientDescription); descrever o número e tipos de dispositivos sensores instalados no ambiente (NumberSensorsInstalled, TypeSensorsInstalle, ApplicationsInstalled).

- SensorLocalizations: Descreve a localização dos dispositivos sensores instalados no ambiente. As propriedades definidas para esta classe agrupam-se para: identificar o dispositivo sensor (SensorID) e sua data de instalação (SensorInstallationDate) ; descrever o lugar onde o sensor está instalado (PlaceDescription) e descrever se este lugar tem alguns valores ou limites de operação (OperativeDescription), isto é, por exemplo: valores mínimos ou máximos de operação de um forno industrial, estes valores são utilizados para determinar seu correto funcionamento ou não; descrever seu posicionamento exato utilizando coordenadas do sistema GPS (Latitude, Longitude, Altitude). Estas informações são modeladas para cada dispositivo sensor instalado no ambiente.

\subsubsection{Application Schema}

O Application Schema é o vocabulário que descreve as características e informações da aplicação de sensoriamento (instalada nos dispositivos sensores) em propriedades, relações e valores. Para cada aplicação desenvolvida e instalada nos dispositivos sensores, precisase de modelar as características da aplicação, determinando os parâmetros dos fenômenos a serem monitorados e a formatação dos pacotes de dados gerados, isto para facilitar o processo automático de aquisição e processamento dos dados.

O Application Schema está inspirado pelos sistemas de sensores e modelos de processos desenvolvidos no SensorML (BOTTS, 2003). A caracterização destas informações podem ser relevantes para múltiplos casos, como por exemplo: para processo de documentação e reformulação das aplicações utilizadas. O nosso Application Schema está composto pelas classes: 
- ApplicationsCharacteristics: Descreve de forma geral as características da aplicação. As propriedades definidas para esta classe agrupam-se para: identificar e descrever a aplicação (ApplicationID, ApplicationDescription, ApplicationInstallDate); determinar os fenômenos monitorados (MonitoredPhenomenon).

- ProcessModel: Descreve as fórmulas, definidas pelos fabricantes dos dispositivos sensores, encarregadas de calcular os valores obtidos pelos dispositivos sensores. Por exemplo: se a aplicação instalada no dispositivo sensor adquire dados de temperatura do ambiente, o Process Model permite calcular os valores da temperatura em função da fórmula determinada pelo fabricante do chip sensor de temperatura. Nesse sentido, as propriedades definidas para esta classe são: o ProcessModel, que descreve a fórmula; RawDatapacket e FormatRawDataPacket que descrevem a seqüência de bits coletados e a correspondência destes bits com um determinado formato respectivamente, isto é, por exemplo: se o RawDatapacket está representado pela seqüencia de bits "EF01AA12000EEA" (valores hexadecimais), o FormatRawDataPacket determina a ordem e formato dos bits transmitidos, isto é, FormatRawDataPacket determina que os quatro primeiros bits do RawDatapacket (EF01) representam o valor da temperatura do ambiente e assim por diante.

- DeveloperCharacteristics: Descreve o desenvolvedor da aplicação. As propriedades definidas para esta classe são: AuthorName, OrganizationName, PositionName e ElectronicMailAddress.

\subsubsection{Sensor Data Schema}

O Sensor Data Schema é o vocabulário que descreve as características e informações que permitem automatizar e simplificar o processo da armazenagem dos dados coletados. O Sensor Data Schema permite formatar e armazenar os dados obtidos em arquivos RDF. O Sensor Data Schema está composto pelas classes:

- DataCharacteristics: Informa as datas de início e de fim do processo de coleta de dados (CollectedStartDate, CollectedEndDate).

- SensorData: Formata e armazena os dados obtidos pelos dispositivos sensores de forma clara para o entendimento do usuário. Cada propriedade definida para esta classe identifica um tipo de dado em específico e que são: SensorID e ApplicationID, que identificam o dispositivo sensor e a aplicação de sensoriamento que geraram os dados; DataPacket, que é a seqüência total de dados transmitidos pelo dispositivo sensor; DestData, ValueData e Sequence, que são os valores predefinidos pelo desenvolvedor e que são as informações a serem aproveitadas pela aplicação. 
Destaca-se que os RDF Schemas projetados na presente dissertação foram aproveitados pelas aplicações de sensoriamento e modelagem semântica de dados em ambientes submarinos (ROCA; ZUñIGA; KOFUJI, 2007) e veiculares (ZUñIGA; ROCA; KOFUJI, 2007) desenvolvidas pelo PAD.

\subsubsection{User Phone Profile Schema}

O User Phone Profile é um arquivo RDF que é armazenado na memória do dispositivo móvel e que descreve as preferências do usuário e ajuda na implementação de interfaces de interação intuitivas. O nosso User Phone Profile foi baseado no HumanML (BROOKS; CAGLe, 2002) e UserML (HECKMAnN, 2005). Nesse sentido, o User Phone Profile é composto pelas classes:

- UserDemographics: Descreve o informações pessoais do usuário como: UserName, UserFullName, UserAge, UserSex e UserAddress.

- UserPreferences: Descreve informações sobre as políticas de privacidade como: Password, UserLevel. Além disso, também são descritas propriedades para indicar as preferências ou limitações nas interfaces de interação como: InterfacePreference, TimePreference.

- UserInterests: Descreve o tipo de dados relevantes para o usuário, isto é, dados presentes no ambiente que o usuário tem interesse de conhecer como: TypeInformation e TypeApplication.

- UserProperties: Descreve informações sobre o comportamento do usuário, isto é, fatores físicos como: UserDisabilities. Além disso, também são descritas propriedades para indicar o comportamento nas atividades diárias como: ActivityStates.

Portanto, o Sensor Schema, o Ambient Schema e o Application Schema permitem modelar semanticamente a perspectiva do ambiente do cenário geral de aplicação apresentado, simplificando os processos de aquisição e processamento dos dados gerados pelos dispositivos sensores no ambiente. Já o Sensor Data Schema e o User Phone Profile Schema permitem armazenar em arquivos RDF os dados obtidos pelos dispositivos sensores e as preferências dos usuários respectivamente. Estes Schemas e suas classes são resumidas no esquema apresentado na figura 6.8 . 


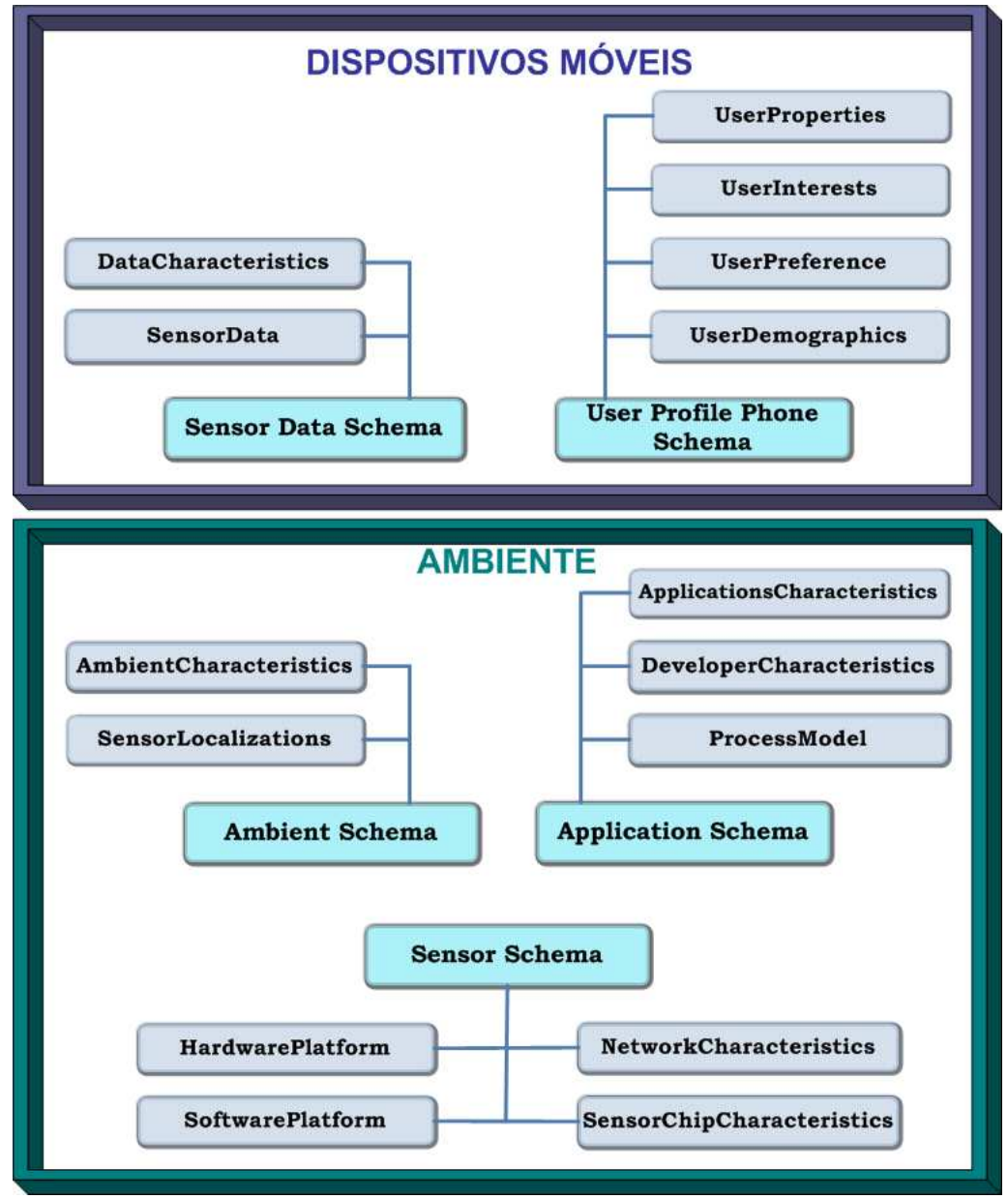

Figura 6.8: Sinergia dos Schemas Projetados nesta Dissertação.

Note-se que todos os Schemas projetados nesta dissertação, foram implementados utilizando a ferramenta Altova Semantic Works (ALTOVA, 2008) em uma sintaxe XML.

\subsection{Mecanismos de Aquisição de Dados}

Nesta seção são apresentados conceitos referentes à aquisição de dados gerados pelas câmeras dos dispositivos móveis e dos dados obtidos pelos dispositivos sensores. Nesse sentido, estes processos de aquisição são implementados utilizando a plataforma Java para dispositivos móveis (J2ME), isto para melhorar a compreensão e descrição dos conceitos e tecnologias no desenvolvimento de aplicações do tipo Handheld AR.

\subsubsection{Aquisição de Dados pela Câmera}

O fluxo de processamento na aquisição de dados pela câmera está baseado na captura do vídeo e o reconhecimento do marcador, o que é descrito a seguir. 


\subsubsection{Aquisição de Imagens}

É o processo de aquisição de streams de vídeo feito pela câmera embutida no dispositivo móvel em tempo real. A diversidade de modelos e características das câmeras e dos dispositivos móveis, aumentam a dificuldade no desenvolvimento deste tipo de processos. Nesse sentido, na subseção 3.3.1 foram apresentados mecanismos para acessar a câmera dos dispositivos móveis em função da plataforma e das interfaces nativas do dispositivo móvel.

Nesse sentido, nós desenvolvemos, em Java, a classe CameraPAD para a aquisição de imagens pela câmera do dispositivos móvel. A Mobile Media API (MMAPI) é uma biblioteca utilizada como base na implementação da CameraPAD. Destaca-se nesta classe a implementação da verificação das características básicas do dispositivo móvel, isto é, uma câmera embutida. Para isso, utiliza-se o comando System.getProperty(video.snapshot .encoding) para recuperar os formatos de vídeo suportados pelo dispositivo, como é apresentado na figura 6.9. Se o comando retorna null, significa que o dispositivo móvel não suporta formatos de vídeo e portanto não tem uma câmera embutida.

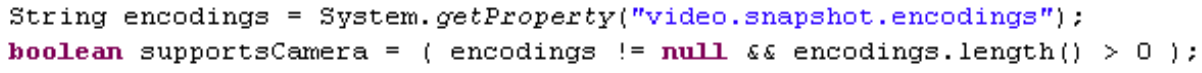

Figura 6.9: Verificação da Câmera.

Já o método void IniciaCamera() da classe CameraPAD é o encarregado do processo de aquisição de streams de vídeo, como é apresentado na figura 6.10.

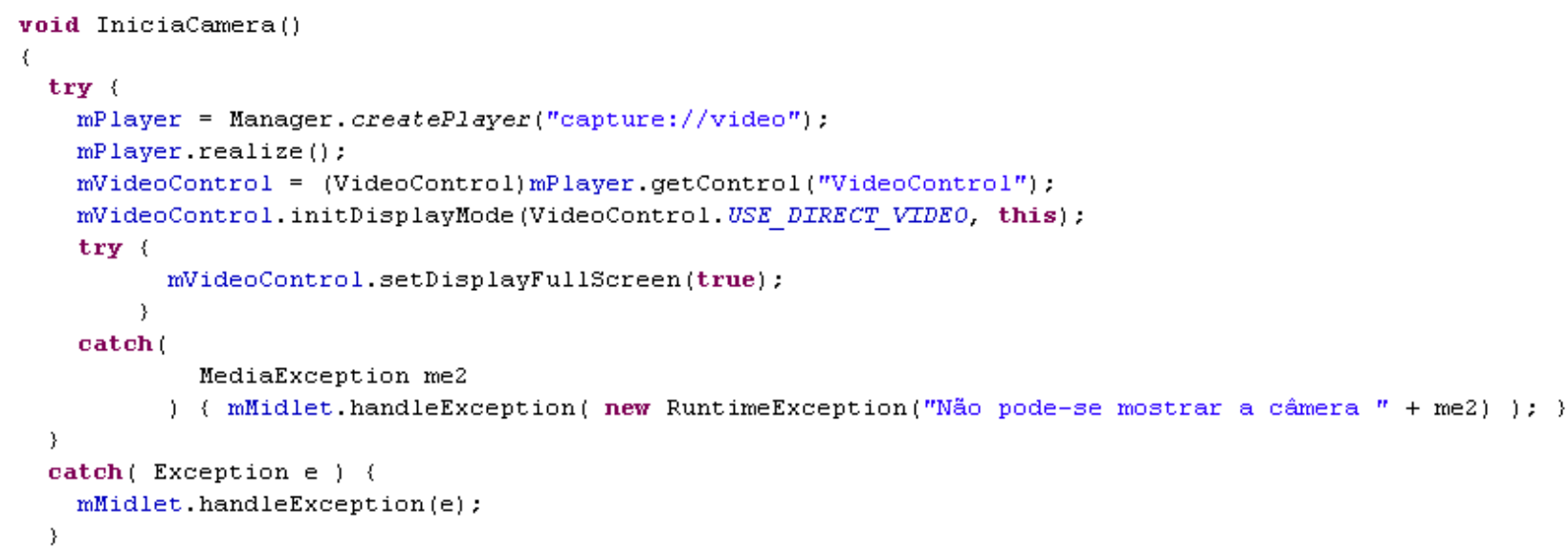

Figura 6.10: Acesso e Controle da Câmera.

Neste método, o objeto mPlayer cria o acesso à câmera e o objeto mVideoControl proporciona funções de controle como play, stop, snapshot, volume, etc. 
Já o método public void capturar(), através do objeto mVideoControl e do comando VideoControl.getSnapshot(String imageType) permite à classe CameraPAD tirar fotos, capturando a imagem e a colocando-la no objeto mImage, como é apresentado na figura 6.11.

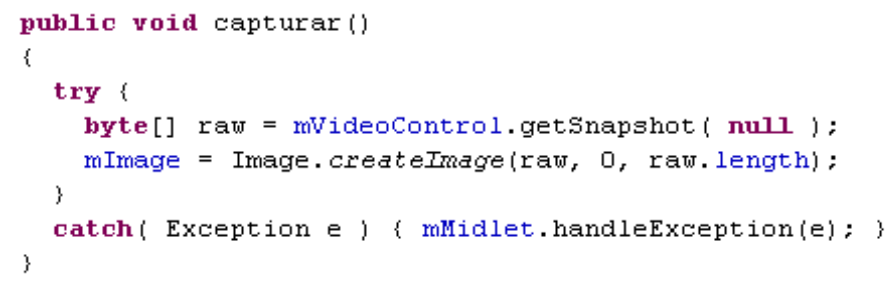

Figura 6.11: Captura da Imagem.

Para que a classe CameraPAD funcione adequadamente em um telefone celular, este precisa ter uma câmera embutida e suporte para a plataforma Java, em especial à biblioteca Mobile Media API. Porém, na pesquisa bibliográfica feita, descobriu-se que aparelhos específicos como: o Nokia 6680, Nokia 6020, Motorola RAZR V3, Motorola V600 e LG U8138, geram erro (MediaException) ao tentar criar o acesso à câmera, mesmo cumprindo com os requisitos estabelecidos.

\subsubsection{Reconhecimento de Marcadores}

Tendo a imagem do mundo real, a análise desta imagem permite descobrir se tem algum marcador relevante na cena capturada. Na subseção 3.3.2, nós analisamos e apresentamos os diversos tipos de marcadores e ferramentas disponíveis para o reconhecimento destes marcadores. Desta análise, determinou-se a utilização do SemacodeTag (SEMACODE, 2007) como ferramenta para a criação de marcadores, e a biblioteca Semacode Reader como o algoritmo de reconhecimento dos marcadores, isto porque o Semacode é um projeto open source que permite a criação de diversos marcadores através da Internet e permite a modificação do código fonte do algoritmo de reconhecimento para aplicações não comerciais. Note-se que o Semacode implementa e reconhece marcadores do tipo DataMatrix (DATAMATRIX, 2007).

Os marcadores a serem utilizados na presente pesquisa foram criados através do web site do Semacode (www.semacode.org/tag). Esta ferramenta on-line permite criar marcadores que armazenam as informações em um formato de endereço url, como é apresentado na figura 6.12.a. Além disso, a ferramenta permite a opção de adicionar um titulo para o marcador. Já a figura 6.12.b apresenta um marcador criado que contém o valor de "Sensor1". 


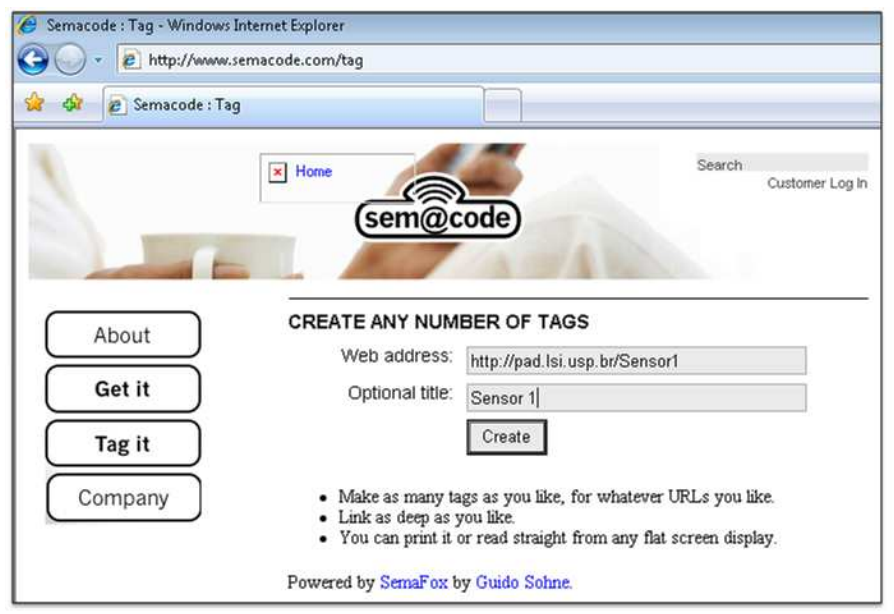

(a) Ferramenta On-line para a Criação de Marcadores

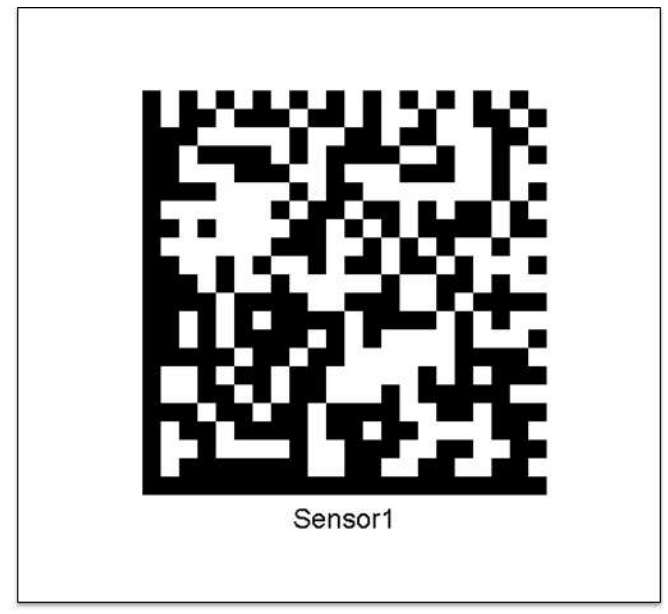

(b) Marcador Criado para o Sensor 1

Figura 6.12: Criação de Marcadores.

Nesse sentido, nós criamos a classe SemacodePAD, que utiliza a biblioteca SemacodeReaderLib.jar para o reconhecimento dos marcadores. A SemacodePAD recebe a imagem capturada na classe CameraPAD e utiliza as classes: contactless, contactless.visual, util, imagerec e dmcodec, empacotadas no SemacodeReaderLib.jar, para descobrir e reconhecer marcadores na imagem capturada. Já o método void decodificar() envia como parâmetros o objeto mImage e um objeto tipo string com o tipo de marcador a decodificar para o método VisualTagConnection() da classe contactless.visual, como é apresentado na figura 6.13. Já a classe contactless.visual decodifica a imagem do marcador, e se é o padrão é reconhecido, ela retorna o endereço url associado. Se o padrão não é reconhecido, este método gera um erro de exceção, que é exibido como uma mensagem de erro na tela do dispositivo móvel.

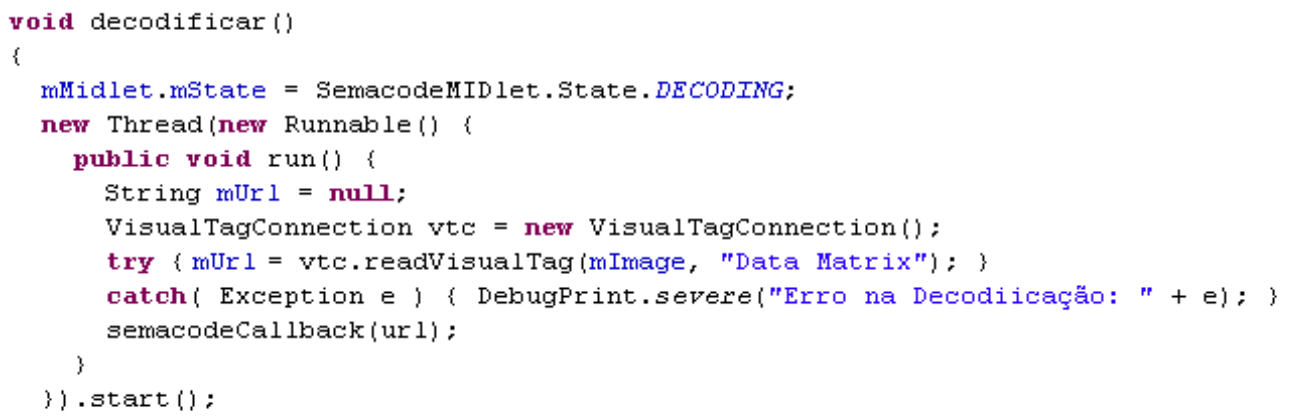

Figura 6.13: Reconhecimento de Marcadores.

Portanto, o algoritmo de reconhecimento foi implementado na SemacodeReaderLib.jar pelo Semacode. Já a classe SemacodePAD, que nós desenvolvemos, utiliza este algoritmo para o reconhecimento de marcadores na implementação de uma aplicação do tipo Hand- 
held AR. Nesse sentido, a SemacodePAD utiliza um objeto tipo string chamado mUrl, para receber o valor do endereço url projetado no marcador, quando este for reconhecido e decodificado. O valor do endereço url, na verdade, armazena uma palavra-chave que identifica o marcador e que é armazenada no objeto $m U r l$. Logo, o $m U r l$ é disponibilizado para seu análise e processamento pelo componente lógico da aplicação. Note-se que a SemacodePAD só permite o reconhecimento de um marcador por vez.

\subsubsection{Aquisição de Dados pelos Dispositivos Sensores}

O fluxo de processamento na aquisição de dados pelos dispositivos sensores está baseado na transmissão dos dados através de uma interface de comunicação sem fio e o processamento semântico destes dados, o que é descrito a seguir.

\subsubsection{Aquisição de Dados (Raw Data)}

Os dispositivos sensores com interfaces de comunicação sem fio implementam algum protocolo como Bluetooth ou ZigBee para a transmissão dos dados. Já no caso das RSSF e especialmente da plataforma TmoteSky (MOTEIV, 2007) (utilizada na presente pesquisa), é utilizado o protocolo Zigbee para a transmissão dos dados. Nesse sentido, os dados coletados pelos nós sensores da RSSF são transmitidos para uma Estação Base (EB), a qual retransmite para o dispositivo móvel. Em geral, os dispositivos sensores com interfaces de comunicação sem fio, precisam ser descobertos e precisam estabelecer uma conexão com o dispositivo móvel para transmitir os dados.

Nesse sentido, nós desenvolvemos a classe BluetoothPAD, baseada na Bluetooth Java Api ou JSR-82 (KLINGSHEIM, 2004) para a descoberta (de serviços e dispositivos) e conexão com os dispositivos sensores. O Device Inquiry é o processo de descoberta de dispositivos e serviços que estejam na área de alcance. O Device Inquiry ou modo de descoberta pode ser implementado por General/Unlimited Inquiry Access Code (GIAC), como por Limited Inquiry Access Code (LIAC).

No modo GIAC, o dispositivo poderá ser descoberto a todo instante sem considerar o limite de tempo. Já no LIAC, o dispositivo poderá ser descoberto apenas dentro de um determinado limite de tempo. Para determinar o modo de implementação (GIAC ou LIAC) é utilizada a classe LocalDevice e seus métodos getDiscoverable e setDiscoverable. Já a classe DiscoveryAgent utiliza seu método startInquiry() para começar a descoberta de dispositivos. Este método implementa a interface DiscoveryListener para acessar a cada dispositivo descoberto através do método DiscoveryDevice. 
Logo, os dispositivos descobertos são listados pelos seus nomes, como por exemplo: "Nokia 6600", "Sony Ericsson W300i", etc. Conhecendo o nome, o passo seguinte é descobrir os serviços disponíveis, neste caso, a transmissão dos dados obtidos pelos dispositivos sensores. Cada dispositivo em particular tem um UUID (Universally Unique Identifier) que irá identificar sua aplicação e serviços.

Para começar a recepção dos dados, precisa-se estabelecer uma conexão. Para isso é utilizado o protocolo RFCOMM, para a transmissão e recepção de dados em tempo real (streaming data) (KLINGSHEIM, 2004). O dispositivo móvel atua como um servidor e utiliza as interfaces StreamConnectionNotifier e StreamConnection para criar a conexão utilizando o método Connector.open(), o qual irá receber como parâmetro uma URL. O formato dessa URL é definida pela JSR-82 com o prefixo "btspp://". O resto da URL irá conter parâmetros como relação ao dispositivo móvel, ao dispositivo sensor e à autenticação. Já os objetos InputStream e OutputStream são utilizados para ler e escrever os dados gerados pelos dispositivos sensores.

A figura 6.14 apresenta o método ConectaBluetooth(), que resume os processos de descoberta de dispositivos bluetooth e de estabelecimento da conexão utilizando o protocolo RFCOMM.

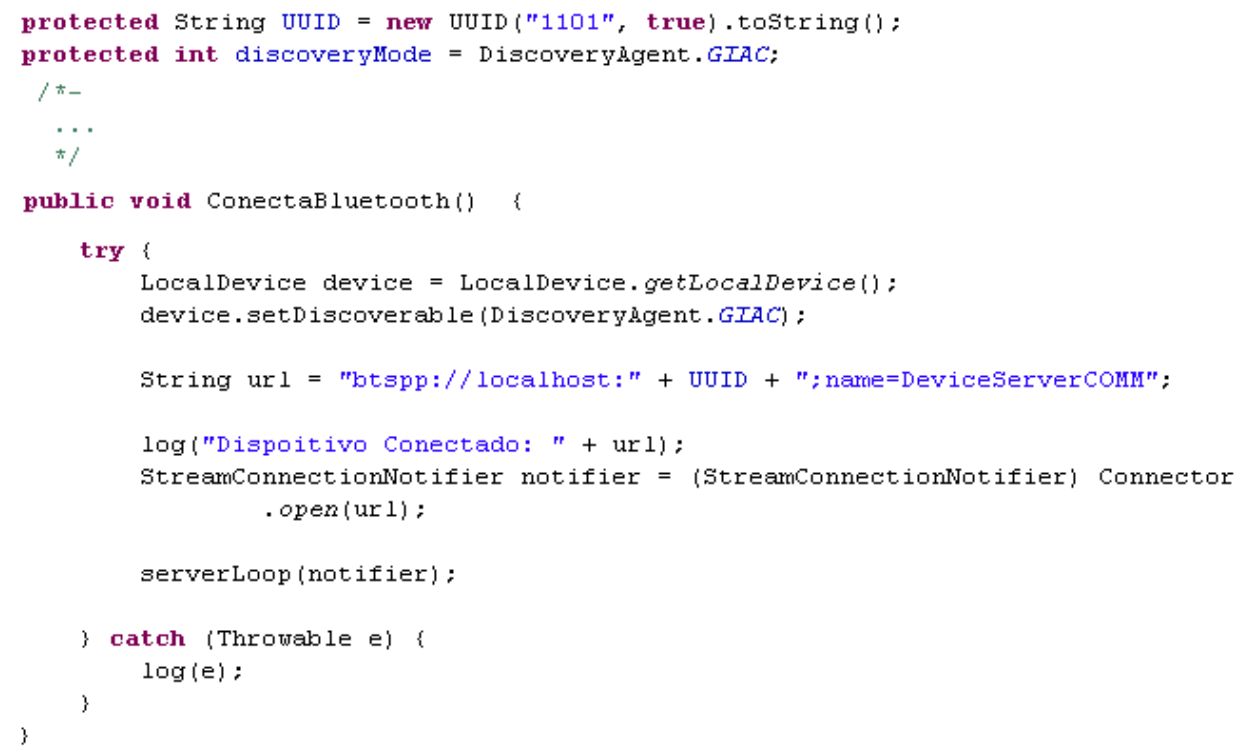

Figura 6.14: Descoberta e Conexão com Dispositivos Bluetooth.

Portanto, a BluetoothPAD foi projetada como uma classe servidor instalada no dispositivo móvel e que fica descobrindo dispositivos sensores e serviços, para logo estabelecer uma conexão que permita tornar acessíveis estes serviços, que em nosso caso é coletar os dados transmitidos pelos dispositivos sensores. 


\subsubsection{Processamento Semântico de Dados}

Com os dados gerados pelos dispositivos sensores armazenados na memória do dispositivo móvel, o passo seguinte é processar semanticamente estes dados, isto porque os dados chegam como dados brutos (raw data). Nesse sentido, a modelagem semântica é representada pelos RDF Schemas ou vocabulários descritos na seção 6.4 (neste mesmo capítulo). Estes RDF Schemas são utilizados para agregar as tags aos dados brutos, o que gera um enriquecimento semântico dos dados.

A figura 6.15 descreve a seqüência lógica que se deve seguir para utilizar esta modelagem semântica em um processamento semântico de dados. Isto é, os dados brutos são decodificados em função do Application Schema e as fórmulas encarregadas de calcular os valores obtidos pelos dispositivos sensores. Logo, o SensorSchema e o AmbientSchema são utilizados para agregar tags relevantes para os dados decodificados. Finalmente, as informações semanticamente processadas são armazenadas em função do SensorDataSchema.

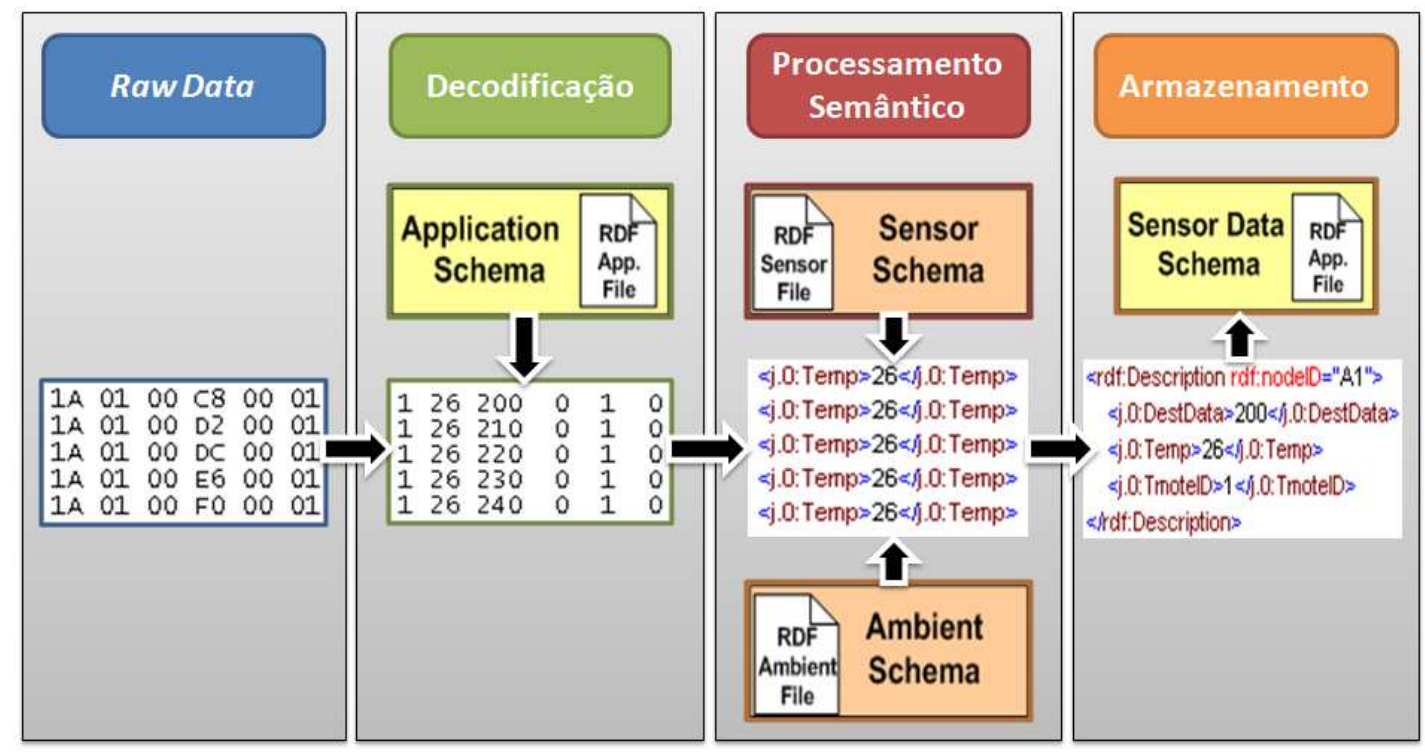

Figura 6.15: Seqüência Lógica da Modelagem e Processamento Semântico.

Nesse sentido, o Sensor Schema, o Ambient Schema, o Application Schema e o Sensor Data Schema foram projetados como arquivos RDFS, como é apresentado na figura 6.16, que mostra parte de nosso Sensor Schema em formato RDFS. Porém, estes Schemas precisam ser portados (adaptados) para uma linguagem de programação compatível com a plataforma em que esteja sendo implementada a aplicação do tipo Handheld $A R$, isto para facilitar o processamento semântico e automático dos dados. 


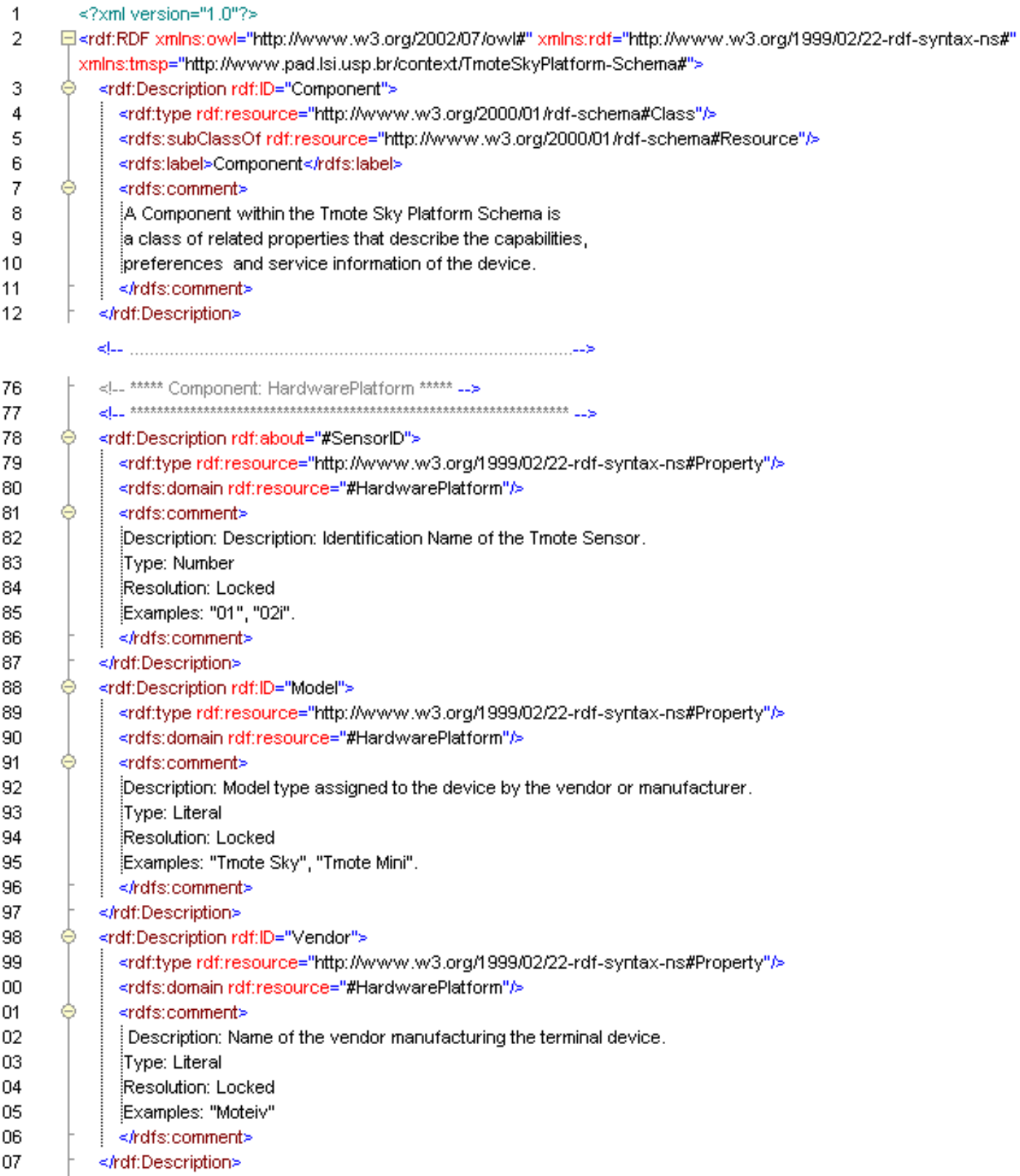

Figura 6.16: O Sensor Schema em formato RDF.

Em nosso caso, foi escolhida a ferramenta Jena (Semantic Web Framework for Java) (JENA, 2007), a qual permite portar os RDF Schemas em classes Java. Portanto, nós criamos as classes Java SensorSchema, ApplicationSchema, AmbientSchema e SensorDataSchema. Para isso, foi utilizada a API de Jena (Jena-2.5.4.jar), utilizando os métodos createDefaultModel(), createResource() e createProperty() para criar vocabulários, recursos e propriedades respectivamente. Por exemplo, a figura 6.17 apresenta a classe Java SensorSchema que foi adaptada do Sensor Schema apresentado na figura 6.16. 


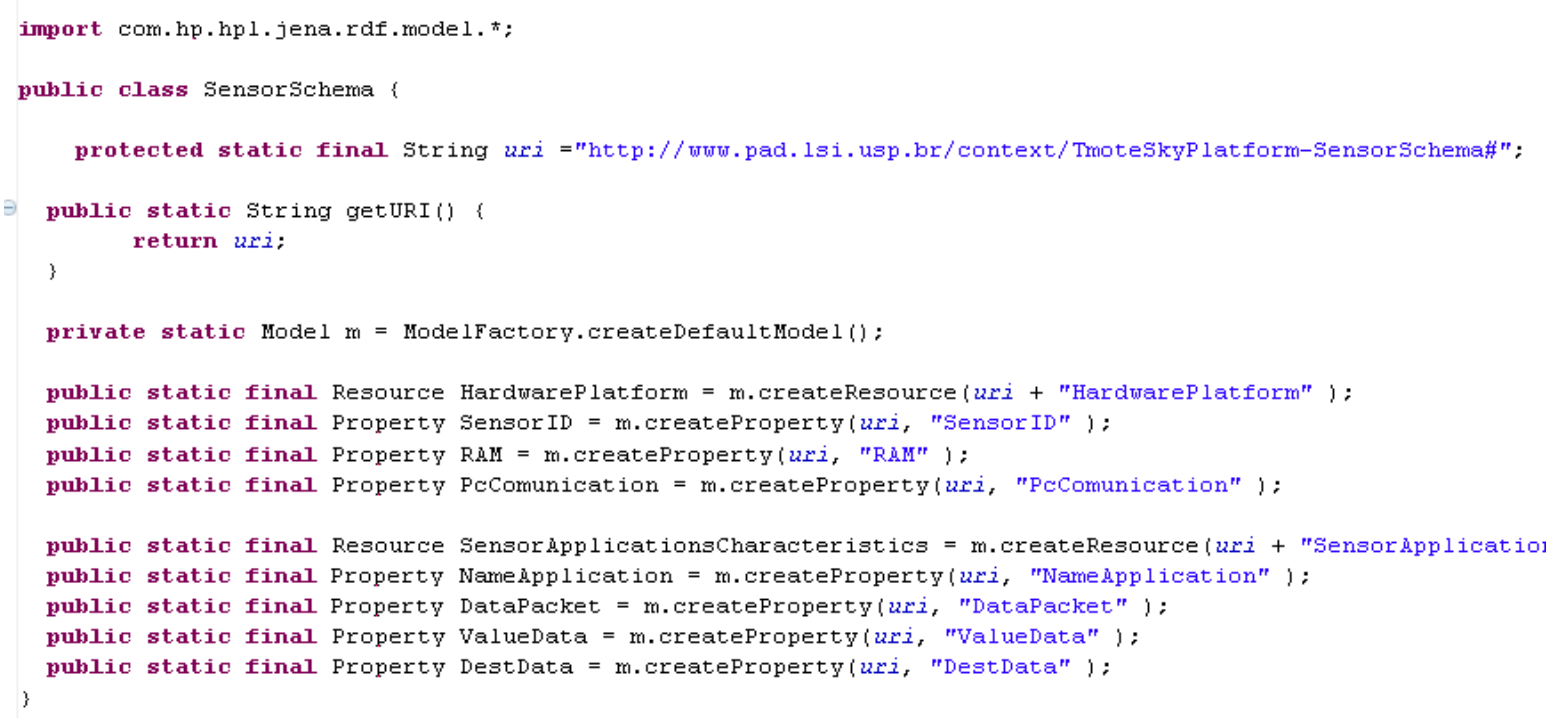

Figura 6.17: Classe Java SensorSchema.

Estas classes Java são integradas à aplicação do tipo Handheld $A R$ utilizando a classe RDF Tagging Application. Nesse sentido, nós desenvolvemos a classe RDF Tagging Application em base ao trabalho do Lewis et al. (2006) e que segue a seqüência lógica da modelagem e processamento semântico, anteriormente apresentada. Portanto, a $R D F$ Tagging Application utiliza a BluetoothPAD para acessar os dados gerados pelos dispositivos sensores, para logo decodificá-los, processá-los e armazená-los, utilizando as classes Java SensorSchema, AmbientSchema, ApplicationSchema e SensorDataSchema. Já a figura 6.18 apresenta um diagrama esquemático deste processo semântico de dados.

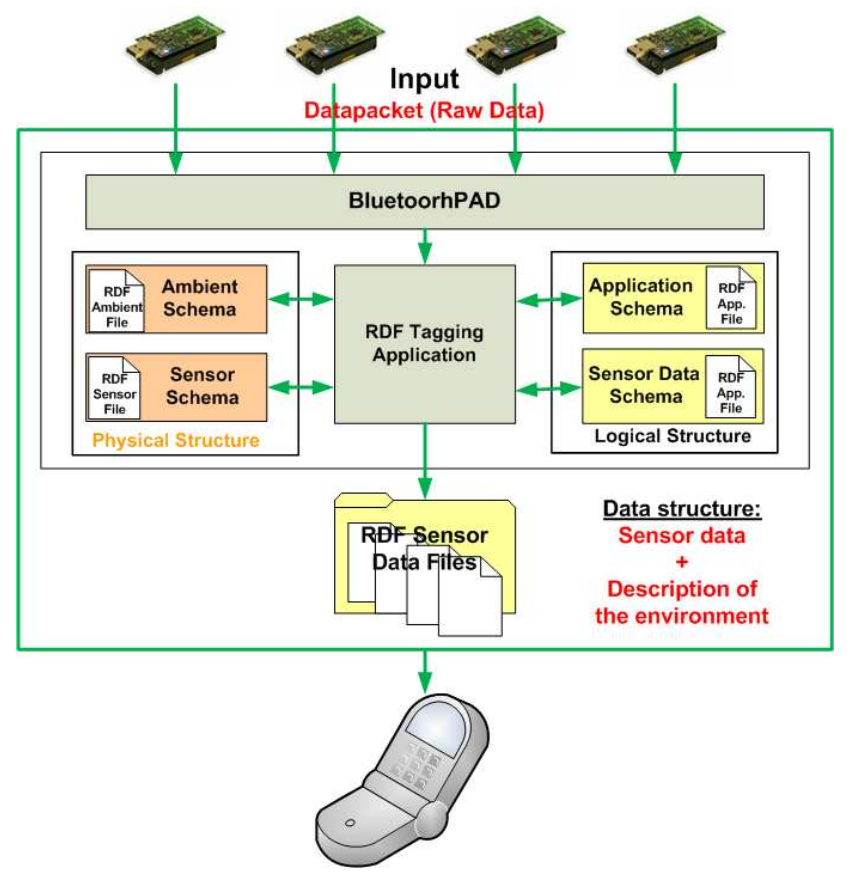

Figura 6.18: Diagrama Esquemático do Processamento Semântico de Dados. 
Os arquivos RDF criados pela RDF Tagging Application contém os dados gerados pelos dispositivos sensores. A estratégia de armazenar (temporal ou permanentemente) ou não estes arquivos RDF, deve ser definido previamente. Note-se que o armazenamento acontece porque as aplicações do tipo Handheld $A R$ podem atuar como sistemas de coleta de dados em ambientes urbanos e rurais.

Além disso, o fato de portar os RDF Schemas para classes Java, não exclui a disponibilização dos Schemas em seus formatos originais para outras aplicações ou interesses. Já para efeitos de minimizar o custo computacional, os dados gerados pelos dispositivos sensores em vez de ser armazenados em arquivos RDF, podem ser armazenados temporalmente em um objeto do tipo StringBuffer, o qual é disponibilizado para sua análise e processamento pelo componente lógico da aplicação

Finalmente, destaca-se que como parte desta dissertação, foi escrito o artigo (ZUñIGA; KOFUJI, 2007) que descreve o processo de coleta de dados gerados por uma RSSF, sua transmissão até um dispositivo móvel e seu posterior processamento semântico utilizando o RDF Tagging Application, para gerar e visualizar metadados. Isto é, por exemplo, o Sensor Schema pode descrever a exatidão do chip sensor encarregado de monitorar a temperatura. Este valor de precisão pode ser utilizado na tomada de decisões em aplicações de alto risco. Note-se também que neste artigo as informações foram disponibilizadas aos usuários como elementos textuais.

\subsection{Componente Lógico da Aplicação}

O componente lógico da aplicação define a lógica do tipo de aplicação implementada (jogos, sistemas de informação, sensoriamento, etc.). Nesse sentido, este componente utiliza os dados adquiridos pela câmera (objeto $m U r l$ ) e dispositivos sensores (objeto StringBuffer) para analisar o perfil do usuário (User Phone Profile - RDF) e em função da lógica da aplicação implementada, determinar qual é a melhor forma de representar estas informações como objetos virtuais.

Além disso, a lógica deste componente inclui consultas ou regras de inferência. Por exemplo, para o caso em que acontece um incêndio (exemplo apresentado no capítulo 4, na parte final da seção 4.2) em um prédio monitorado por dispositivos sensores de temperatura e luminosidade, as regras que determinam se está acontecendo um incêndio são a combinação de fatores como a detecção de alta luminosidade e temperatura para a mesma área. Portanto, as regras podem ser codificadas como: "alta luminosidade (candlepower) $>=10$; e temperatura $>=80$, quando ambos dispositivos sensores se encontram entre se a uma distância $<=1$ metros, isto durante um período maior a 20 segundos". 
O resultado da inferência também é apresentada ao usuário como um objeto virtual em função de seu perfil. Note-se que este perfil permite ao sistema de renderização decidir qual objeto virtual é utilizado para a representação das informações. Isto pode ser interpretado como uma interface de interação intuitiva bastante simples. Já a figura 6.19 apresenta um diagrama esquemático do componente lógico da aplicação.

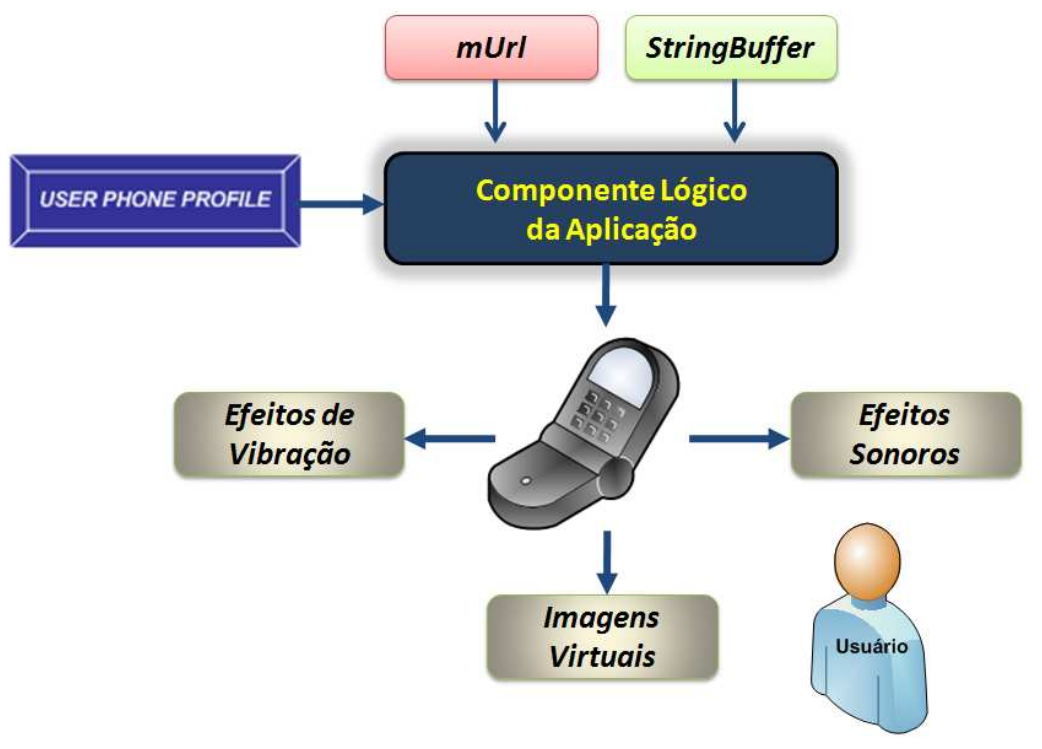

Figura 6.19: Diagrama Esquemático do Componente Lógico da Aplicação.

\subsection{Renderização de Objetos Virtuais}

A renderização de objetos virtuais é o processo de representação das informações como imagens virtuais, efeitos de vibração e efeitos sonoros. Como uma prova de conceito do processo de renderização, estes objetos virtuais foram implementados na plataforma J2ME, isto para manter a interoperabilidade com as classes anteriormente desenvolvidas (CameraPAD, SemacodePAD, BluetoothPAD e RDF Tagging Application). Além disso, justifica-se escolha da plataforma J2ME por prover suporte para um maior número de dispositivos móveis.

As imagens virtuais podem ser representadas por esquemas de cores, gráficos $2 \mathrm{D}$ e 3D. Já a renderização de gráficos 3D é a forma mais comum de representação de imagens virtuais em aplicações do tipo Handheld $A R$. Nesse sentido, o processo de renderização de gráficos 3D está composto por três subprocessos: Modeling, encarregado de determinar a forma e características da imagem virtual (color, textura, etc.); Scene, encarregado de montar a cena onde sera colocada a imagem virtual; e Rendering subprocesso final que gera a imagem virtual. Além disso, este processo de renderização pode ser feito em Immediate mode e Retained mode. 
O Immediate mode é um processo de renderização de baixo nível, onde o usuário tem total controle sobre o processo de renderização. Os gráficos 3D são descritos em um nível de vértice ou vertex ${ }^{1}$ e são renderizados a cada frame. Já o Retained mode descreve um nível elevado de renderização. Nesta modalidade, gráficos 3D e seus relacionamentos são descritos como um todo (cena) e não em base a vértices. Uma cena é composta por objetos (malhas, texturas, animações, luzes, etc.) que juntos formam um ambiente virtual.

A M3G API permite implementar o Immediate mode utilizando a Java OpenGL ES API ou JSR-239. Já o Retained mode permite a renderização de cenas através do carregamento de arquivos (por exemplo: arquivos m3g produzidos por ferramentas como Blender $3 D^{2}$ ou Strata $3 D^{3}$ ) que contém estas cenas.

A figura 6.20.a apresenta o código fonte para criação de um objeto g3d, que manipula uma imagem virtual. Também é apresentado o método Loader.load() que permite carregar uma cena 3D previamente produzida em um arquivo .m3g (Por exemplo: bullx2smooth.m3g). Já o método setPerspective() é utilizado para ajustar os atributos da câmera e o método setViewport() abre uma nova "janela" dentro da tela nas coordenadas passadas como parâmetros para inserir a cena (imagem virtual). Finalmente, o método render() executa o processo de renderização da cena. Já a figura 6.20.b mostra a renderização do arquivo "bullx2smooth.m3g".
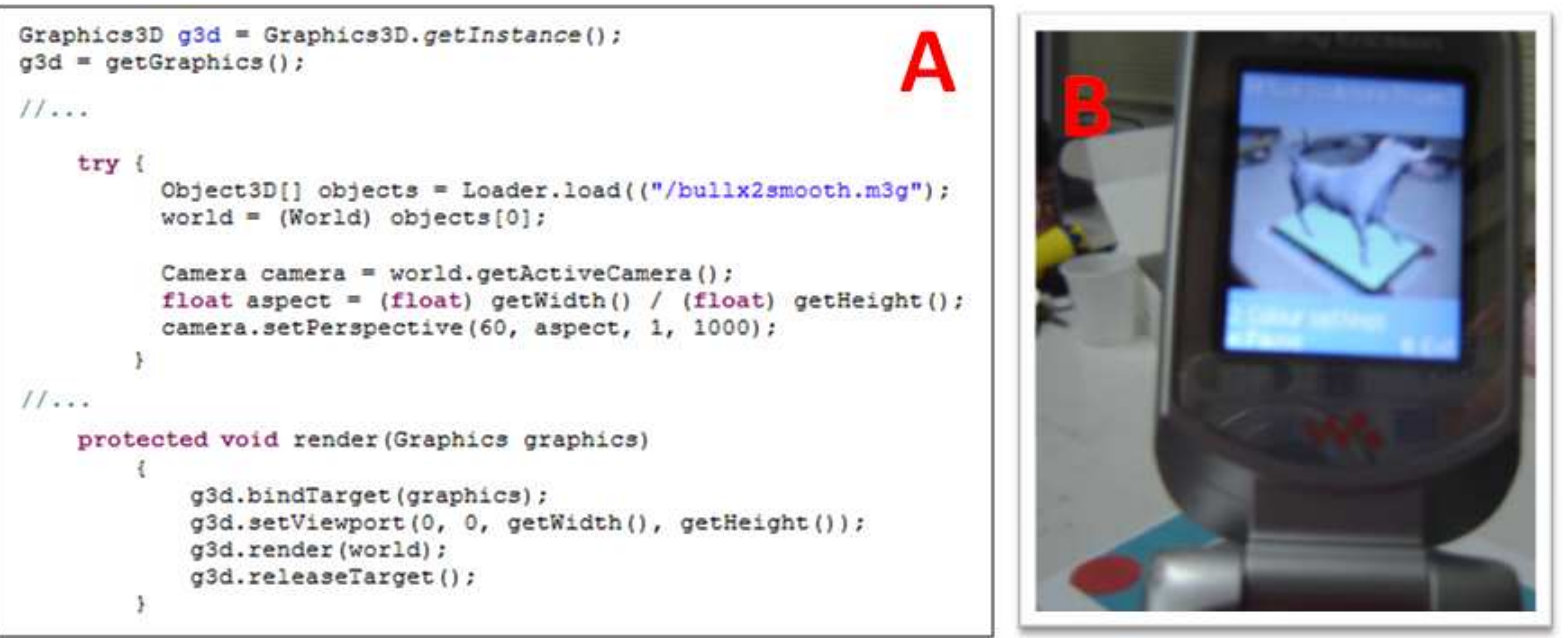

Figura 6.20: Renderização de Imagens Virtuais.

\footnotetext{
${ }^{1}$ Vertex (Vértice): Um vértice (ou vértices) é a unidade básica e método mais comum para a produção de gráficos 3D. Um vértice é representado por um ponto ou nó, onde linhas (arestas) originárias ou finais se intersectam.

${ }^{2}$ http://www.blender.org/

${ }^{3}$ http://www.strata.com/strata3d
} 
A representação dos efeitos de vibração é feita utilizando a Nokia UI API (NOKIA, 2007c) para dispositivos móveis da Nokia. Nesse sentido, é preciso importar a biblioteca "com.nokia.mid.ui.DeviceControl", a qual manipula os métodos startvibra() e stopvibra(). O método startvibra(int freq, long duration) implementa parâmetros que determinam a freqüência e o tempo de duração (em milissegundos) do efeito de vibração, como é apresentado na figura 6.21.

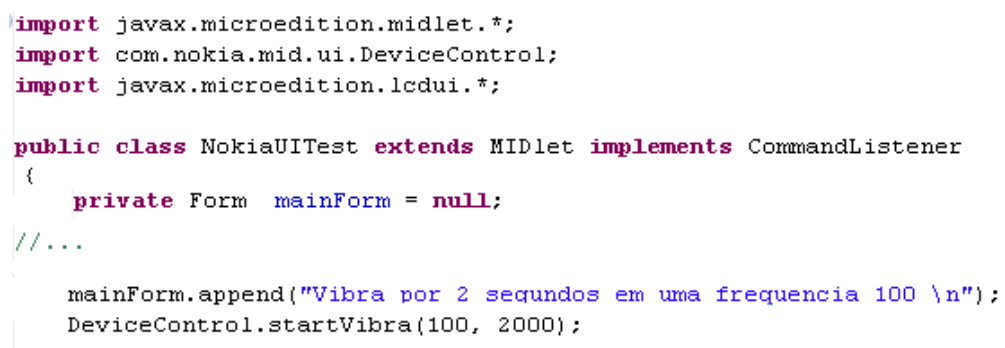

Figura 6.21: Renderização de Efeitos de Vibração.

Já outras fabricantes de telefones celulares como a Vodafone, Motorolla e Siemens implementam bibliotecas proprietárias para a renderização de efeitos de vibração para seus telefones celulares. Os métodos implementados por estes fabricantes são apresentados na figura 6.22. Finalmente, a plataforma J2ME oferece um método nativo (Display.vibrate()) para a renderização de efeitos de vibração, porém, este método só implementa o parâmetro de tempo. Além disso, pela pesquisa bibliográfica feita e pelos testes que nós realizamos, se demonstra que nem sempre este método funciona adequadamente.

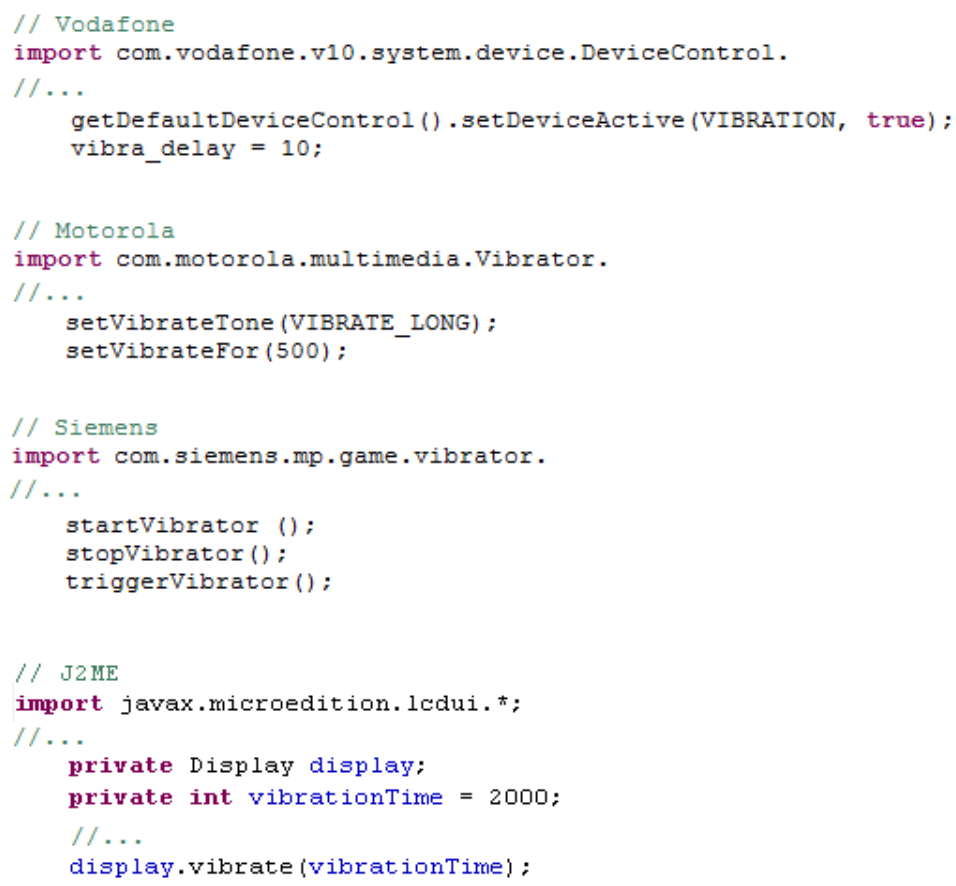

Figura 6.22: Bibliotecas Proprietárias para Efeitos de Vibração. 
A renderização de efeitos sonoros na plataforma J2ME é suportada pelas bibliotecas MIDP 2.0 Sound API e Mobile Media API (MMAPI). Além disso, a biblioteca Flash Lite (NOKIA, 2007b) provê novas funcionalidades que permitem reproduzir streams de áudio em diversos formatos suportados por dispositivos Nokia da Serie 60 e 40, como streams de áudio em formato MIDI. Diferentemente dos formatos de áudio, como WAV e MP3, o formato MIDI contém dados de desempenho, como o pitch (freqüência real de um som), duração (tempo), o volume e timbre de cada nota da composição, o que permite a reprodução (renderização) de efeitos sonoros 3D. Nesse sentido, a renderização de efeitos sonoros 3D pode ser utilizado como formas de representação de informações. Porém, este tipo de representação de informações precisa de maiores estudos, para determinar como estes efeitos sonoros são interpretados pelos usuários.

Portanto, na presente pesquisa, a renderização de efeitos sonoros foi implementada pela reprodução de streams de áudio (arquivos mp3) previamente armazenados no dispositivo móvel e que são reproduzidos em função dos dados coletados e das preferências do usuário. Nesse sentido, a figura 6.23 apresenta o método getResourceAsStream() para acessar o arquivo mp3 a ser reproduzido. Além disso, também são apresentados os objetos player e volumecontrol (vc) para gerenciar o processo de reprodução de sons. Já os métodos prefetch() e start() iniciam a reprodução do som.

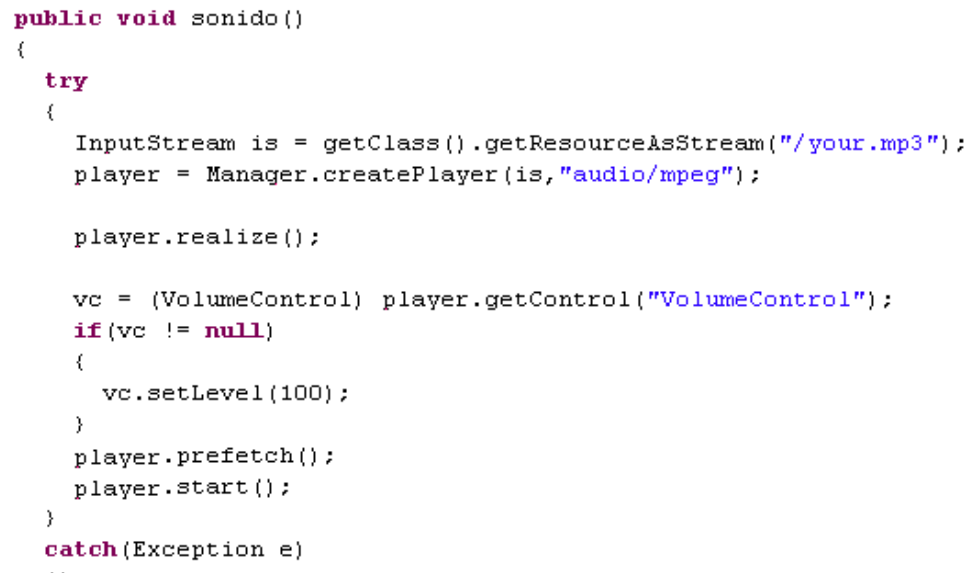

Figura 6.23: Renderização de streams de Áudio.

Finalmente, as seções 6.5, 6.6 e 6.7 (deste capítulo) descreveram de forma geral a implementação dos componentes funcionais de uma aplicação do tipo Handheld $A R$ que utiliza dispositivos sensores e telefones celulares. Embora estas seções tinham apresentado uma implementação na plataforma J2ME, nada impede que estes componentes sejam implementados em outras plataformas como Windows Mobile ou Symbian, isto até porque estas seções descrevem um fluxo lógico de implementação independente da plataforma. 


\section{$7 \quad$ Estudo de Caso}

Este capítulo apresenta uma aplicação do tipo Handheld AR para o monitoramento de temperatura, a qual é chamada de "protótipo". Nesse sentido, nas seções deste capitulo são descritos os materiais, o cenário, os serviços oferecidos, o fluxo de desenvolvimento e as avaliações do protótipo.

\subsection{Materiais para o Desenvolvimento}

- Dispositivos Sensores: Foi utilizada uma RSSF da plataforma TmoteSky para o sensoriamento da temperatura. Esta RSSF é composta por nós sensores programáveis e uma estação base, os quais implementam na sua arquitetura de hardware chips sensores. Uma especificação técnica mais detalhada destes dispositivos foi apresentada na subseção 2.2.1.1 do capítulo 2 .

- Dispositivos Móveis: A tabela 7.1 apresenta as características dos dispositivos móveis nos quais foi instalado o protótipo.

Tabela 7.1: Características dos Telefones Celulares Utilizados

\begin{tabular}{|l|l|l|}
\cline { 2 - 3 } \multicolumn{1}{c|}{} & \multicolumn{1}{c|}{ Nokia 6600 } & \multicolumn{1}{c|}{ Sony Ericsson W300i } \\
\hline Sistema Operacional & Symbian 7.0 & Sony Ericsson v4.09.1 \\
\hline Plataforma de & S60 2nd Edition & Java \\
\cline { 2 - 3 } Desenvolvimento & Java & MP3, AAC, AMR, WAV, MIDI \\
\hline Formatos de Som & MP3, MIDI & MP4, 3GP \\
\hline Formatos de Vídeo & MP4, 3GP & $128 x 160$ pixels \\
\hline Tela & $176 \times$ x 208 pixels & $262 \mathrm{~K}$ TFT \\
\hline Cores & 16 bit & 20 MB \\
\hline Memória Interna & 9 MB & 256 MB \\
\hline Cartão de Memória & 32 MB & Bluetooth, Infrared \\
\hline Interface Sem Fio & Bluetooth, Infrared & VGA camera \\
\hline Câmera & VGA camera w/ 2x digital zoom & \\
\hline
\end{tabular}


- Ambiente de Desenvolvimento: Foram utilizadas as seguintes ferramentas de hardware e software:

- Foi utilizado um laptop dual core de $1.67 \mathrm{GHz}$ com uma memória RAM de $1 \mathrm{~GB}$ e HD de 80 GB como dispositivo de hardware para o desenvolvimento da presente pesquisa;

- Foi instalado e utilizado como IDE de desenvolvimento o Eclipse SDK Version 3.3.0;

- Foi instalado um pacote adicional para o Eclipse SDK chamado EclipseME Version 1.7.9, o qual permite desenvolver aplicações para dispositivos móveis;

- Foi instalado o JDK (Java Development Kit) Version 1.6.03 para utilizar a plataforma Java como linguagem de programação a ser utilizada pelo IDE de desenvolvimento;

- Foi instalado o Sun JavaTM Wireless Toolkit for CLDC Version 2.5.2 para prover suporte ao desenvolvimento de aplicações para dispositivos móveis na plataforma Java. Além disso, este pacote também prove suporte a simuladores de telefones celulares;

- Foi instalado o Nokia UI API v1.1 para prover suporte para aplicações em telefones celulares da Nokia, em especial para o desenvolvimento dos efeitos de vibração;

- Foi instalado o Nokia PC Suite For 6600 e o My Phone Explorer Version 1.6.7 para permitir a transmissão e instalação das aplicações desenvolvidas para os telefones celulares;

- Foi utilizado o dispositivo BToes Bluetooth para permitir a comunicação sem fio entre a laptop e os telefones celulares.

\subsection{Definição do Estudo de Caso}

\subsubsection{Cenário}

Nós desenvolvíamos um estudo de caso baseado no sensoriamento e monitoramento de um ambiente controlado, neste caso a sala de servidores do PAD, composta por quatro (4) servidores (computadores servidores). A figura 7.1.a apresenta a sala de pesquisa do PAD (Grupo de Sistemas Pervasivos e de Alto Desempenho). E a figura 7.1.b apresenta a alocação dos servidores, dos nós sensores e dos marcadores nesta sala.

Já a tabela 7.2 descreve os nomes e tipo de servidores alocados na sala do PAD. 


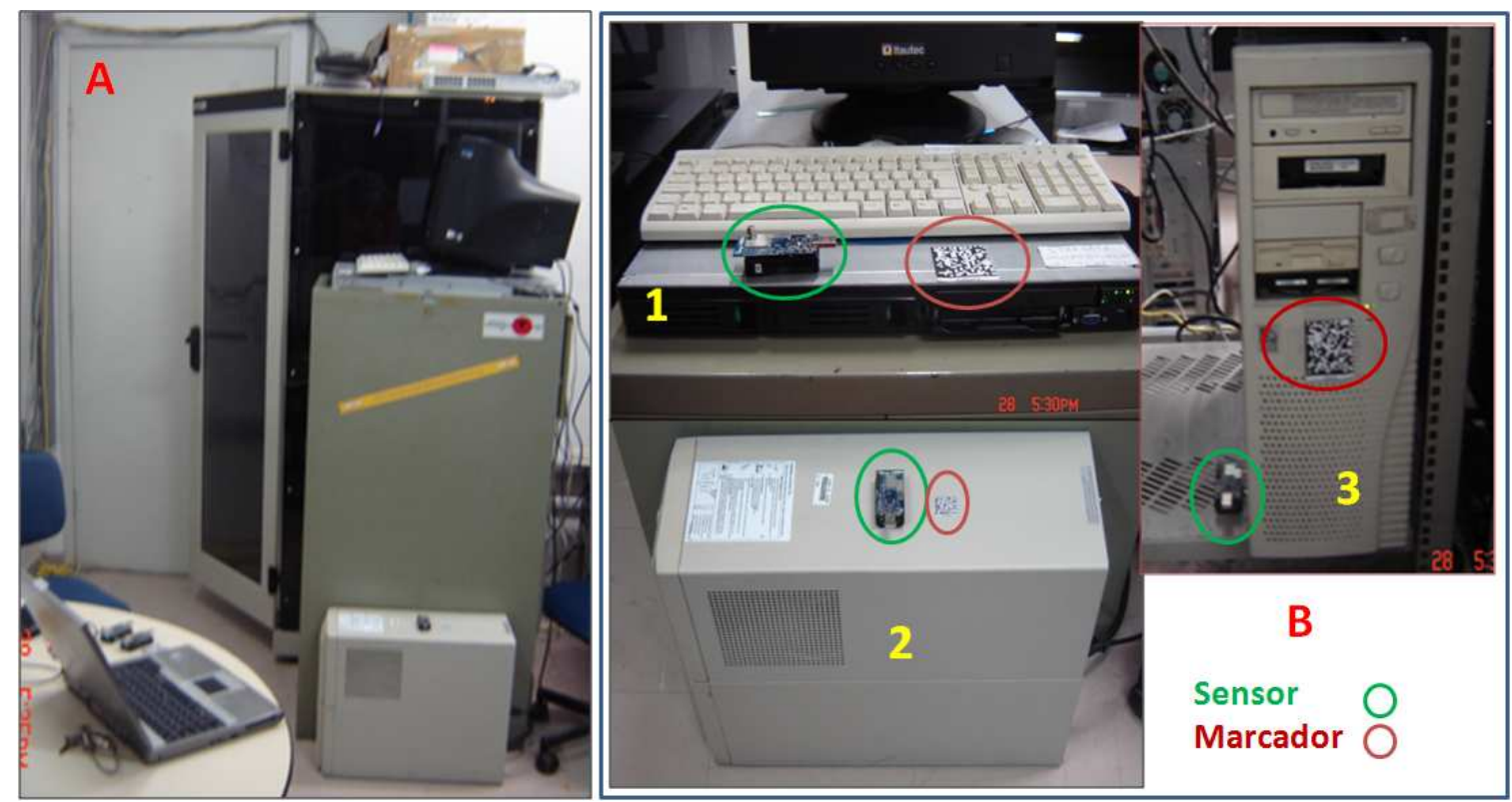

Figura 7.1: Sala de Pesquisa do PAD.

Tabela 7.2: Servidores do PAD

\begin{tabular}{|l|l|l|l|}
\cline { 2 - 4 } \multicolumn{1}{c|}{} & \multicolumn{1}{c|}{$\mathbf{1}$} & \multicolumn{1}{c|}{$\mathbf{2}$} & \multicolumn{1}{c|}{$\mathbf{3}$} \\
\hline Nome & Mercurio & Marte & Venus \\
\hline Tipo & Printer Server & Web Mail Server & Web Server \\
\hline
\end{tabular}

\subsubsection{Serviços Oferecidos}

Nosso protótipo foi projetado para monitorar a temperatura dos servidores instalados na sala do PAD, permitindo assim prever problemas de aquecimento e em conseqüência falhas nos equipamentos ou quedas no desempenho. Além disso, forma projetados marcadores para proporcionar serviços de informação através de imagens virtuais que identificam o tipo de servidor.

Também foi implementada uma lógica de inferência para gerar um alerta de aquecimento nos servidores. Nesse sentido, a temperatura ideal de funcionamento dos servidores em média é de $15^{\circ} \mathrm{C}$. Já temperatura máxima de funcionamento não deve ultrapassar os $58^{\circ} \mathrm{C}$, isto pela especificação dos fabricantes.

Portanto, para o caso em que a temperatura chegar a $50^{\circ} \mathrm{C}$, deve ser gerada uma alerta de aquecimento no servidor. Nesse sentido, a lógica de inferência foi codificada como: "temperatura $>=50$, durante um tempo $>=20$ segundos", então gerar alerta. O resultado da inferência também foi apresentada ao usuário como um objeto virtual. 


\subsubsection{Plataforma de Implementação}

Para o desenvolvimento de nosso protótipo, foi utilizada a plataforma J2ME e a ferramenta Semacode ${ }^{1}$ para a criação e decodificação dos marcadores. Como parte da implementação deste trabalho, nós desenvolvemos as classes encarregadas da aquisição e processamento dos dados gerados pelos sensores e pelas câmeras, reconhecimento de marcadores, renderização das imagens virtuais, dos efeitos de vibração, dos efeitos sonoros, e a modelagem das preferências do usuário (perfil do usuário). Nesse sentido, a figura 7.2 resome a implementação das classes projetadas (apresentadas no capítulo 6) em função da arquitetura proposta para este tipo de aplicações.

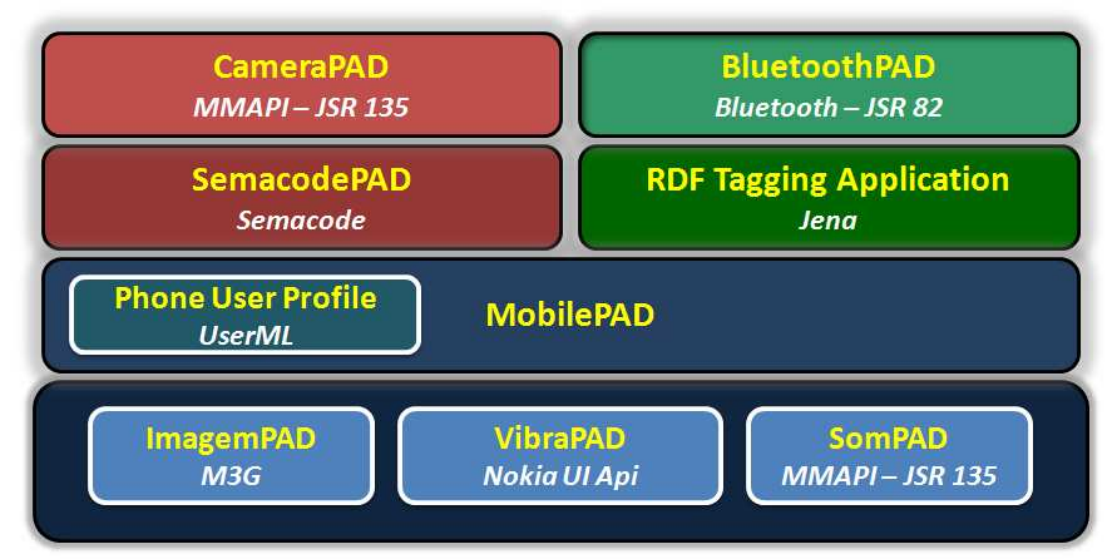

Figura 7.2: Arquitetura Baseada na Plataforma J2ME.

Note-se que uma vez que o protótipo da aplicação do tipo Handheld AR seja totalmente implementada, ela precisa ser exportada em arquivos .JAR e .JAD, que serão posteriormente utilizados para a instalação do protótipo no dispositivo móvel. Nesse sentido, o EclipseME (plug-in do Eclipse) permite a criação destes arquivos de forma simples. É só fazer click direito sobre a nossa aplicação, logo escolher a opção J2ME e logo Create Package. Uma pasta de nome deployed é criada contendo os arquivos JAR e JAD.

\subsection{Desenvolvimento do Protótipo}

Em casos nos quais os dispositivos sensores e dispositivos móveis possuam uma mesma interface de comunicação sem fio, como por exemplo o protocolo Bluetooth, a conexão e transmissão de dados entre estes dispositivos será direta. Já no caso das RSSF, especificamente na plataforma TmoteSky, a interface de comunicação sem fio é baseada no protocolo Zigbee. Portanto, para a implementação de nosso protótipo utilizando a

\footnotetext{
${ }^{1}$ Semacode: http://www.semacode.org/
} 
plataforma TmoteSky e um dispositivo móvel como o telefone celular Nokia 6600 ou Sony Ericsson W300i, nós precisamos criar uma "Ponte" para a transmissão dos dados, como foi proposto em (RAUHALA; GUNNARSSON; HENRYSSON, 2006).

Nesse sentido, nós instalamos quatro nós sensores, um em cada servidor descrito na 7.2. Já o quarto nó sensor foi instalado no meio da sala do PAD só para conhecer a temperatura ambiente. A coleta dos dados foi feita em períodos de 10 minutos. Neste período de tempo, os nós sensores coletaram e transmitiram os dados para a estação base utilizando o protocolo Zigbee. Já a estação base transmite os dados coletados para uma laptop através de um cabo USB. A laptop funciona como uma "ponte" já que nela não é feito nenhum processamento, os dados que ingressam da estação base são retransmitidos através de uma interface Bluetooth para o telefone celular no qual será feito todo o processamento da aplicação. Este esquema da ponte é apresentado na figura 7.3.

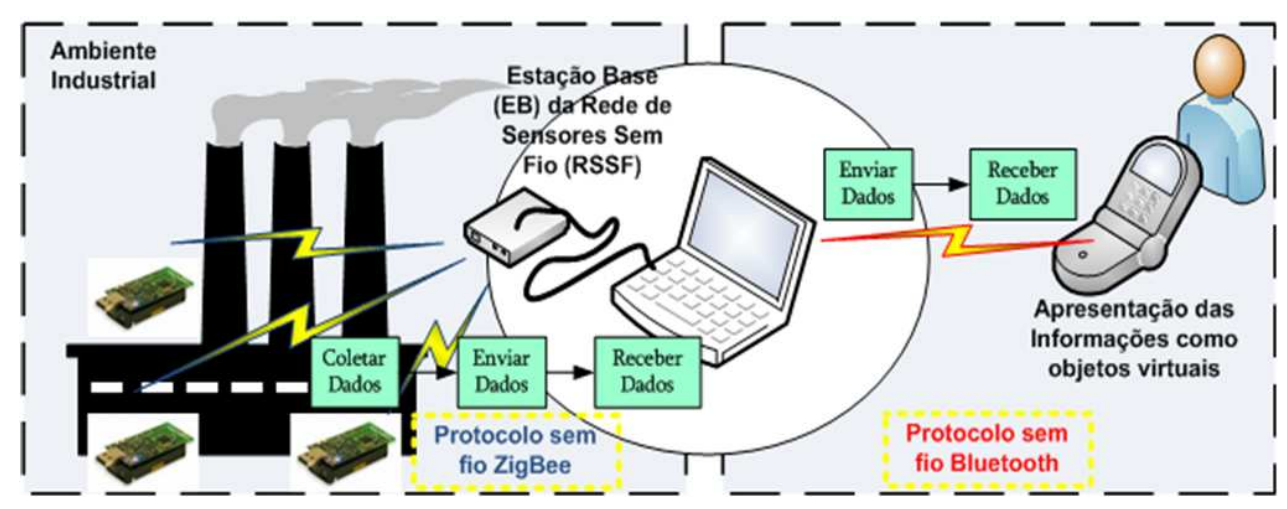

Figura 7.3: Transmissão dos Dados Obtidos pelos Nós Sensores.

Além dos dispositivos sensores, também foram alocados marcadores para identificar os servidores do PAD, como foi apresentado na figura 7.1.b. Estes marcadores foram criados utilizando a ferramenta on-line do Semacode (http://www.semacode.com/tag). Tanto os dispositivos sensores como os marcadores são utilizados como meios para a aquisição de dados e interação com a aplicação do tipo Handheld $A R$ desenvolvida para o estudo de caso (protótipo).

Já a figura 7.4 apresenta o fluxo de processamento que acontece no desenvolvimento, implementação e execução de nosso protótipo para o cenário apresentado.

1. O primeiro passo, foi a modelagem das informações relevantes dos dispositivos sensores e do ambiente (servidores) em arquivos RDF, para isso foram utilizados o Sensor Schema e Ambient Schema. Também são modeladas informações do fenômeno a ser monitorado (temperatura) no Application Schema e da forma como serão gerados e armazenados os dados obtidos pelos sensores no Sensor Data Schema; 


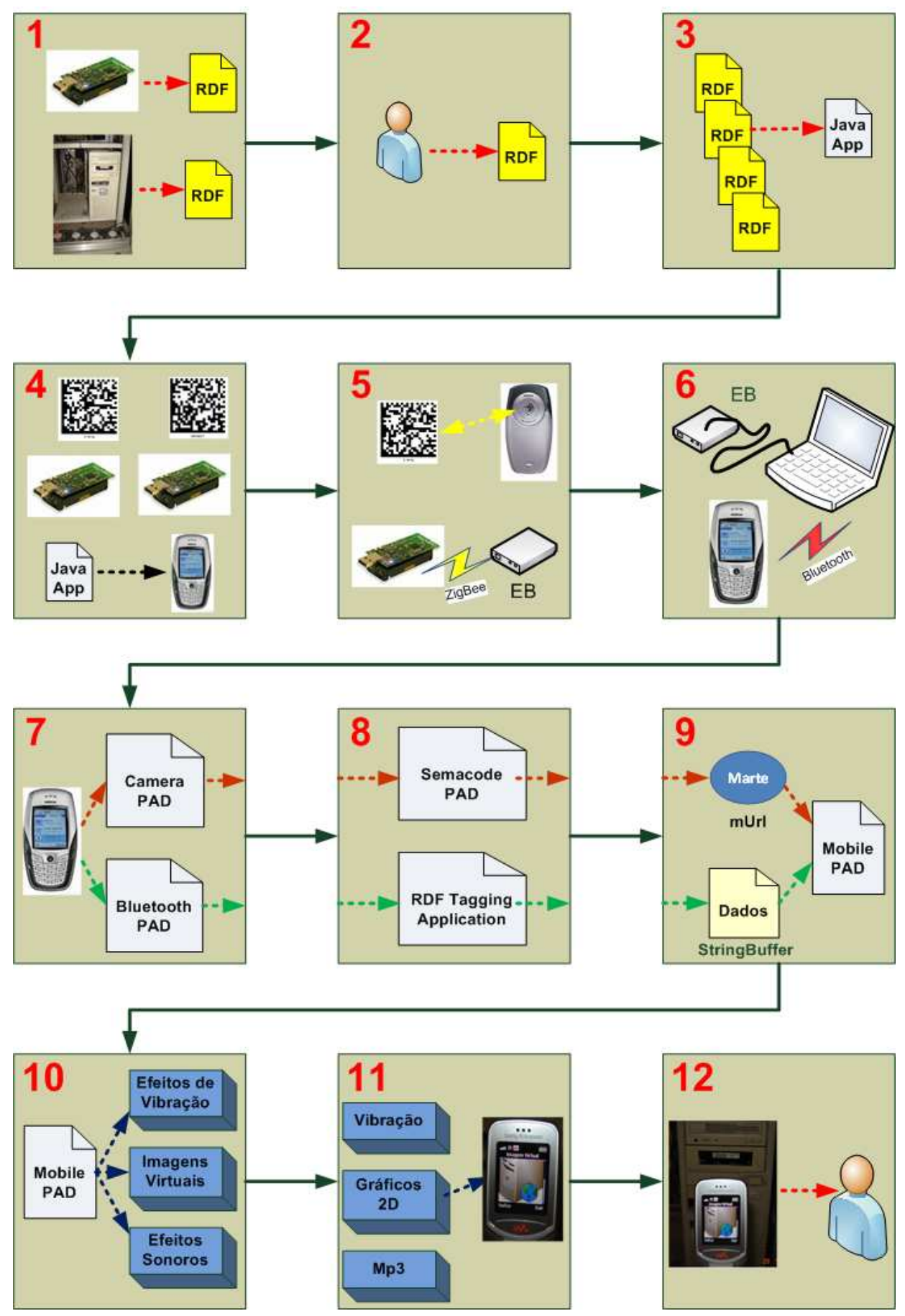

Figura 7.4: Fluxo de Processamento do Estudo de Caso.

2. Logo, foram modeladas as preferências do usuário em um perfil (User Phone Profile - $R D F)$. Neste caso, foram modeladas as preferências do chefe coordenador do PAD, as quais são apresentadas na figura 7.5. Note-se que a forma como as informações são apresentadas dependem destas preferências do usuário;

3. Note-se que todas as informações modeladas em arquivos RDF, precisam ser portadas (adaptadas) para a linguagem Java, isto para que estas informações possam ser manipuladas pelo aplicação de monitoramento do tipo Handheld AR (protótipo); 


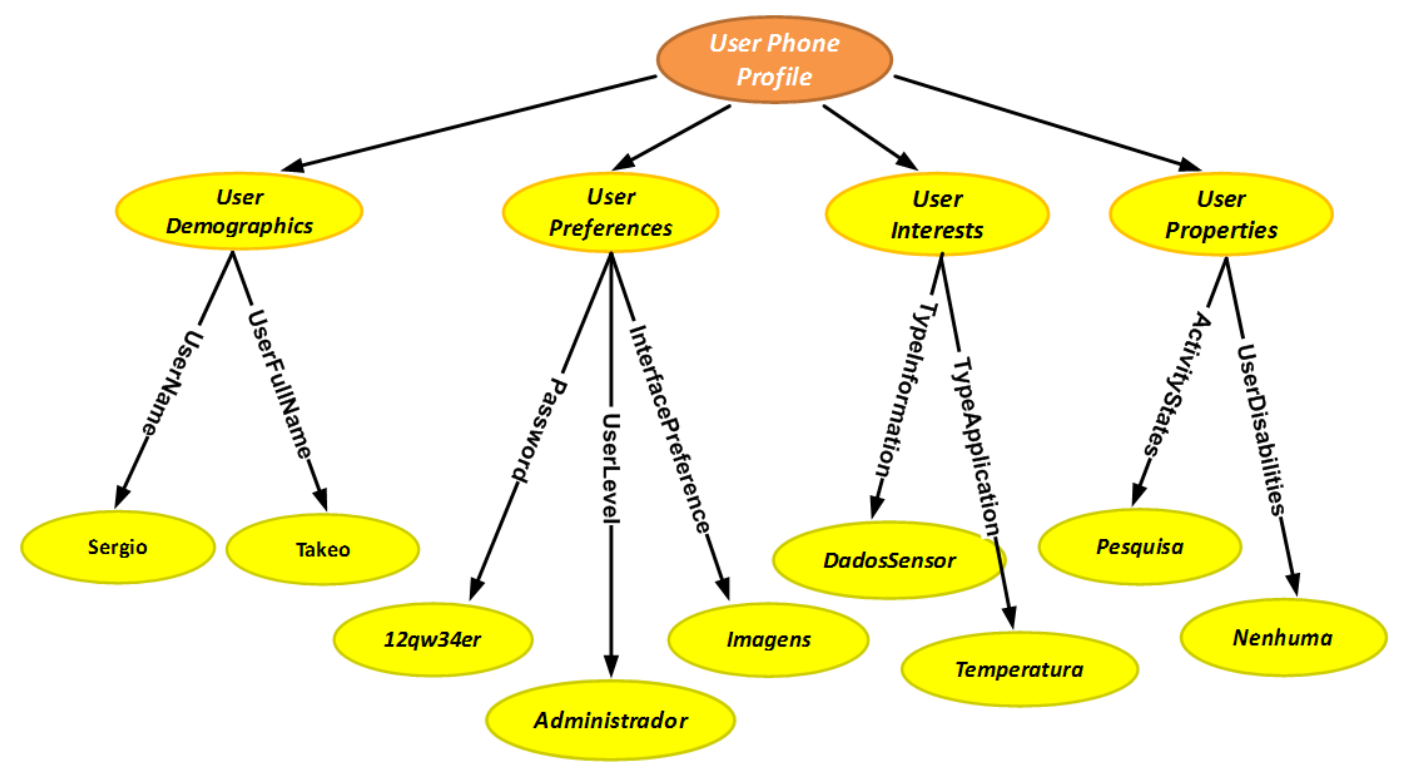

Figura 7.5: User Phone Profile do Administrador do PAD.

4. O passo seguinte é alocar os elementos de interação (marcadores e nós sensores). Para este estudo de caso foram criados 3 marcadores, os quais identificam os servidores do PAD através da palavra-chave codificada neles. Além disso, foram alocados quatro nós sensores, três para monitorar os servidores e um para conhecer a temperatura da sala. Logo, o protótipo é instalado no telefone celular, para o qual foi utilizado um dispositivo Bluetooth (BToes) e o Nokia PC Suite For 6600 ou o My Phone Explorer Version 1.6.7 para transmitir o arquivo executável (.JAR) do protótipo;

5. Os nós sensores coletam e transmitem os dados para a Estação Base (EB), mesmo sem o protótipo haver sido executado. Com a execução do protótipo, um menu contextual permite a escolha da aquisição de dados pela câmera ou pelos dispositivos sensores. Ao ser escolhida a opção da câmera, o protótipo ativa a câmera do dispositivo para a captura de imagens;

6. Já no caso de ser escolhida a opção de dispositivos sensores, o protótipo abre uma conexão via Bluetooth com a laptop. A laptop executa a classe BluetoothPAD cliente, que permite a transmissão de dados da RSSF para o dispositivo móvel;

7. A opção da câmera, utiliza a CameraPAD para capturar imagens do mundo real. Nesse sentido o usuário pode utilizar a opção capturar para começar o processo de reconhecimento. Já a opção de dispositivos sensores, uma lista com os nomes dos clientes (neste caso a laptop) é apresentada, para permitir a escolha do cliente com o qual se estabelecera a conexão. 
8. Com a imagem capturada, a classe SemacodePAD começa o processo de reconhecimento procurando um marcador relevante na imagem capturada. Em caso não ter nenhum marcador na imagem ou o marcador não ser relevante para aplicação a o protótipo devolve uma mensagem de erro no reconhecimento. Pelo contrário, se o marcador for reconhecido o protótipo devolve a palavra-chave decodifica para logo ser armazenada no objeto $m U r l$; Já com os dados transmitidos pela RSSF no telefone celular, a classe RDF Tagging Application utiliza os Schemas (portados em Java) para processar e armazenar semanticamente os dados coletados. As informações geradas são armazenadas em um objeto tipo string buffer chamado SbDados;

9. A classe MobilePAD que representa o componente lógico da aplicação utiliza as informações armazenadas nos objetos SbDados e $m U R L$ para determinar a forma de representação destas informações como objetos virtuais. Além disso, e constantemente verificada a lógica de inferência que gera um alerta de aquecimento nos servidores;

10. A MobilePAD determina como as informações são apresentadas como objetos virtuais em função do perfil do usuário. Por exemplo, se a propriedade UserDisabilities do perfil de usuário fosse "Surda", os objetos virtuais so poderiam ser representados como imagens virtuais e efeitos de vibração. Isto pode ser interpretado como uma interface de interação intuitiva, desde o ponto de vista mais simples. Já para nosso estudo de caso, a propriedade UserDisabilities não apresenta nenhuma informação relevante;

11. Nosso protótipo foi projetado para representar os marcadores associados aos servidores como imagens virtuais (gráficos 2D). Já os dados coletados pela RSSF são apresentados como informações contextuais na tela do telefone celular;

12. Finalmente, o telefone celular interage com o usuário apresentando as informações adquiridas e processadas pelo protótipo. Neste caso, os dados como o tipo de servidor e informações da temperatura. O usuário pode finalizar a execução do protótipo ou retornar ao menu principal.

Note-se que a implementação de nosso estudo de caso seguiu as orientações (guidelines) de desenvolvimento descritas na presente dissertação. Porém, por ser esta uma prova de conceito, nem todas características apresentadas nas orientações (guidelines) foram totalmente implementadas. 


\subsection{Avaliações}

\subsubsection{Avaliações do Reconhecimento dos Marcadores}

Para o cenário apresentado na subseção 7.2.1 e para o modelo de desenvolvimento apresentado na seção 7.3, a aquisição das informações através das câmeras dos telefones celulares "Nokia 6600" e "Sony Ericsson W300i" foram feitas baixo os seguintes parâmetros:

- Dois períodos de tempo: Um chamado de "manhã", que é o período de tempo entre as $8 \mathrm{am}$ e 1pm, no qual a iluminação do cenário é feita apenas de la luz natural. E o período chamado de "noite", que é o período de tempo entre as 5pm e 8pm, no qual a iluminação do cenário é feita pelas lâmpadas da sala de servidores do PAD. Este parâmetro foi definido para determinar como a luminosidade do ambiente afeta o reconhecimento dos marcadores;

- Três tamanhos de marcadores: Foram definidos os tamanhos "2,5 x 2,5 cm", "3,3 x 3,3 cm" e " 5 x 5 cm". O primeiro e terceiro tamanho foram definidos para comparar-los com os resultados apresentado no artigo de Kato e Tan (2007) para o reconhecimento de marcadores. Já o segundo parâmetro foi definido em função da especificação do DataMatrix para o uso deste tipo de marcador;

- Três distâncias: Foram definidas três distâncias que descrevem o espaço entre o marcador e à câmera do telefone celular. Estas distâncias são de "5 cm", "10 cm" e "15 cm". Estes valores foram definidos para comparar-los com os resultados apresentado no artigo de Kato e Tan (2007) para o reconhecimento de marcadores;

- FFR (First-Read Rate): O número de vezes que a aplicação conseguiu reconhecer o marcador para cada uma das combinações formadas pelos parâmetros "períodos de tempo", "tamanhos" e "distâncias" anteriormente definidos. O número de leituras (vezes que a aplicação tenta reconhecer o marcador) para cada uma das combinações foi definido em 50.

Nesse sentido, foram realizados testes em base a estes parâmetros para os três servidores instalados na sala do PAD. Portanto a figura 7.6 apresenta o quadro com os resultados do número de vezes que a aplicação conseguiu reconhecer o marcador (parâmetro FFR). Estes resultados são apresentados em porcentagens. 


\begin{tabular}{|c|c|c|c|c|c|c|c|c|c|c|c|c|c|}
\hline & & \multicolumn{12}{|c|}{ SERVIDOR } \\
\hline & & \multicolumn{4}{|c|}{$\%$ FRR - Mercurio } & \multicolumn{4}{|c|}{$\%$ FRR - Marte } & \multicolumn{4}{|c|}{$\%$ FRR - Venus } \\
\hline \multicolumn{2}{|c|}{ MARCADOR } & \multicolumn{2}{|c|}{ Manhã } & \multicolumn{2}{|c|}{ Tarde } & \multicolumn{2}{|c|}{ Manhã } & \multicolumn{2}{|c|}{ Tarde } & \multicolumn{2}{|c|}{ Manhã } & \multicolumn{2}{|c|}{ Tarde } \\
\hline Tamanho & Distância & 6600 & w300i & 6600 & w300i & 6600 & w300i & 6600 & w300i & 6600 & w300i & 6600 & w300i \\
\hline \multirow{3}{*}{$2,5 \mathrm{~cm}$} & $5 \mathrm{~cm}$ & $56 \%$ & $52 \%$ & $58 \%$ & $54 \%$ & $58 \%$ & $54 \%$ & $60 \%$ & $54 \%$ & $44 \%$ & $38 \%$ & $50 \%$ & $40 \%$ \\
\hline & $10 \mathrm{~cm}$ & $30 \%$ & $26 \%$ & $32 \%$ & $28 \%$ & $32 \%$ & $28 \%$ & $32 \%$ & $30 \%$ & $22 \%$ & $16 \%$ & $30 \%$ & $16 \%$ \\
\hline & $15 \mathrm{~cm}$ & $6 \%$ & $2 \%$ & $8 \%$ & $2 \%$ & $4 \%$ & $0 \%$ & $4 \%$ & $2 \%$ & $0 \%$ & $0 \%$ & $0 \%$ & $0 \%$ \\
\hline \multirow{3}{*}{$3,3 \mathrm{~cm}$} & $5 \mathrm{~cm}$ & $66 \%$ & $62 \%$ & $68 \%$ & $62 \%$ & $66 \%$ & $60 \%$ & $66 \%$ & $62 \%$ & $54 \%$ & $44 \%$ & $64 \%$ & $62 \%$ \\
\hline & $10 \mathrm{~cm}$ & $46 \%$ & $42 \%$ & $50 \%$ & $46 \%$ & $50 \%$ & $46 \%$ & $54 \%$ & $48 \%$ & $44 \%$ & $38 \%$ & $48 \%$ & $42 \%$ \\
\hline & $15 \mathrm{~cm}$ & $26 \%$ & $22 \%$ & $30 \%$ & $26 \%$ & $26 \%$ & $22 \%$ & $30 \%$ & $26 \%$ & $18 \%$ & $16 \%$ & $24 \%$ & $16 \%$ \\
\hline \multirow{3}{*}{$5 \mathrm{~cm}$} & $5 \mathrm{~cm}$ & $0 \%$ & $0 \%$ & $0 \%$ & $0 \%$ & $0 \%$ & $0 \%$ & $0 \%$ & $0 \%$ & $0 \%$ & $0 \%$ & $0 \%$ & $0 \%$ \\
\hline & $10 \mathrm{~cm}$ & $70 \%$ & $68 \%$ & $72 \%$ & $66 \%$ & $72 \%$ & $68 \%$ & $74 \%$ & $68 \%$ & $68 \%$ & $62 \%$ & $68 \%$ & $64 \%$ \\
\hline & $15 \mathrm{~cm}$ & $64 \%$ & $54 \%$ & $62 \%$ & $56 \%$ & $60 \%$ & $56 \%$ & $64 \%$ & $58 \%$ & $58 \%$ & $52 \%$ & $54 \%$ & $54 \%$ \\
\hline
\end{tabular}

Figura 7.6: Quadro de Resultado de \% FFR.

Note-se que os resultados obtidos, especificamente para os parâmetros de tamanho do marcador "2,5 x 2,5 cm" e "5 x 5 cm" e telefone celular "Nokia 6600", ao serem comparados com os resultados do Kato e Tan (2007), apresentaram uma menor taxa de reconhecimento (\% FFR). Nesse sentido, foi simulado um cenário de controle, isto é, foi feito o reconhecimento dos marcadores nos três tamanhos sobre uma mesa e utilizando uma lâmpada para incrementar a luminosidade. A figura 7.7.a e a figura 7.7.b apresentam o cenário montado. Este cenário de controle gerou uma maior taxa de reconhecimento comparada com os testes feitos na sala de servidores do PAD. Já resultados do cenário de controle são apresentados na figura 7.7.c. Note-se que no cenário de controle, condições como distância (entre o marcador e a câmera) e a alocação do telefone celular, foram bem mais controladas e adequadas que na sala de servidores do PAD.
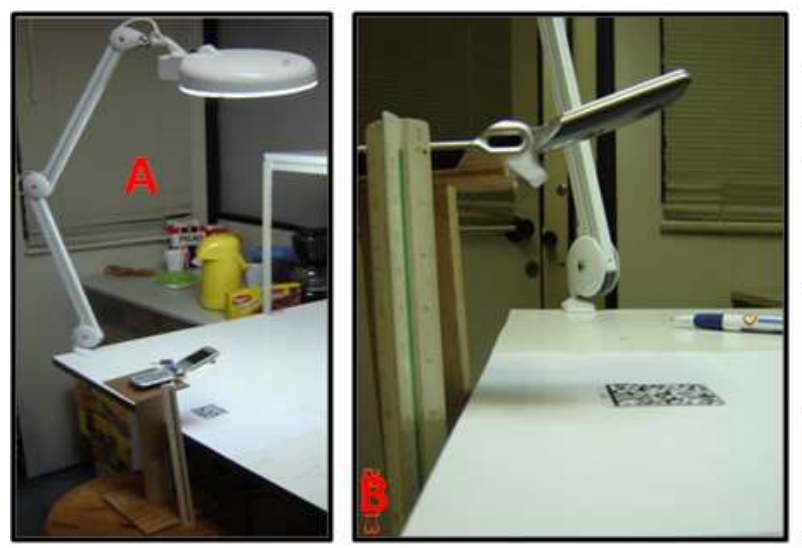

\begin{tabular}{|c|c|c|c|}
\hline \multicolumn{2}{|c|}{ C } & \multirow{2}{*}{\multicolumn{2}{|c|}{$\begin{array}{c}\text { Cenário de Controle } \\
\% \mathrm{FRR}\end{array}$}} \\
\hline \multicolumn{2}{|c|}{ MARCADOR } & & \\
\hline Tamanho & Distância & 6600 & w300i \\
\hline \multirow{3}{*}{$2,5 \mathrm{~cm}$} & $5 \mathrm{~cm}$ & $74 \%$ & $68 \%$ \\
\hline & $10 \mathrm{~cm}$ & $40 \%$ & $34 \%$ \\
\hline & $15 \mathrm{~cm}$ & $14 \%$ & $8 \%$ \\
\hline \multirow{3}{*}{$3,3 \mathrm{~cm}$} & $5 \mathrm{~cm}$ & $80 \%$ & $76 \%$ \\
\hline & $10 \mathrm{~cm}$ & $60 \%$ & $56 \%$ \\
\hline & $15 \mathrm{~cm}$ & $36 \%$ & $24 \%$ \\
\hline \multirow{3}{*}{$5 \mathrm{~cm}$} & $5 \mathrm{~cm}$ & $0 \%$ & $0 \%$ \\
\hline & $10 \mathrm{~cm}$ & $82 \%$ & $80 \%$ \\
\hline & $15 \mathrm{~cm}$ & $76 \%$ & $70 \%$ \\
\hline
\end{tabular}

Figura 7.7: Reconhecimento de Marcadores em um Cenário de Controle.

Portanto, define-se que os dados obtidos, na sala dos servidores do PAD, apresentam uma menor taxa de reconhecimento comparados com os dados obtidos para o cenário de controle e os de resultado apresentado em (KATO; TAN, 2007). Isto porque estes cenário apresentam condições de luminosidade especificamente instaladas para o reconhecimento 
dos marcadores, já a sala de servidores do PAD, apresenta condições de luminosidade do dia-a-dia, sendo este cenário mais realista. Fato que explica porque a taxa de reconhecimento do servidor Venus, sempre foi menor que a dos servidores Marte e Mercurio, sendo que a alocação do Venus sempre apresento menores condições de luminosidade em comparação aos outros dois servidores, como é apresentado na figura 7.8.

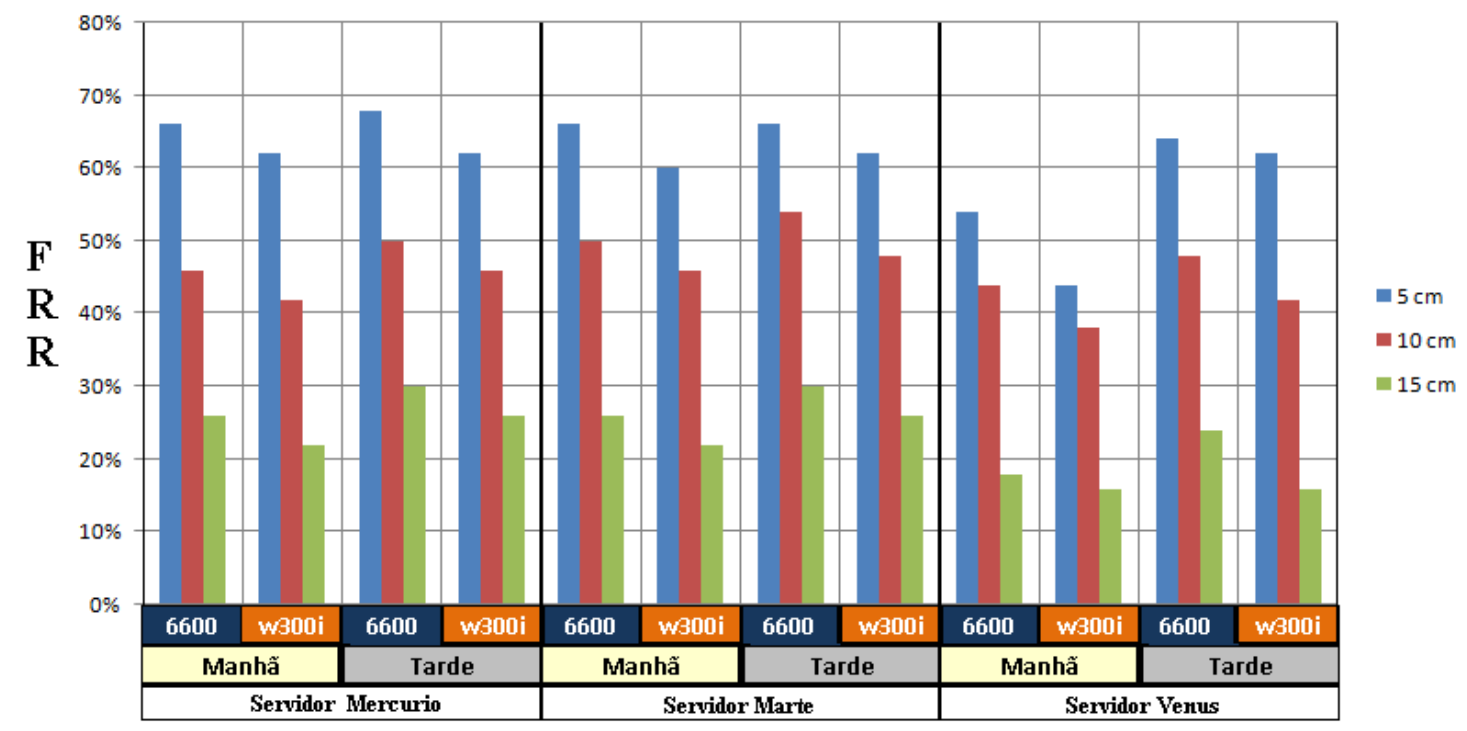

Figura 7.8: Resultados do Reconhecimento de Marcadores na Sala de Servidores do PAD.

Também foi percebido, que mesmo que os dois modelos de telefones celulares possuam uma câmera VGA, o fato de que o Nokia 6600 ter um digital zoom de 2x, permitiu que a taxa de reconhecimento deste telefone sempre fosse maior ou igual, quando comparada com o Sony Ericsson w300i. Além disso, note-se que os marcadores de tamanho de 5 $\mathrm{cm}$, não são reconhecidos a uma distância menor a $10 \mathrm{~cm}$, isto porque o marcador não se consegue enquadrar totalmente na câmera. Finalmente, determina-se que as condições de iluminação e o ângulo em que a câmera captura a imagem, do marcador, representam fatores que afetam o processo de reconhecimento.

\subsubsection{Avaliações dos Dados Transmitidos pela RSSF}

A RSSF que coletava os dados de temperatura, tinha instalada nos seus nós sensores a aplicação OscilloscopeRF apresentada na dissertação de ROCA (2008). Esta aplicação gera pacotes de dados por cada nó sensor e de um tamanho de 36 bytes. Cada pacote é enviado a cada segundo (o tempo de captura de dados pelos nós sensor é determinada pela aplicação instalada em cada nó sensor). Sendo 4 nós sensores os que coletam os dados, em total são transmitidos 144 bytes por segundo. Estes dados foram transmitidos através de uma interface ZigBee para a estação base e logo para a laptop. 
Nesse sentido, foi analisada a taxa de transmissão de dados entre a laptop e os telefones celulares "Nokia 6600" e "Sony Ericsson W300i". Para isso foi calculado o tempo que demora esta transmissão de dados utilizando o método System.currentTimeMillis(). Este método permite calcular o tempo que transcorre entre o início e fim da transmissão dos dados na classe BluetoothPAD.

Além disso, foram simuladas transmissões de dados para quantidades de 1 Kbyte, 10 Kbytes, 25 Kbytes e 100 Kbytes. Isto para determinar tempos de transmissão para taxas de dados mais altas que as geradas pela RSSF. Portanto, a figura 7.9 apresenta o quadro que descreve os tempos de transmissão em função da quantidade de dados transmitidos pela RSSF e pelos dados simulados.

\begin{tabular}{|c|c|c|c|c|c|c|c|}
\hline & & De & a & De & $\mathbf{a}$ & De & a \\
\hline \multirow{2}{*}{$\begin{array}{l}\text { Número } \\
\text { de Nós }\end{array}$} & \multirow{2}{*}{$\begin{array}{c}\text { Quantidade } \\
\text { de Dados }\end{array}$} & Laptop & 6600 & Laptop & waoti & 6600 & wanoi \\
\hline & & \multicolumn{2}{|c|}{ Milissegundos } & \multicolumn{2}{|c|}{ Milissegundos } & \multicolumn{2}{|c|}{ Milissegundos } \\
\hline 1 & 36 bytes & \multicolumn{2}{|c|}{-} & \multicolumn{2}{|c|}{0.38} & \multicolumn{2}{|c|}{1.41} \\
\hline 4 & 144 bytes & \multicolumn{2}{|c|}{-} & \multicolumn{2}{|c|}{0.87} & \multicolumn{2}{|c|}{5.63} \\
\hline \multicolumn{2}{|c|}{ Quantidade de Dados } & \multicolumn{2}{|c|}{ Milissegundos } & \multicolumn{2}{|c|}{ Milissegundos } & \multicolumn{2}{|c|}{ Segundos } \\
\hline \multicolumn{2}{|c|}{1 kbyte } & \multicolumn{2}{|c|}{10.81} & \multicolumn{2}{|c|}{7.96} & \multicolumn{2}{|c|}{0.04} \\
\hline \multicolumn{2}{|c|}{10 kbytes } & \multicolumn{2}{|c|}{125.87} & \multicolumn{2}{|c|}{88.89} & \multicolumn{2}{|c|}{0.4} \\
\hline \multicolumn{2}{|c|}{25 kbytes } & \multicolumn{2}{|c|}{337.78} & \multicolumn{2}{|c|}{154.67} & \multicolumn{2}{|c|}{1} \\
\hline \multicolumn{2}{|c|}{100 Kbytes } & \multicolumn{2}{|c|}{1400.89} & \multicolumn{2}{|c|}{938.67} & \multicolumn{2}{|c|}{4} \\
\hline
\end{tabular}

Figura 7.9: Resultados da Transmissão de Dados na Sala de Servidores do PAD.

Note-se que os valores 36 bytes e 144 bytes, correspondem ao dados reais que são transmitidos por segundo pela aplicação OscilloscopeRF. Note-se também que o cálculo para a transmissão destes valores entre a laptop e o "Nokia 6600", não foi determinada, isto porque o método System.currentTimeMillis() gerava um erro do tipo Symbian Os Error $=-7$, que significa perda de precisão no cálculo. Nesse sentido, a 7.3 resume as taxas de transição aproximadas por segundo entra a laptop e os telefones celulares.

Tabela 7.3: Taxas Aproximadas de Transmissão em $K B / s$

\begin{tabular}{|l|c|}
\hline \multicolumn{1}{|c|}{ De - A } & Aprox. KB/s \\
\hline Laptop - Nokia 6600 & $71 \mathrm{~KB} / \mathrm{s}$ \\
\hline Laptop -Sony Ericsson w300i & $106 \mathrm{~KB} / \mathrm{s}$ \\
\hline Nokia 6600 - Sony Ericsson w300i & $25 \mathrm{~KB} / \mathrm{s}$ \\
\hline
\end{tabular}

Destaca-se, que a transmissão entre a laptop e o "Sony Ericsson W300i" foi $33 \%$ maior comparada com a transmissão entre a laptop e o "Nokia 6600". Este ganho na velocidade é produzido pelas melhores capacidades de hardware (processador e memória) 
do "Sony Ericsson W300i". Já a medição entre os dois telefones celulares só foi feito como uma forma de conhecer a transmissão entre eles e portanto não tem maior relevância no presente estudo de caso.

Finalmente, determina-se que os 4 nós sensores utilizados, apresentam taxas de transmissão de dados que permitem um adequado processo de transmissão e coleta de dados por parte dos telefones celulares. Porém, note-se que para aplicações nas quais não seja utilizado uma laptop como "ponte", isto é, conexão direta entre o dispositivo sensor e o telefone celular, se precisará de novas analises nas taxas de transmissão de dados (trabalho futuro) para garantir a qualidade das aplicações de sensoriamento e monitoramento do tipo Handheld AR.

\subsubsection{Avaliações do Resultado da Lógica de Inferência}

Entre os serviços oferecidos pelo nosso protótipo está a implementação de uma alerta de aquecimento nos servidores. Nesse sentido, a temperatura máxima de funcionamento não deve ultrapassar os $50^{\circ} \mathrm{C}$ durante um tempo maior ou igual a 20 segundos.

A implementação desta lógica é relativamente simples, isto em função dos dados semanticamente modelados. Nesse sentido, foram simuladas essas condições de operação para o servidor Mercurio. Já a 7.4 apresenta estas condições e resultados obtidos para estas simulações.

Tabela 7.4: Resultados das Regras de Inferência

\begin{tabular}{|c|c|c|}
\hline \multicolumn{2}{|c|}{ Dados Simulados } & Resultados \\
\hline Temperatura & Tempo & Alerta \\
\hline 45 & 20 & Não \\
\hline 50 & 15 & Não \\
\hline 50 & 20 & Sim \\
\hline 50 & 25 & Sim \\
\hline 55 & 15 & Sim \\
\hline
\end{tabular}

A lógica implementada para a geração das alertas (resultados), analisa os dados armazenados na variável SbDados, a qual contem os dados semanticamente modelados, incluindo tags e valores. Nesse sentido, se verifica o valor da temperatura (Temp) e o valor de identificação do nó sensor (SensorID). Quando o SensorID está associado a um servidor, e além disso, a temperatura (Temp) para este SensorID ultrapassa o valor de 50, é incrementado em um (1) uma variável chamada de "contador" e ao mesmo tempo é iniciado um objeto timer do tipo System.currentTimeMillis(). Quando o timer chegar a 
20000 (equivalente a 20 segundos), verifica-se se a variável contador está em 20, se for o caso é gerada a alerta, se não as variáveis contador e timer são zeradas.

Portanto, para simulações nas quais a temperatura é maior ou igual a $50^{\circ} \mathrm{C}$ durante um tempo maior ou igual a 20 segundos, a alerta foi gerada com sucesso. Mas, experimentou-se simular a temperatura para um valor de 55, porém, com um tempo menor ao estabelecido na lógica de inferência. Nesse sentido, que deveria acontecer, gerar ou não a alerta. Foi decidido que para cada 5 graus a mais da temperatura maxima $\left(50^{\circ} \mathrm{C}\right)$, o tempo seja diminuído em 5 segundos ate chegar em zero.

Note-se que está solução é simples e não modela diversas situações, fato pelo qual conclui-se que a modelagem semântica dos dados permite esta inferência simple, porém, para consultas mais complexas, precisa-se de modelos semânticos mais adequados. Nesse sentido, como propostas de trabalhos futuros pretende-se integrar aplicações como o protótipo desenvolvido com modelos semânticos mas complexos, como os apresentados na dissertação de PONCE (2008).

\subsubsection{Avaliações dos Objetos Virtuais}

Para cada vez que um marcador foi reconhecido, a palavra-chave recuperada do objeto $m U r l$ foi associada a um objeto virtual predeterminado. Para os marcadores que representam aos servidores do PAD e que cotem as palavras-chave "Mercurio", "Marte" e "Venus", foram apresentadas imagens virtuais (gráficos 2D), isto porque o valor da variável (tag) InterfacePreference é "Imagens" (valor modelado no perfil de usuário projetado para este estudo de caso, ver seção 7.3). Portanto, os objetos foram representados como se mostra na figura 7.10 .
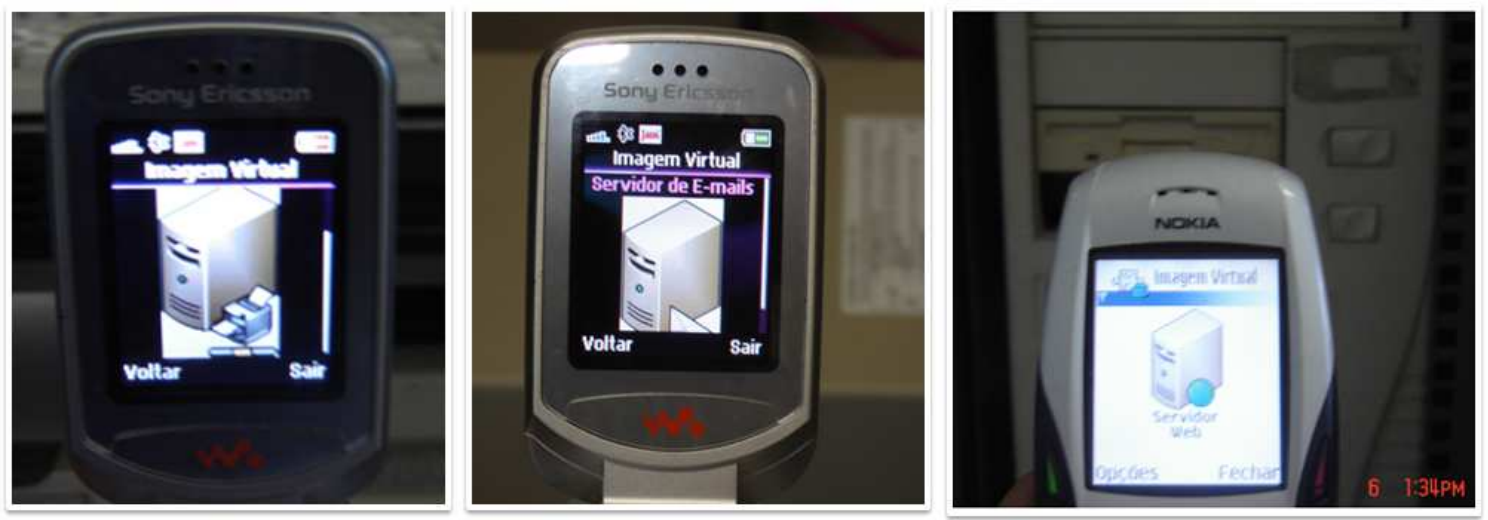

Figura 7.10: Renderização de Imagens Virtuais para os Servidores do PAD. 
Além disso, para avaliar a renderização de efeitos de vibração e efeitos sonoros, a variável InterfacePreference foi alterada para "Vibra" e "Som", o que permitiu a implementação de efeitos de vibração por 10 segundos e a reprodução de uma arquivo de áudio (teste.mp3) predeterminado, como é apresentado na figura 7.11.

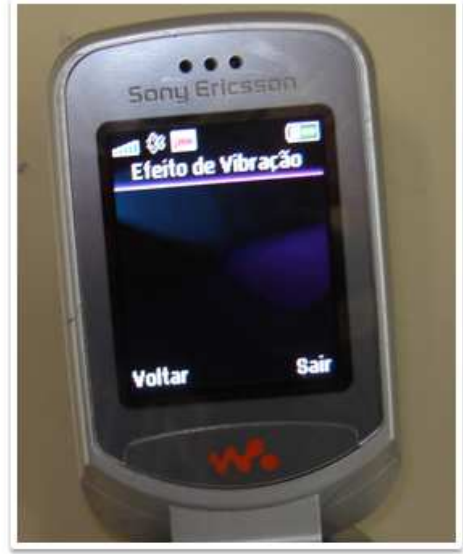

Figura 7.11: Renderização de Efeitos Sonoros e de Vibração.

Já a representação das alerta gerados no caso de aquecimento dos servidores (ver subseção anterior), foram representadas como efeitos de vibração intermitentes, com intervalos de 5 segundos durante 30 segundos.

Já para os dados coletados da RSSF, estabelece-se que interfaces de esquemas de cores, como a apresentada em (RAUHALA; GUNNARSSON; HENRYSSON, 2006) ou a renderização de gráficos 3D em Immediate mode são as melhores formas de representar informações dinâmicas e em tempo real. Porém, no presente protótipo não foi implementada nenhuma destas formas de representar objetos virtuais (trabalhos futuros). Portanto, para a representação das informações de temperatura geradas pela RSSF, optou-se por representar estes dados como informações textuais na tela do telefone celular, como é apresentado na figura 7.12 .
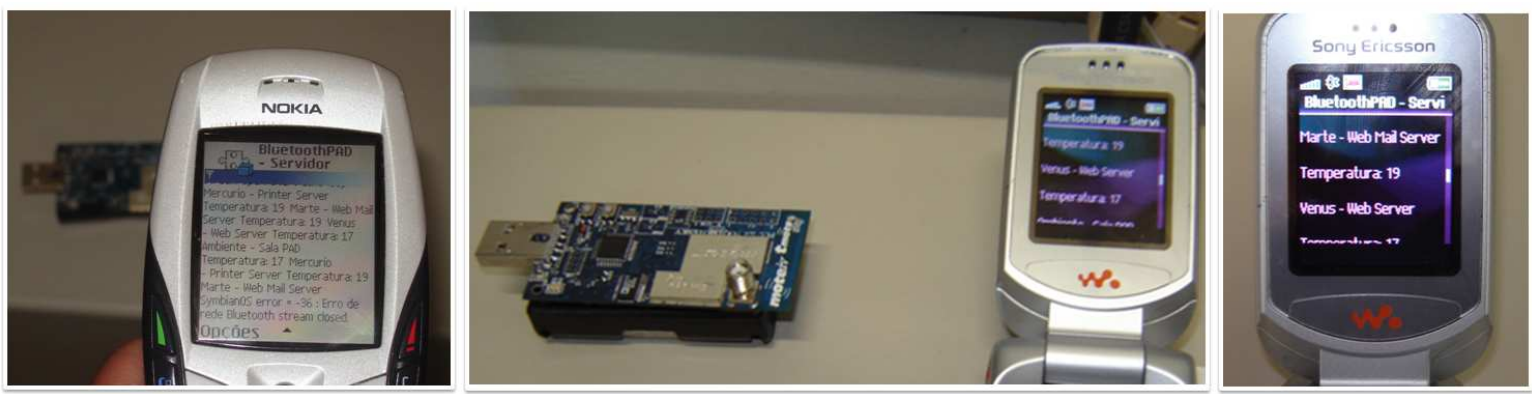

Figura 7.12: Renderização de Objetos Virtuais para os Dados de Temperatura dos Servidores do PAD. 


\subsubsection{Análise de Desempenho}

O protótipo foi compilado em duas configurações: "MDIP 2.0 - CLDC 1.0" para o Nokia 6600 e "MDIP 2.0 - CLDC 1.1" para o Sony Ericsson w300i, isto pelas versões da maquina virtual java instaladas em cada aparelho.

O tamanho do arquivo .JAR para o protótipo foi de $754 \mathrm{~KB}$, tamanho relativamente grande, isto porque o protótipo foi desenvolvido sem a necessidade de otimizar o código fonte e pelos arquivos que representam os gráficos 2D, 3D e mp3. Porém, a instalação da protótipo e seu funcionamento decorreram em parâmetros mais que aceitáveis.

A implementação de interfaces de interação intuitivas, como foi proposto nos objetivos específicos desta dissertação, foi atingido da forma mas simples possível, isto porque a variável InterfacePreference permite definir o tipo de objeto virtual ser apresentado. Porém, espera-se que uma interface de interação intuitiva se adapte automaticamente ao contexto, sendo este um tema a ser abordado como trabalho futuro.

Para estruturar o código fonte foram criadas as classes abstratas ImagemPAD, Vibra$P A D$ e SomPAD, para encapsular os processos de renderização de objetos virtuais.

Parâmetros como estado da bateria dos telefones celulares, marcas, modelos, capacidades de hardware, como memória e processador, foram ignoradas nas avaliações do protótipo, isto por não ser parte do escopo da pesquisa. 


\section{Considerações Finais}

\subsection{Contribuições da Dissertação}

De forma geral este trabalho procura incentivar e facilitar o desenvolvimento de aplicações de realidade aumentada em telefones celulares, sendo a principal contribuição os elementos teóricos e conceituais descritos. Fato que justifica a extensão da presente dissertação. Portanto, as contribuições atingidas são resumidas a seguir:

- Caracterização e resumo dos conceitos, elementos, dispositivos, vantagens, desafios e limitações de implementar conceitos de RA em telefones celulares, em especial em aplicações que capturam informações do ambiente através de dispositivos sensores com interfaces de comunicação sem fio;

- Desenvolvimento de RDF Schemas, que permitem descrever e modelar semanticamente os dispositivos sensores, os ambientes, os dados obtidos e as aplicações. Também são desenvolvidos RDF Schemas que permitem a modelagem do perfil do usuário, determinando as suas preferências. Todos estes Schemas apresentam um modelo semanticamente estruturado que pode ser reaproveitado por tecnologias e aplicações da web semântica e ontologias;

- Simplificação do processo de desenvolvimento de aplicações de RA para telefones celulares, isto baseado na metodologia, cenário de aplicação, arquitetura e fluxos de processo definidos, como por exemplo:

- Processos de aquisição de dados dos dispositivos sensores (BluetoothPAD) e da câmera (CameraPAD);

- Processamento dos dados adquiridos (SemacodePAD e RDF Tagging Application);

- Lógica de inferência sobre os dados relevantes para o usuário (MobilePAD);

- Processos de renderização de objetos virtuais (ImagemPAD, VibraPAD e Som$P A D)$. 
- Desenvolvimento do conceito de "objeto virtual" e sua implementação na plataforma J2ME, isto para tornar transparente o processo de renderização de imagens virtuais, efeitos sonoros e efeitos de vibração.

- Apresentar uma nova abordagem para aplicações de monitoramento, sensoriamento, coleta de dados e interação em ambientes inteligentes e ubíquos, visando atingir um grande número de usuários com diversas características e necessidades na forma de visualizar as informações.

\subsection{Limitações da Dissertação}

- Mesmo que o cenário geral de aplicação apresentado na figura 6.1 mostre a utilização de diversos dispositivos sensores e dispositivos móveis, a implementação do estudo de caso e a implementação e suporte de mecanismos (classes) de aquisição dados e apresentação de informações limita-se para uma RSSF da plataforma TmoteSky, telefones celulares com suporte para uma interface Bluetooth e a plataforma Java, isto por serem os dispositivos e ferramentas disponíveis.

- O processo de desenvolvimento das aplicações de sensoriamento instaladas na RSSF e a especificação do seu funcionamento não é parte da presente pesquisa, limitandonos apenas ao problema da aquisição dos dados gerados pela RSSF, e a sua representação nos telefones celulares como objetos virtuais.

- Implementações baseadas em hardware (aceleração gráfica por GPU) ou aprimoramento do código, na procura da melhora do desempenho da aplicação, não é parte do escopo da presente pesquisa.

\subsection{Conclusões}

- Estabelece-se a viabilidade do uso de telefones celulares para coletar dados gerados por dispositivos sensores com interfaces de comunicação sem fio e do uso de técnicas de RA para a apresentação das informações adquiridas;

- Demonstra-se que o uso de aplicações de RA em telefones celulares permite suportar e massificar a diversidade e quantidade de usuários, incluindo usuários com necessidades especiais como deficiências físicas;

- A modelagem de RDF e RDF Schemas apresentadas no presente trabalho permite a descrição dos usuários, ambientes, sensores e aplicações de sensoriamento, cujos 
modelos semânticos podem ser reaproveitados por diversos tipos de aplicações, o que foi demonstrado nos artigos publicados como parte do decorrer da presente pesquisa;

- Demonstra-se que o uso de objetos virtuais como forma de representação das informações, permite incrementar o grau de informação percebida pelos usuários e interação com diferentes ambientes. Porém, estudos mais aprofundados são requeridos para a representação de informações mais complexas por efeitos sonoros e efeitos de vibração;

- A simplificação dos processos de desenvolvimento através de uma documentação clara dos mesmos (apresentada nesta dissertação) e a maturidade das tecnologias de RA e dispositivos sensores (com interfaces de comunicação sem fio) permitem o rápido crescimento de aplicação do tipo Handheld $A R$ en múltiplas áreas de atuação, gerando uma perspectiva interessante no mercado de aplicações emergentes na área de telefonia celular;

- Utiliza-se o armazenamento das informações baixo uma estrutura RDF, para permitir a usabilidade destas informações por diversos tipos de aplicações, como em trabalhos de gerenciamento de dados, repositórios de dados e sensor services;

- Estabelece-se que o uso de perfis de usuário (user profiles) para descrever preferências, permite prover informações personalizadas e dar suporte às interfaces de interação intuitivas. Porém, note-se que as interfaces de interação intuitivas apresentadas no estudo de caso são bastantes simples, isto por ser apenas uma prova de conceito;

- Demonstra-se que o estudo de caso permitiu implementar os conceitos definidos na presente pesquisa e avaliar de forma clara o protótipo como uma prova de conceito da metodologia proposta;

- Demonstra-se que as taxas de reconhecimento de marcadores e taxas de transmissão de dados são bastante adequadas para a implementação de aplicações do tipo Handheld $A R$, em especial aplicações que adquirem dados em tempo real;

- Finalmente, conclui-se que o objetivo desta dissertação foi atingido satisfatoriamente por permitir a complementação de informações não disponíveis na literatura, objetivando instruir e auxiliar aos interessados no desenvolvimento de aplicações de Realidade Aumentada com características semelhantes às apresentadas no cenário de aplicação e arquitetura proposta, como foi resumido no artigo (ZUñIGA; KOFUJI, 2008). 


\subsection{Perspectivas e Trabalhos Futuros}

- Pretende-se dar continuidade à presente pesquisa no desenvolvimento do trabalho de doutorado, objetivando desenvolver um Framework, que inclua um IDE de desenvolvimento que proporcione as ferramentas de software necessárias para a implementação de aplicações do tipo Handhled $A R$ baseadas no cenário geral de aplicação apresentado. Além disso, o Framework devera implementar mecanismos avançados para a consulta de inferência, melhora do desempenho das aplicações e renderização de gráficos 3D em Immediate mode;

- Também pretende-se estudar a integração deste Framework com outras pesquisas do PAD como ambientes inteligentes, gerenciamento de RSSF e reconhecimento de objetos (faces) em computadores distribuídos e de alto desempenho.

\subsection{Publicação de Artigos em Eventos Nacionais e Internacionais}

1. ZUÑIGA, J. C., KOFUJI, S. T.; Uma Metodologia para o Desenvolvimento de Aplicações de Realidade Aumentada em Telefones Celulares Utilizando Dispositivos de Sensoriamento. In: Proceedings X Symposium on Virtual and Augmented Reality (SVR08), 2008, João Pessoa, Paraíba, Brasil. Anais... Porto Alegre: SBC, 2008, p. 50-54.

2. ZUÑIGA, J. C., KOFUJI, S. T.; Visualização de Metadados de Sensores Utilizando Realidade Aumentada em Telefones Celulares. In: Anais de Workshop de Realidade Virtual e Aumentada (WRVA 2007). 2007, Itumbiara, Goiás, Brasil. p. 144-147.

3. ZUÑIGA, J. C., ROCA, I, KOFUJI, S. T.; Modelagem de Dados e Sensores para aplicações em Intra-Vehicle Wireless Sensor Networks; In: Proceedings of the I Workshop on Pervasive and Ubiquitous Computing (WPUC 2007). 2007, Gramado, Rio Grande do Sul, Brasil.

4. ROCA, I, ZUÑIGA, J. C., KOFUJI, S. T.; Sensor Modeling and Sensor Data for Under Water Acoustic Sensor Networks (UW-ASN) Applications. (Poster); In: Proceedings The Second ACM International Workshop on UnderWater Networks (WUWNet), 2007, Montreal, Canadá. Anais... New York: ACM Press, 2007.

5. ZUÑIGA, J. C., KOFUJI, S. T.; Implementabilidade da Realidade Aumentada Móvel em Telefones Celulares 3G. In: Anais da $5^{\mathrm{a}}$ Conferencia Iberoamericana en Sistemas, Cibernética e Informática (CISCI 2006), 2006, Orlando, Florida, EUA. 


\section{Referências}

ALTOVA. Semantic works. website: Disponível em: <www.altova.com/semanticworks>. Acesso em Março, 01, 2008.

ANDEL, M.; PETROVSKI, A. Interactive Collaborative Augmented Reality using a Distributed Scene Graph on Mobile Phones. Dissertação (Mestrado) — Linköping University, 2006.

ARTOOLKIT. Website: Disponível em: <http://www.hitl.washington.edu/artoolkit/>. Acesso em Março, 07, 2007.

ARTOOLKITPLUS. Website: Disponível em: <http://studierstube.icg.tugraz.ac.at/handheld-ar/artoolkitplus>. Acesso em Março, 07, 2007.

ASSAD, M.; CARMICHAEL, D. J.; CUTTING, D.; HUDSON, A. Ar phone: Accessible augmented reality in the intelligent environment. OZCHI'03: Australiasian Computer Human Interaction Conference, p. 232-235, 2003.

AZUMA, R. A survey of augmented reality. SIGGRAPH'95: In Computer Graphics Proceedings, p. 1-38, 1997.

AZUMA, R.; BAILLOT, Y.; BEHRINGER, R.; FEINER, S.; JULIER, S.; MACINTYRE, B. Recent advances in augmented reality. IEEE Computer Graphics and Applications, v. 21 , n. 6 , p. $34-47,2001$.

BECKETT, D.; MCBRIDE, B. Rdf/xml syntax specification. Disponivel em: <http://www.w3.org/TR/rdf-syntax-grammar/> Acesso em Junho, 05, 2007.

BENERS-LEE, T.; HENDLER, J.; LASSILA, O. The semantic web. Scientific American, 2001.

BERTELSEN, O.; NIELSEN, C. Augmented reality as a design tool for mobile interfaces. Symposium on Designing Interactive Systems, 2000.

BILLINGHURST, M.; HENRYSSON, A. Research directions in handheld ar. The International Journal of Virtual Reality, v. 5, n. 2, p. 51-58, 2006.

BOTTS, M. Sensor model language (sensorml): Xml-based language for in-situ and remote sensors. NIST Workshop on Data Exchange Standards at the Jobsite, 2003.

BRICKLEY, D.; GUHA, R.; MCBRIDE, B. Rdf vocabulary description language 1.0: Rdf schema w3c recommendation. Disponivel em: <http://www.w3.org/TR/rdf-schema/> Acesso em Junho, 05, 2007.

BROLL, G.; SIORPAES, S.; RUKZIO, E.; PAOLUCCI, M.; HAMARD, J.; WAGNER, M.; SCHMIDT, A. Supporting service interaction in the real world. PERMID'06:

Pervasive Mobile Interaction Devices, 2006. 
BROOKS, R.; CAGLE, K. The web services component model and HumanML - building personalization into the emerging web component architecture. [S.l.], 2002.

BRUNS, E.; BROMBACH, B.; ZEIDLER, T.; BIMBER, O. Enabling mobile phones to support large-scale museum guidance. IEEE MultiMedia, 2007.

COLORCODE. Web site, disponível em: <http://www.colorzip.co.jp/en/>. Acesso em Dezembro, 07, 2007.

CORREIA, N. Mobile Augmented Reality. 2003. Faculdade de Ciências e Tecnologia Universidade de Évora - Portugal.

CVIBRACONTROL. Class reference. website: Disponível em: $<$ http://www.forum.nokia.com/document/classcvibracontrol.html>. Acesso em Março, 07, 2007.

DANADO, J. C. Realidade Aumentada. 2005. Faculdade de Ciências e Tecnologia Universidade de Évora - Portugal.

DATAMATRIX. Automatic identification and data capture techniques, data matrix bar code symbology specification. ISO/IEC 16022, International Organization for Standardization, 2006.

DATAMATRIX. Web site, disponível em: <http://idautomation.com/datamatrixfaq.html>. Acesso em Junho, 07, 2007.

DIGITAL. Future web site, disponível em: <http://www.digitalfuturesoft.com/dfttsmobilesdk.php>. Acesso em Março, 07, 2008.

DIRECT3D. Mobile, disponível em: <http://msdn2.microsoft.com/enus/library/aa452478.aspx>. Acesso em Junho, 07, 2007.

DIRECTSHOW. Web site, disponível em: <http://msdn2.microsoft.com/enus/library/ms783323.aspx>. Acesso em Junho, 07, 2007.

DIRECTX. Web site, disponível em: <http://www.gamesforwindows.com/enus/aboutgfw/pages/directx10.aspx>. Acesso em Junho, 07, 2007.

DSVIDEOLIB. Web site, disponível em: < http://sourceforge.net/projects/dsvideolib>. Acesso em Junho, 07, 2007.

DUNSER, A.; GRASSET, R.; SEICHTER, H.; BILLINGHURST, M. Applying hci principles to ar systems design. MRUI'07: 2nd International Workshop at the IEEE Virtual Reality Conference, 2007.

FIALA, M. Artag revision 1: A fiducial marker system using digital techniques. NRC Institute for Information Technology Canada, 2004.

FINKENZELLER, K. Radio-Frequency Identification: Fundamentals and Applications. [S.l.]: Wiley and Sons, 2003. ISBN 0-471-98851-0.

FORMAN, G. H.; ZAHORJAN, J. The challenges of mobile computing. Computer, IEEE Computer Society Press, Los Alamitos, CA, USA, v. 27, n. 4, p. 38-47, 1994. ISSN 0018-9162. 
FORSTADIUS, J.; LASSILA, O.; SEPPäNEN, T. Rdf-based model for context-aware reasoning in rich service environment. PerCom 2005 Workshops, 2005.

FORTE, M. Especificação de perfis e regras, baseada em ontologias, para adaptação de conteúdo na Internet. Dissertação (Mestrado) — UNIVERSIDADE FEDERAL DE SÃO CARLOS, 2006.

FUKAZAWA, Y.; LUTHER, M.; WAGNER, M.; TOMIOK, A.; NAGANUMA, T.; FUJII, K.; KURAKAKE, S. Situation-aware task-based service recommendation. Fourth International Conference on Mobile Systems, Applications and Services, MobiSys, 2006.

GML. Gml matlab camera calibration toolbox website: Disponível em: $<$ http://research.graphicon.ru/calibration/gml-matlab-camera-calibrationtoolbox.html>. Acesso em Março, 07, 2007.

GOMES, E. C. H. Geração automática de metadados: uma contribuição para a Web semântica. Tese (Doutorado) — Escola Politécnica da Universidade de São Paulo, 2006.

GUNNARSSON, A.-S.; RAUHALA, M.; HENRYSSON, A.; YNNERMAN, A.

Visualization of sensor data using mobile phone augmented reality. ISMAR'06: Fifth IEEE/ACM International Symposium on Mixed and Augmented Reality, 2006.

HANDHELD. Augmented reality project website: Disponível em: <http://studierstube.icg.tu-graz.ac.at/handheld-ar/>. Acesso em Março, 0\%, 2007.

HARRISON, R. Symbian OS C++ for Mobile Phones. [S.l.]: John Willey and Sons, 2004.

HECKMANN, D. Ubiquitous User Modeling. Dissertação (Mestrado) Naturwissenschaftlich-Technischen Fakult"aten der Universit"at des Saarlandes, 2005.

HENRYSSON, A. Bringing Augmented Reality to Mobile Phones. Tese (Doutorado) Department of Science and Technology Linköpings universitet, 2007.

HENRYSSON, A.; BILLINGHURST, M.; OLLILA, M. Face to face collaborative ar on mobile phones. Proceedings of the International Symposium on Mixed and Augmented Reality, 2005.

HENRYSSON, A.; BILLINGHURST, M.; OLLILA, M. Ar tennis. In: SIGGRAPH '06: ACM SIGGRAPH 2006 Sketches. New York, NY, USA: ACM, 2006. p. 13. ISBN 1-59593-364-6.

HENRYSSON, A.; OLLILA, M. Umar: Ubiquitous mobile augmented reality. MUM'04: 3rd international conference on Mobile and ubiquitous multimedia, 2004.

HENRYSSON, A.; OLLILA, M.; BILLINGHURST, M. Mobile phone based ar scene assembly. Proceedings of the International Conference on Mobile and Ubiquitous Multimedia, p. 95-102, 2005.

HäKKILä, J.; KORPIPää, P.; RONKAINEN, S.; TUOMELA, U. Interaction and end-user programming with a context-aware mobile application. Human-Computer Interaction - INTERACT, p. 927-937, 2005. 
JANSEN, W.; AYERS, R. Guidelines on Cell Phone Forensics. [S.l.], May 2007.

JENA. A semantic web framework for java disponível em: $<$ http://jena.sourceforge.net/>. Acesso em Abril, 15, 2007.

JONIETZ, E. 10 emerging technologies. Technology Review - Online Edition, Março 2007.

JSAPI. Java speech api, disponível em: < http://java.sun.com/products/javamedia/speech/>. Acesso em Março, 07, 2008.

JURDAK, R.; LOPES, C. V.; BALDI, P. A framework for modeling sensor networks. Building Software for Pervasive Computing Workshop, 2004.

KANSAL, A.; GORACZKO, M.; ZHAO, F. Building a sensor network of mobile phones. In: IPSN '0\%: Proceedings of the 6th international conference on Information processing in sensor networks. New York, NY, USA: ACM, 2007. p. 547-548.

KATO, H.; TAN, K. T. Pervasive 2d barcodes for camera phone applications. IEEE Pervasive Computing, IEEE Educational Activities Department, Piscataway, NJ, USA, v. 6, n. 4, p. 76-85, 2007. ISSN 1536-1268.

KHOSLA, R.; CHOWDHURY, B. Real-time rfid-based intelligent healthcare diagnosis system. Lecture Notes in Computer Science Medical Biometrics, v. 4901, p. 184-191, 2008 .

KäHäRI, M.; MURPHY, D. Mara - sensor based augmented reality system for mobile imaging device. 5th IEEE and ACM International Symposium on Mixed and Augmented Reality - Ismar 06, 2006.

KIRNER, C.; TORI, R. Introdução à Realidade Virtual, Realidade Misturada e Hiper-realidade. [S.l.]: Realidade Virtual: Conceitos, Tecnologia e Tendências, 2004. $3-20 \mathrm{p}$.

KJELDSKOV, J. Interaction design for handheld computers. In proceedings of APCHIO2, 2002.

KLATZKY, R. L.; LEDERMAN, S. J. Modality specificity in cognition: The case of touch. American Psychological Association Press, 2000.

KLIMT. Website: Disponível em: <http://studierstube.icg.tu-graz.ac.at/klimt/index>. Acesso em Março, 07, 2007.

KLINGSHEIM, A. N. J2ME Bluetooth Programming. Dissertação (Mestrado) University of Bergen, 2004.

KLYNE, G.; CARROLL, J.; MCBRIDE, B. Resource description framework (rdf): Concepts and abstract syntax. Disponivel em: <http://www.w3.org/TR/rdf-concepts/> Acesso em Junho, 05, 2007.

KLYNE, G.; REYNOLDS, F.; WOODROW, C.; OHTO, H.; HJELM, J.; BUTLER, M. H.; TRAN, L. Composite capability/preference profiles (cc/pp): Structure and vocabularies 1.0. Disponivel em: <http://www.w3.org/TR/2004/REC-CCPP-structvocab-20040115/> Acesso em Junho, 05, 2007. 
LAHR, P. S.; LOURENçO, P. C.; DAINESE, C. A. Rastreamento em realidade aumentada com artoolkit e marcadores. Workshop de Realidade Aumentada (WRA), 2004 .

LEWIS, M.; CAMERON, D.; XIE, S.; ARPINAR, B. Es3n - a semantic approach to data management in sensor networks. ISWC'06: Semantic Sensor Networks Workshop of the 5th International Semantic Web Conference, 2006.

LIMA, J. P. S. do M. Um framework de realidade aumentada para o desenvolvimento de aplicações portáveis para a plataforma pocket pc. Universidade Federal de Pernambuco (UFPE) - Centro de Informática (CIn), 2007.

LóPEZ, D.; MENDONçA, P.; HOPPER, A. A low-cost vision based location system for ubiquitous computing. Personal and Ubiquitous Computing Journal, 2002.

LóPEZ, D.; RODRIGUEZ, A.; VáZQUEZ, I. Accesibilidad para discapacitados a través de teléfonos y servicios móviles adaptables. JANT'04: Jornadas de Accesibilidad y Nuevas Tecnologías, 2004.

MADHAVAPEDDY, A.; SCOTT, D.; SHARP, R.; UPTON, E. Using camera phones to enhance human-computer interaction. 6th International Conference Ubiquitous Computing (UbiComp 04), 2004.

MARINO, M. T. Integração de Informações em Ambientes Cientificos na Web: Uma Abordagem Baseada na Arquitetura RDF. Dissertação (Mestrado) - Universidade Federal do Rio de Janeiro, 2001.

MCGUINNESS, D. L.; HARMELEN, F. van. Owl - web ontology language. Disponivel em: <http://www.w3.org/TR/owl-features/> Acesso em Junho, 05, 2007.

MEDINA, A.; SANCHEZ, J. A.; CHAVEZ, R. O. Rdf-based model for encoding document hierarchies. 17th International Conference on Electronics, Communications and Computers, 2007.

MEGERIAN, S.; KOUSHANFAR, F.; QU, G.; VELTRI, G.; POTKONJAK, M. Exposure in wireless sensor networks: theory and practical solutions. Wireless Networks, Kluwer Academic Publishers, v. 8, n. 5, p. 443-454, 2002.

MILGRAM, P.; KISHINO, F. A taxonomy of mixed reality visual displays. IEICE Transactions on Information Systems, 1994.

MILLER, E. An introduction to the resource description framework. D-Lib Magazine, 1998.

MMAPI. - jsr 135. web site, disponível em: < http://java.sun.com/products/mmapi/>. Acesso em Junho, 07, 2007.

MOBILE. 3d graphics api for j2me (m3g). web site, disponível em: <http://jcp.org/en/jsr/detailid=184>. Acesso em Junho, 07, 2007.

MONTEIRO, J. D. A. Desenvolvimento de aplicações multi-plataformas para dispositivos móveis. Dissertação (Mestrado) — Instituto de Ciências Matemáticas e de Computação - ICMC-USP, 2006.

MOTEIV. TmoteSky Ultra low power IEEE 802.15.4 Compliant Wireless Sensor Module. [S.l.], 2007. 
NETO, R. de F. B.; PIMENTEL, M. da G. C. Interoperabilidade semântica entre aplicações cientes de contexto. impósio Brasileiro de Sistemas Multimídia e WebWebmidia 03, 2003.

NETO, S. G.; FARIAS, T.; TEICHRIEB, V.; KELNER, J. Criação de aplicações de realidade aumentada em dispositivos móveis baseados em Symbian OS. III Workshop de Realidade Aumentada, 2006.

NI, L.; ZHU, Y.; MA, J.; LI, M.; LUO, Q.; LIU, Y.; CHEUNG, S.; YANG, Q. Semantic sensor net: An extensible framework. Proceedings of International Conference on Computer Networks and Mobile Computing, 2005.

NILSEN, T. Guidelines for the Design of Augmented Reality Strategy Games. Dissertação (Mestrado) — University of Canterbury, 2006.

NOGUCHI, H.; MORI, T.; SATO, T. Automatic generation and connection of program components based on rdf sensor description in network middleware. IEEE/RSJ International Conference on Intelligent Robots and Systems, 2006.

NOKIA. Center research, website: Disponível em: <http://research.nokia.com/research/>. Acesso em Março, 07, 2007.

NOKIA. Flash Lite 1.1: Sound for Nokia S60 and Series 40 Devices. [S.1.], 2007.

NOKIA. Ui api v1.0. website: Disponível em: <http://java2me.org/nokiaui/doc/index.html>. Acesso em Março, 07, 2007.

OAKLEY, I.; MCGEE, M.; BREWSTER, S.; GRAY, P. Putting the feel in look and feel. ACM Conference on Human Factors and Computing Systems, 2000.

OMA. Open mobile alliance - user agent profile (uaprof) v2.0. Disponivel em: $<w w w . o p e n m o b i l e a l l i a n c e . o r g / r e l e a s e-p r o g r a m / d o c s / U A P r o f />$ Acesso em Junho, 05, 2007.

OPENGL. Web site, disponível em: <http://www.opengl.org/>. Acesso em Junho, 07, 2007.

OPENGLES. Website: Disponível em: <http://www.khronos.org/opengles/>. Acesso em Março, 0\%, 2007.

OPENNETCF. Smart device framework 2.2. website: Disponível em: <http://www.opennetcf.com/>. Acesso em Março, 0\%, 2007.

PEñAFIEL, J.; ZAYAS, J. FUNDAMENTOS DEL SISTEMA GPS Y APLICACIONES EN LA TOPOGRAFIA. [S.1.], 2001.

PEREIRA, M. R.; AMORIM, C. L.; STELlinG, M. C. Tutorial sobre Redes de Sensores. [S.l.], 2004.

PERUGINI, S.; RAMAKRISHNAN, N. Personalizing interactions with information systems. Advances in Computers Information Repositories, 2003.

PETERSON, E. DIOMEDES: An integrated automotive diagnostics system that is customizable, low-cost, and non-intrusive built on a wireless sensor network. Dissertação (Mestrado) — UNIVERSITY OF CALIFORNIA, Santa Barbara, 2007. 
PONCE, E. MODELAGEM DE CONTEXTO UTILIZANDO ONTOLOGIAS. Dissertação (Mestrado) — Escola Politécnica da Universidade de São Paulo, 2008.

PRUDHOMMEAUX, E.; SEABORNE, A. Sparql query language for rdf. Disponivel em: <http://www.w3.org/TR/rdf-sparql-query/> Acesso em Junho, 05, 2007.

QRCODE. Automatic identification and data capture techniques, qr code 2005 bar code symbology. ISO/IEC 18004, International Organization for Standardization, 2006.

QRCODE. Web site, disponível em: <http://www.denso-wave.com/qrcode/indexe.html>. Acesso em Junho, 0\%, 2007.

QUIN, L. Extensible markup language (xml). Disponível em: <http://www.w3.org/XML/> Acesso em Junho, 05, 2007.

RAUHALA, M.; GUNNARSSON, A.-S.; HENRYSSON, A. A novel interface to sensor networks using handheld augmented reality. MobileHCI'06: Proceedings of the 8th conference on Human-computer interaction with mobile devices and services, 2006.

ROCA, I. REDE DE SENSORES SEM FIOS EM AMBIENTES VEICULARES BASEADO NO PADRÃO ZIGBEE. Dissertação (Mestrado) — Escola Politécnica da Universidade de São Paulo, 2008.

ROCA, I.; ZUñIGA, J. C.; KOFUJI, S. T. Sensor modeling and sensor data for underwater acoustic sensor networks (uw-asn). Second ACM International Workshop on UnderWater Networks (WUWNet), 2007.

RODRIGUES, C. E. M. Um dispositivo hÁptico de auxÍlio À navegaÇÃo para deficientes visuais. Universidade Federal de Pernambuco (UFPE) - Centro de Informática (CIn), 2006.

ROHS, M. Real-world interaction with camera-phones. 2nd International Symposium in Ubiquitous Computing Systems (UCS 04), 2004.

ROHS, M. Linking Physical and Virtual Worlds with Visual Markers and Handheld Devices. Tese (Doutorado) — Swiss Federal Institute of Technology Zurich, 2005.

RUIZ, L. B.; CORREIA, L. H. A.; VIEIRA, L. F. M.; MACEDO, D. F.; NAKAMURA, E. F.; FIGUEIREDO, C. M. S. Arquiteturas para redes de sensores sem fio. Simpósio Brasileiro de Redes de Computadores (SBRC), 2004.

RUKZIO, E.; ROHS, M.; WAGNER, D.; HAMARD, J. Development of interactive applications for mobile devices. MobileHCI '05: Proceedings of the 7th international conference on Human computer interaction with mobile devices $\& 5$ services, 2005.

SCHWEIGHOFER, G.; PINZ, A. Robust pose estimation from a planar target. IEEE Transactions on Pattern Analysis and Machine Intelligence, 2006.

SEMACODE. Web site, disponível em: <http://www.semacode.org/>. Acesso em Junho, 07, 2007.

SENSORAPI. - jsr 256. web site, disponível em: <http://jcp.org/en/jsr/detailid=256>. Acesso em Fevereiro, 08, 2008.

SERVANT, F.-P. Semantic web technologies in technical automotive documentation. In: 3rd International Workshop in OWL Experiences and Directions. [S.l.: s.n.], 2007. 
SERVANT, F.-P. Use case: Semantic web technologies in automotive repair and diagnostic. <http://www.w3.org/2001/sw/sweo/public/usecases/renault/>. May, 2007.

SHOTCODE. Web site, disponível em: <http://www.shotcode.com/home>. Acesso em Junho, 0\%, 2007.

SINGH, S.; CHEOK, A. D.; NG, G. L.; FARBIZ, F. Reality comic book and notes for children using mobile phones. Lecture Notes in Computer Science Image and Video Retrieval, 2004.

SPEECH. Api and sdk web site, disponível em: <http://msdn.microsoft.com/enus/library/aa939839.aspx>. Acesso em Março, 07, 2008.

SPERBERG-MCQUEEN, C.; THOMPSON, H. Xml schema. Disponivel em: <http://www.w3.org/XML/Schema> Acesso em Junho, 05, 2007.

STUDIERSTUBE. Website: Disponível em: <http://studierstube.icg.tu-graz.ac.at/>. Acesso em Março, 0\%, 2007.

TACK-DON, H.; CHEOL-HO, C.; NAM-KYU, L.; EUN-DONG, S. Machine Readable Code Image and Method of Encoding and Decoding the Same. 2006. US Patent 7,020,327, US Patent and Trademark Office.

TAURION, C. Internet Móvel Tecnologias, Aplicações e Modelos. [S.l.]: Editora Campus, 2002.

TOLKSDORF, R.; NIXON, L. J. B.; BONTAS, E. P.; NGUYEN, D. M.; LIEBSCH, F. Enabling real world semantic web applications through a coordination middleware. ESWC'05: 2nd European Semantic Web Conference, 2005.

TORI, R.; KIRNER, C.; SISCOUTTO, R. Fundamentos e Tecnologia de Realidade Virtual e Aumentada. [S.1.]: Apostila do Pré-Simpósio VIII Symposium on Virtual Reality, 2006.

TRäSKBäACK, M.; HALLER, M. Mixed reality training application for an oil refinery: user requirements. VRCAI'04: ACM SIGGRAPH international conference on Virtual Reality continuum and its applications in industry, 2004.

VIBRATECLASS. Website: Disponível em: <http://www.opennetcf.com/library/sdf/html/26f6f98d-60b4-55aa-646694352bbb3b38.htm>. Acesso em Março, 07, 2007.

VITA. Visual information technology and applications, website: Disponível em: <http://vita.itn.liu.se/>. Acesso em Março, 07, 2007.

VSCODE. Web site, disponível em: <www.veritecinc.com>. Acesso em Junho, 07, 2007.

W3C. World wide web consortium website: Disponível em: <http://www.w3.org/>. Acesso em Abril, 0\%, 2007.

WAGNER, D.; PINTARIC, T.; LEDERMANN, F.; SCHMALSTIEG, D. Towards massively multi-user augmented reality on handheld devices. Pervasive, p. 208-219, 2005.

WAGNER, D.; SCHMALSTIEG, D. First steps towards handheld augmented reality. ISWC'03: Proceedings of the 7th IEEE International Symposium on Wearable Computers, IEEE Computer Society, Washington, DC, USA, p. 127, 2003. 
WAGNER, D.; SCHMALSTIEG, D. Artoolkitplus for pose tracking on mobile devices. Proceedings of 12th Computer Vision Winter Workshop, 2007.

WAGNER, D.; SCHMALSTIEG, D.; BILLINGHURST, M. Handheld ar for collaborative edutainment. Book Advances in Artificial Reality and Tele-Existence, 2006.

WAH, C. K.; LI, Q. Is-sdm: An in-network semantic sensor data model. In: $A C M$ symposium on Applied computing. [S.l.]: ACM Press, 2007.

WEISER, M. The computer for the 21st century. Scientific American Special Issue on Communications, Computers, and Networks, 1991.

WEISER, M. Some computer science issues in ubiquitous computing. Communications of the ACM, 1993.

WEISS, S. Handheld Usability. [S.l.]: Wiley, 2002.

WINDOWS. Mobile directx and direct3d. web site, disponível em: $<$ http://msdn2.microsoft.com/en-us/library/ms172504>. Acesso em Junho, 07, 2007.

WOODWARD, C. Feature detection applications on camera phones. VTT Technical Research Centre of Finland, 2006.

ZUñIGA, J. C.; KOFUJI, S. T. Implementabilidade da realidade aumentada móvel em telefones celulares 3g. $5^{a}$ Conferencia Iberoamericana en Sistemas, Cibernética e Informática (CISCI 2006), 2006.

ZUñIGA, J. C.; KOFUJI, S. T. Visualização de metadados de sensores utilizando realidade aumentada em telefones celulares. Workshop de Realidade Virtual e Aumentada (WRVA), 2007.

ZUñIGA, J. C.; KOFUJI, S. T. Uma metodologia para o desenvolvimento de aplicações de realidade aumentada em telefones celulares utilizando dispositivos de sensoriamento. X Symposium on Virtual and Augmented Reality (SVR08), 2008.

ZUñIGA, J. C.; ROCA, I.; KOFUJI, S. T. Modelagem de dados e sensores para aplicações em intra-vehicle wireless sensor networks. I Workshop on Pervasive and Ubiquitous Computing part of 19th Intern. Symposium on Computer Architecture and High Performance Computing (SBAC-PAD), 2007. 